Review

\title{
A Review on High-Capacity and High-Voltage Cathodes for Next- Generation Lithium-ion Batteries
}

Shuvajit Ghosh ${ }^{\dagger}$, Udita Bhattacharjee ${ }^{\dagger}$, Subhajit Bhowmik ${ }^{\dagger}$, Surendra K. Martha *

Department of Chemistry, Indian Institute of Technology Hyderabad, Kandi, Sangareddy, 502285

Telangana, India; E-Mails: cy20resch01001@iith.ac.in; cy18resch11005@iith.ac.in; cy20resch11022@iith.ac.in; martha@chy.iith.ac.in

+ These authors contributed equally to this work.

* Correspondence: Surendra K. Martha; E-Mail: martha@chy.iith.ac.in

Academic Editor: Ahamed Irshad

Special Issue: Batteries: Past, Present and Future

Journal of Energy and Power Technology Received: June 30, 2021

2022, volume 4, issue 1

Accepted: November 22, 2021

doi:10.21926/jept.2201002

Published: January 10, 2022

\begin{abstract}
lithium-ion battery (LIB) is at the forefront of energy research. Over four decades of research and development have led electric mobility to a reality. Numerous materials capable of storing lithium reversibly, either as an anode or as a cathode, are reported on a daily basis. But very few among them, such as $\mathrm{LiCoO}_{2}$, lithium nickel manganese cobalt oxide (Li-NMC) variants ( $\mathrm{LiNi}_{0.33} \mathrm{Mn}_{0.33} \mathrm{Co}_{0.33} \mathrm{O}_{2}, \quad \mathrm{LiNi}_{0.5} \mathrm{Mn}_{0.3} \mathrm{CO}_{0.2} \mathrm{O}_{2}, \quad \mathrm{LiNi}_{0.6} \mathrm{Mn}_{0.2} \mathrm{CO}_{0.2} \mathrm{O}_{2}$, and $\mathrm{LiNi} 0.8 \mathrm{Mn}_{0.1} \mathrm{CO}_{0.1} \mathrm{O}_{2}$ ), $\mathrm{LiNi}_{0.8} \mathrm{CO}_{0.15} \mathrm{Al}_{0.05} \mathrm{O}_{2}$, $\mathrm{LiFePO}_{4}$, graphite, and $\mathrm{Li}_{4} \mathrm{Ti}_{5} \mathrm{O}_{12}$ are successful at commercial scale. Future energy requirements demand a push in the energy density of LIBs to meet the criteria of electric aviation, power trains, stationary grids, etc. All these applications have different needs which cannot be satisfied by a particular set of materials. Therefore, various materials need to be utilized in widespread fields of battery applications in the near future. This review discusses potential cathode materials that show a capacity of $\geq 250 \mathrm{mAh} \mathrm{g}^{-1}$ (Li-rich oxides, conversion materials, etc.) or average voltage of $\geq 4 \mathrm{~V} \mathrm{vs.} \mathrm{Li}^{+} / \mathrm{Li}$ (polyanionic materials, spinel
\end{abstract}

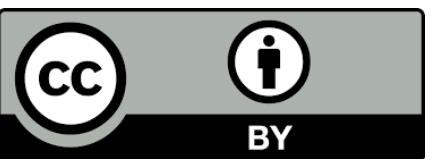

(C) 2022 by the author. This is an open access article distributed under the conditions of the Creative Commons by Attribution License, which permits unrestricted use, distribution, and reproduction in any medium or format, provided the original work is correctly cited. 
oxides, etc.). Failure mechanisms, challenges, and way-outs to overcome all the issues are put forward to determine commercial viability.

\section{Keywords}

Lithium-ion battery; high energy; high voltage; cathode material

\section{Introduction}

Research on energy conversion and storage has been rising for the last few decades, and lithiumion batteries (LIBs) have dominated this space ever since their invention. First marketed by SONY in 1991, LIBs have established a monopoly in the market of portable electronics devices [1]. LIBs come with a unique blend of characteristics such as 150-200 mAh g ${ }^{-1}$ specific capacity, 3.3-4 V average voltage, 200-250 $\mathrm{Wh} \mathrm{kg}^{-1}$ gravimetric energy density, 350-600 $\mathrm{Wh} \mathrm{L}^{-1}$ volumetric energy density, at least 3 years of life, $>99 \%$ energy efficiency, $0.3-2.5 \%$ self-discharge rate per month, and almost no maintenance [2-4]. However, recent concerns over global warming and other environmental issues incentivized the demands of electric mobility (e-mobility) to shrug off the dependence on pollutioncausing fuels. Superior electrochemical properties make LIBs the automatic choice for e-mobility. But the energy density and safety aspects of LIBs need to be reconsidered for applications like longhaul electric trucks, electric trains, electric aviation, etc. At the same time, the cost is required to be lowered for stationary grid storage [5-7].

Conventional LIBs comprise a $\mathrm{Li}$-ion insertion anode (e.g., graphite, $\mathrm{Li}_{4} \mathrm{Ti}_{5} \mathrm{O}_{12}$, metal oxides, alloys, etc.) and a cathode (e.g., layered metal oxide like $\mathrm{LiCoO}_{2}$, spinel oxides like $\mathrm{LiMn}_{2} \mathrm{O}_{4}$, or olivine $\mathrm{LiFePO}_{4}$, etc.). The electrolyte used for the traditional system is a Li-salt (e.g., LiPF $\mathrm{LiBF}_{4}$ ) in organic solvents like a mixture of alkyl carbonates (e.g., ethylene carbonate, dimethyl carbonate, etc.). A full Li-ion cell consists of $10-15 \%$ of lithium [8, 9]. Reversible to and fro movement of $\mathrm{Li}^{+}$and $\mathrm{e}^{-}$via an inner and outer circuit, respectively, results in the interconversion between electrical and chemical energy.

The cathode materials for LIBs can be classified into insertion type and conversion type based on mechanisms $[4,10,11]$. Conventionally, the cathode materials used for LIBs are insertion-type metal oxides such as layered $\mathrm{LiMO}_{2}\left(\mathrm{M}=\mathrm{Co}, \mathrm{Ni}, \mathrm{Mn}\right.$ ), $\mathrm{LiNi}_{1-\mathrm{y}-\mathrm{Z}} \mathrm{Mn}_{\mathrm{y}} \mathrm{Co}_{z} \mathrm{O}_{2}(\mathrm{Li}-\mathrm{NMC}), \mathrm{Li}_{x} \mathrm{Mn}_{2} \mathrm{O}_{4}$ type spinel, polyanionic based transition metal phosphates (e.g., LiFePO${ }_{4}$ ), etc. The electrode reaction for insertion-type materials does not involve any structural change in the host matrix and hence performs with stability during prolonged cycling. But the redox reaction for this type of material is $\mathrm{Li}$-site limited and involves the transfer of a maximum of one electron per formula unit. The $\mathrm{LiMO}_{2}$ type cathode materials deliver practical capacities in the range of 140-220 $\mathrm{mAh} \mathrm{g}^{-1}$. The upper cutoff voltages for $\mathrm{LiCOO}_{2}$ and $\mathrm{LiNiO}_{2}$ cannot be increased beyond 4.2 and $4.3 \mathrm{~V}$, respectively, as oxygen gas is released due to their thermal instability. $\mathrm{LiCoO}_{2}$ further undergoes structural distortion to tetragonal phase from the electrochemically active hexagonal phase beyond $4.2 \mathrm{~V}$. $\mathrm{LiNiO}_{2}$ also suffers degradation through $\mathrm{Li} / \mathrm{Ni}$ cation mixing (antisite disorder) [12-16]. $\mathrm{LiMnO}_{2}$ is chemically stable at higher voltages (till $\sim 4.8 \mathrm{~V}$ ) as no exothermic gas evolution occurs. But during cycling, performance degradation is observed due to the dissolution of active form to inactive components [4]. Thus, a mixed oxide in different compositions of $\mathrm{LiNi}_{1-\mathrm{y}-\mathrm{M}} \mathrm{Mn}_{\mathrm{y}} \mathrm{Co}_{2} \mathrm{O}_{2}$ (Li-NMC) was reported to 
cycle with stabile capacity (140-180 $\mathrm{mAh} \mathrm{g}^{-1}$ as compared to LMO due to the synergistic effects of the conductivity of $\mathrm{Co}$, high voltage of $\mathrm{Ni}$, and thermal stability of $\mathrm{Mn}$. $\mathrm{Ni}$ and Co are electrochemically active, and Mn acts as a stabilizer). Li and Mn-rich NMCs are stable up to $4.8 \mathrm{~V}$ and delivered a capacity of $\sim 250 \mathrm{mAh} \mathrm{g}^{-1}$ during initial cycles. Still, the performance degrades due to the formation of various by-products through secondary reactions such as activation of $\mathrm{Li}_{2} \mathrm{MnO}_{3}$ beyond 4.4 V [17-19]. $\mathrm{Li}_{x} \mathrm{Mn}_{2} \mathrm{O}_{4}$ shows a theoretical capacity of $148 \mathrm{mAh} \mathrm{g}^{-1}$ with the extraction of 1 lithium at an average potential of $4 \mathrm{~V}$, indicating higher thermal stability than $\mathrm{LCO}$. The main reason behind the degradation of spinel $\mathrm{Li}_{x} \mathrm{Mn}_{2} \mathrm{O}_{4}(0<x<1)$ is considered to be Jahn Teller distortion and $\mathrm{Mn}^{3+}$ disproportionation reactions below 3V [20-22]. The disproportionation reaction can be controlled by maintaining the oxidation state of $\mathrm{Mn}$ above 3.5 through doping other metals like $\mathrm{Ni}$, $\mathrm{Ti}, \mathrm{Mg}$, etc., and surface coatings with highly conductive carbons like carbon nanotubes (CNTs), graphene, etc. [10]. Olivine structures, such as those of $\mathrm{LiMPO}_{4}(\mathrm{M}=\mathrm{Fe}, \mathrm{Mn}, \mathrm{Ni}, \mathrm{Co})$, are characterized by high structural stability and Li-ion storage capacities around $170 \mathrm{mAh} \mathrm{g}^{-1}$ [23]. $\mathrm{LiFePO}_{4}$ has an average voltage of $3.5 \mathrm{~V}$ vs. $\mathrm{Li} / \mathrm{Li}^{+}$, and $\mathrm{LiMnPO}_{4}, \mathrm{LiCoPO}_{4}$, and $\mathrm{LiNiPO}_{4}$ have a $\mathrm{Li}$ insertion potential of $4.1,4.8$, and $5.1 \mathrm{~V}$, respectively $[10,23,24]$. Phospo-olivines composed of stable mixed metallic compositions are being explored as high-energy cathode materials due to their higher lithium insertion potential.

The overall performance of LIBs is cathode-limited in terms of ion storage capacity and voltage output. The reversible capacity of commercial graphite and silicon anode is much higher than that of conventional cathodes. Thus, to balance the capacity ratio of cathode and anode in a lithium-ion cell, an excess amount of active cathode material must be used to increase the total weight of the cell. The extra cathode portion comes with a cost as it contains expensive transition metals, also increasing the total cost of the cell. High-capacity cathode materials may cut down that extra cost and weight per cell of a LIB module. High voltage cathode materials are advantageous from the perspective of LIB modules. If the voltage of each cell is relatively higher, a lesser number of cells are required to reach the targeted module voltage decreasing the complexity of cell packing. Moreover, the requirement of a lower current to deliver a particular power value reduces IR (internal resistance) loss. The criteria to balance all the properties like higher energy density, improved safety, low cost, etc., in a single material is challenging, and the research window on novel cathode materials is always open $[25,26]$. The energy density of the material can be increased by either pushing the capacity or lifting the voltage. Techniques for capacity increment are exclusively studied, but the paths for voltage upliftment are less explored. Elaborate discussions on commercial cathode materials are available in the literature [27-31]. Scope of this article is stressed on the materials that show either capacity $>250 \mathrm{mAh} \mathrm{g}^{-1}$ (lithium excess layered oxides, lithium excess cation disordered rock salt oxides, conversion cathodes) or voltage $>4 \mathrm{~V}$ (polyanionic oxides, spinel oxides) and yet to be commercialized. Figure 1 depicts the material that follows the selection criteria. This review focuses on understanding the crystal structure, lithium storing mechanism, potential shortcomings, and probable way-outs of cathode materials. Also, a historical timeline of the development of cathode materials for LIBs is given briefly, and the remaining challenges for commercialization are sketched. 


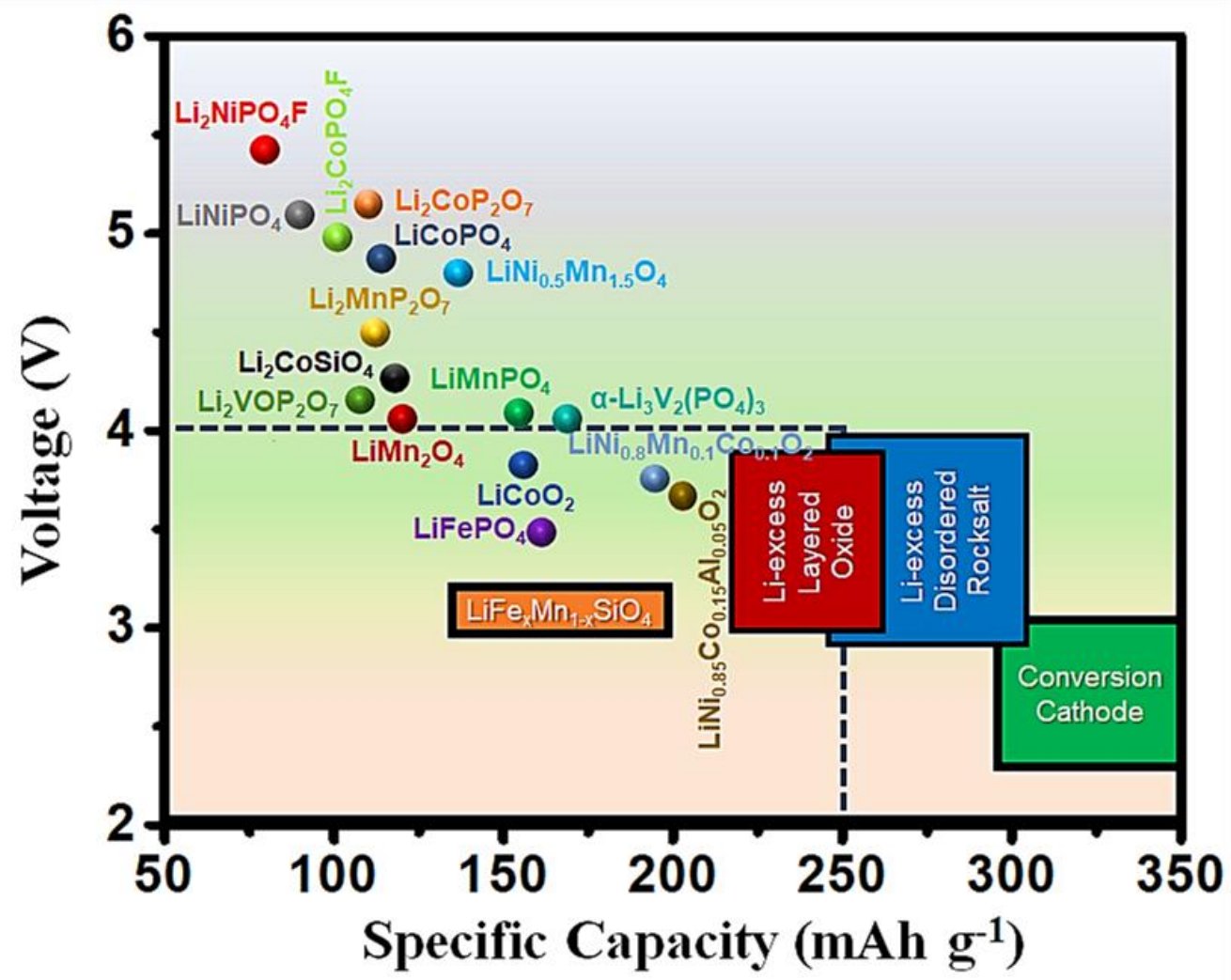

Figure 1 Approximate range of average discharge voltage and specific capacity of LIB cathode materials. Materials that lie beyond the $4 \mathrm{~V}-250 \mathrm{mAh} \mathrm{g}^{-1}$ range (dotted line square) are chosen to discuss in this review.

\section{Historical Development of LIBS}

During the decade of 1960-1970s, research on energy storage and conversion became concentrated towards the electrochemistry of $\mathrm{H}^{+} /$alkali metal ion storing at solid state $[32,33]$. The electrochemical concept of the modern-day LIBs came into the limelight after the unveiling of guesthost intercalation into the metal oxide matrix by Armand et al. during the 1970s [34]. This work demonstrated the intercalation of ions into Prussian blue-type materials such as iron cyanide bronzes in 1972 [35]. During the same year, Brian Steele at the NATO conference in Italy and other group researchers, including Gamble et al., and Dines et al. (Exxon USA) indicated the applicability of transition metal dichalcogenides as intercalation electrode materials [36-39] In the same conference, Armand revealed demonstrated $\mathrm{CrO}_{3}$ embedded within graphite planes as the electrodes for the first reported Li/Na solid-state batteries with $\beta$-alumina electrolyte [39]. The metal chalcogenides showed faster intercalation kinetics according to the reports by Rao et al. (IBM, USA) and Rouxel group in France during 1974 [40, 41]. During that same period, M.S. Whittingham used layered metal dichalcogenides to store Li-ions. He named the Li-ion storing mechanism as 'the intercalation mechanism', and showed reversible at room temperature (298 K)[42]. In 1976, Exxon, USA, developed $\mathrm{Li} \mid \mathrm{TiS}_{2}$ batteries with energy densities of $130 \mathrm{Wh} \mathrm{kg}^{-1}\left(280 \mathrm{Wh} \mathrm{L}^{-1}\right)$. $\mathrm{TiS}_{2}$ is a hexagonal packed crystal structure having lithium intercalation sites with a theoretical capacity of $240 \mathrm{mAh} \mathrm{g}^{-1}$. But the nominal voltage for these cells is $\sim 2 \mathrm{~V}$, which limited their deliverable energy density. Also, difficulty in material production and spontaneous secondary reactions in the cell resulting in the release of $\mathrm{H}_{2} \mathrm{~S}$ gas became an issue for practical use [10]. 
In the later part of 1979 , Godshall et al. demonstrated the intercalation property of $\mathrm{LiCoO}_{2}$ (popularly abbreviated as LCO) at a high potential of $\sim 3.7 \mathrm{~V}$ at elevated temperature conditions $\left(400-450{ }^{\circ} \mathrm{C}\right.$ ) [43]. Around the same time (in the early 1980s), J.B. Goodenough and coworkers reported the $\mathrm{Li}$-ion intercalation property of $\mathrm{LiCoO}_{2}$ at room temperature and thus, paved the way for feasible high voltage cathode materials for LIBs [44]. In 1983, the lithium intercalation property of the spinel-type oxide, $\mathrm{LiMn}_{2} \mathrm{O}_{4}$ cathodes with higher thermal stability compared to LCO was studied by Thackeray et al. [45]. Meanwhile, reversible Li-ion intercalation into graphitic carbon was being studied by Samar Basu (1981) [46] and Yazami in 1983 [47], which led to the development of the Li-ion battery by Akira Yoshino using the LCO cathode and intercalation-type carbon coke anode in the year 1985 [48]. Around the same time (during 1987), Moli energy Ltd commercialized the Li$\mathrm{MoS}_{2}$ battery (MOLICEL) with an energy density of $60-65 \mathrm{Wh} \mathrm{kg}^{-1}$ and potential in the range $2.3-1.3$ $\mathrm{V}$, but all the batteries were called off due to fire incidents. This unfortunate incident surceased the development of lithium metal batteries (LMBs) during that era [49].

The dominance of LIBs in the energy industry began with the first commercialization of the 18650 cells by Sony Ltd. in 1991 [50]. Following this path-breaking discovery, several attempts were made to improve the energy density and cycling performance using different cathode materials. J.B. Goodenough introduced polyanionic oxides and phosphates for Li-ion insertion cathode, and in 1996 Padhi et al. demonstrated the performance of $1 \mathrm{D}$ olivine $\mathrm{LiFePO}_{4}$ as LIB cathodes [23]. Other polyanionic compounds such as silicates, sulfates, phosphates, vanadium phosphates, fluorophosphates, and fluorosulphates were studied as high voltage cathodes for LIBs thereafter. In 1998, layered lithium manganese oxide cathodes derived from rock salt precursors were introduced [51].

VL18650 based on lithium mixed oxide $\mathrm{LiNi}_{0.8} \mathrm{Co}_{0.15} \mathrm{Al}_{0.05} \mathrm{O}_{2}$ termed as NCA cathodes were commercialized by SAFT for longer temperature range $\left(-20\right.$ to $\left.60^{\circ} \mathrm{C}\right)$ applications. In the early $2000 \mathrm{~s}$, layered mixed oxides $\mathrm{LiNi}_{x} \mathrm{Mn}_{\mathrm{y}} \mathrm{CO}_{z} \mathrm{O}_{2}$, where $\mathrm{x}+\mathrm{y}+\mathrm{z}=1$ (NMC) were demonstrated as LIB cathodes with higher stability, and since then, various compositions of these mixed oxides are studied. Thackeray and the group introduced Lithium-rich NMC with higher capacity in 2005 [52], and the conductivity was enhanced using carbon coating to increase stability. Thereafter, various strategies, including doping with metals such as $\mathrm{Ni}, \mathrm{Al}, \mathrm{Mn}$, compositional optimization, nano-structuring, and composite formation with the carbon of the layered, spinel, and polyanionic cathodes, have been explored and optimized for commercial applications. Other than these types of insertion cathodes, conversion type cathodes with higher capacity have also been studied for LIBs. In 2005, M.S. Whittingham demonstrated two lithium transfer reactions from $\mathrm{Li}_{2} \mathrm{VOPO}_{4}[10,53,54]$. In the late 2000s, the concept of anionic redox was introduced, and for the first time, reversible cathode capacity beyond $250 \mathrm{mAh} \mathrm{g}^{-1}$ was achieved. Measuring the huge success of rechargeable LIBs in all portable electronic sectors, electric mobility, and other potential fields, Nobel Prize was awarded to J.B. Goodenough, Akira Yoshino, and M.S. Whittingham in 2019. Over the last three decades, LIBs have been manufactured by several companies such as Sanyo, Matsushita, Hitachi, Yuasa, Moli, A\&T, SAFT, TESLA, etc., and the research and development in this field have increased exponentially with an increase in the demand for energy with growing civilization. Figure 2 highlights the essential discoveries made in the history of LIB cathodes. 


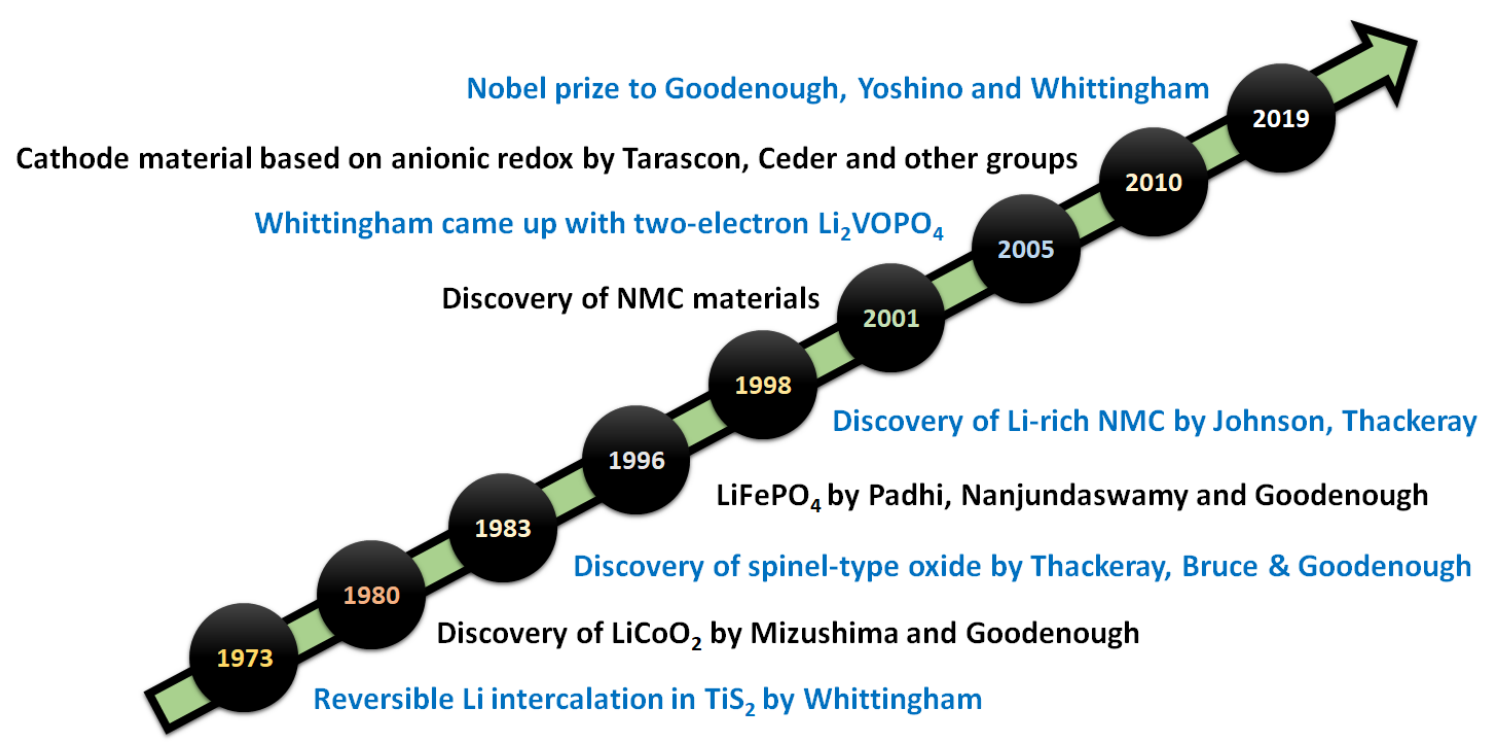

Figure 2 Milestones in the history of LIB cathode discovery.

\section{Description of Two Basis Performance Measuring Unit of Battery: Capacity and Voltage}

\subsection{Capacity of a Battery}

The capacity of a battery reflects its capability to store energy. From the material point of view, it is the ability to store lithium ions reversibly. Lithium ions can be stored at a particular crystal site in intercalation-type materials, or they can react with the host material in conversion-type materials. The storage capacity is determined by the amount of lithium that can be reversibly inserted into the host via a reversible first-order phase transition. Insertion of charged species, i.e., $\mathrm{Li}^{+}$, into a host changes its valence state, which is compensated by oxidation or reduction of TMs and ejection or incorporation of electrons in the metal $d$-band. The factors for determining energy storage capacity: - a) reversibility of TM redox properties, b) the available space for accommodating lithium ions, and c) reversibility of lithium insertion reactions. Pathways to increase capacity include modifying any such property mentioned above. Generally, conversion-type cathodes demonstrate higher capacity than insertion-type materials. Conversion reaction between $L i$ and host generates high capacities, whereas insertion sites inside a crystal are limited by the orientation of the crystalforming elements. This article reviews only those materials which show a capacity of $>250 \mathrm{mAh} \mathrm{g}^{-1}$. Lithium-rich ordered, lithium-rich cation disordered rock salt, and conversion type materials fall under this category.

\subsection{Potential of a Battery}

The difference in chemical potential between the anode $\left(\mu_{\mathrm{a}}\right)$ and cathode $\left(\mu_{\mathrm{c}}\right)$ divided by the magnitude of electronic charge ( $|\mathrm{e}|$ is taken for calculation, neglecting the negative sign) is termed as open-circuit voltage (OCV) or working voltage.

$$
V=\frac{\mu_{a}-\mu_{c}}{|e|}
$$


The voltage is limited by the electrochemical potential window of the electrolyte. The energies of $\mu_{\mathrm{a}}$ and $\mu_{\mathrm{c}}$ should reside in between the energies of the highest occupied molecular orbital (HOMO) and lowest unoccupied molecular orbital (LUMO) of the electrolytes (Figure 3a). Otherwise, electron transfer occurs from HOMO to $\mu_{\mathrm{c}}$ and $\mu_{\mathrm{a}}$ to LUMO, resulting in the oxidation of electrolyte at the cathode and reduction of electrolyte at the anode, respectively [55]. Decomposed product accumulates on the electrode surface to form a surface film called 'electrode-electrolyte interphase (EEI)' or solid-electrolyte interphase (SEI) more commonly at the anode [56]. Porosity, Li-ion conductivity, thickness, chemical stability, and compatibility of the interphase with other cell components are critical for a battery's function. The growth of SEI increases the internal resistance, which causes the voltage and capacity fade. In terms of molecular orbital theory, the relative Fermi level energy in the band structure of LIB cathodes is defined as OCV. Fermi level $\left(E_{F}\right)$ is related to the electrochemical potential. Holes above $E_{F}$ and electrons below $E_{F}$ form a redox couple. If the significant TM redox couple in the structure overlaps with the $0-2 p$ band, then oxygen evolution concomitantly occurs with TM redox. Therefore, the material should be designed in such a way that overlap can be avoided.
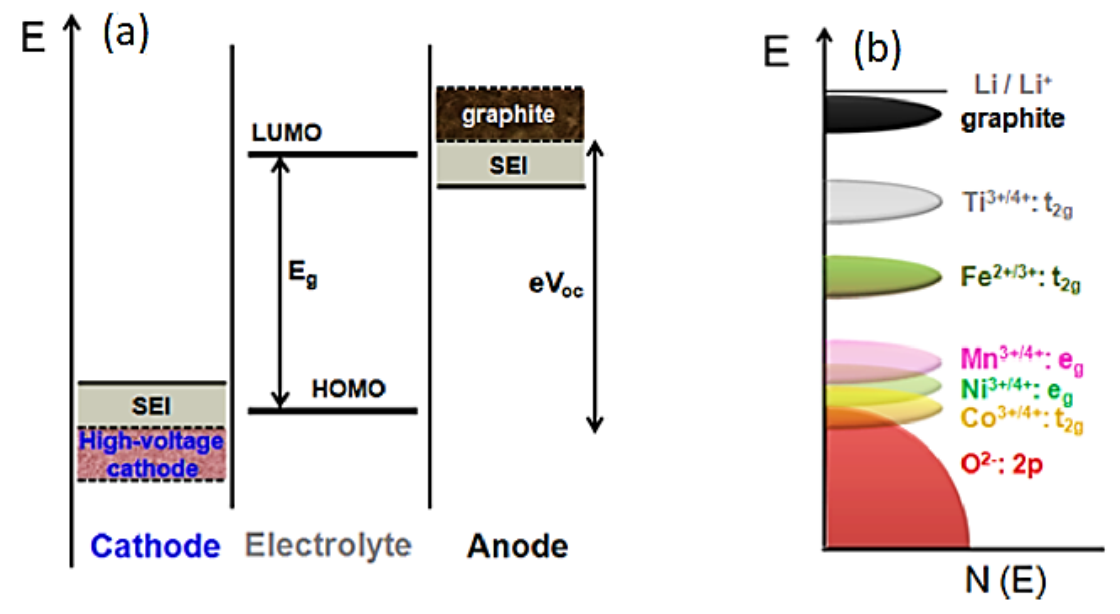

Figure 3 (a) Electrochemical potential window of the electrolyte. Relative energy levels of cathode, anode, and electrolyte at open circuit condition and (b) Relative position of the various transition metal redox couples in between metallic lithium and oxygen energy levels. Reprinted with permission from reference [57]. Copyright 2017 American Chemical Society.

\subsubsection{Origin of Potential Hysteresis}

Asymmetry between the charge and discharge profile is expressed as potential hysteresis. The origin of hysteresis lies in the difference in the energy transfer between the charge and discharge processes. The charge is associated with lithium extraction from the host lattice and ejection of the electron from the d-orbital of TM. During the discharge process, lithium is reinserted into the designated site, and the electron gets back to the d-orbital. The reinsertion of lithium and electron stabilizes the host, energetically excited after charge, while deinsertion of lithium and electron during charge destabilizes the system. Therefore, prior to the process of deinsertion, lithium-ion and electron must be promoted to the excited state. The extra promotion energy accounts for the 
relatively higher energy gain in charge than delivered during discharge [58]. This energy difference is attributed to the potential gap between the charge and discharge processes.

\subsubsection{Raising the Voltage of a Battery}

The electrochemical potential $(E)$ of the electrode material is related to a change in the internal energy due to ion and electron transfer, i.e., Gibbs free energy $(\Delta G)$. Ions exert a dominant effect over electrons. The relation can be expressed as follows:

$$
E=\frac{-\Delta \mathrm{G}}{\mathrm{nF}}
$$

where $\mathrm{n}$ is the number of electrons transferred during the charge and discharge processes, and $\mathrm{F}$ is the Faraday constant. Therefore, the equation predicts that the more energy released during ions or electrons are inserted into the host lattice, or more energy consumed during ions or electrons are released, the higher is the electrochemical potential. The change in the Gibbs free energy depends on the ionic radius, valence state, electronegativity, and local environment of the metal ions in the host.

Insertion Oxides: Going from left to right in a particular period in the transition metal series of the periodic table, the number of d-electrons increases. If the ions are under similar coordination and valence, ionic radius gradually decreases, and the attraction on outermost electrons by atomic nuclei increases. Therefore, greater energy is needed for electron transfer resulting in higher electrochemical potential in going from left to right in a particular period. Extending the similar line of logic, electrochemical potential decreases going down a group in the periodic table as the ionic radius of the ions having the same valence and coordination states decreases down the group. Figure $3 \mathrm{~b}$ provides the relative position of the transition metal redox couples between $\mathrm{Li}^{+} / \mathrm{Li}^{\text {and }} \mathrm{O}$ $2 p$ energy levels [57].

Polyanionic Groups: Polyanionic groups are different from layered oxides. Oxygen is coordinated with $X$ atom besides TM (M), unlike oxides, creating $M-O-X$ linkages instead of $M-O$ linkages. For easy understanding, let us focus on Fe. For instance, in $\mathrm{Fe}_{2}\left(\mathrm{XO}_{4}\right)_{3},(X=\mathrm{Mo}, \mathrm{Si}, \mathrm{P}, \mathrm{S}, \mathrm{W}$, $\mathrm{B}$, etc.), the $\mathrm{FeO}_{6}$ octahedra shares corners with the $\mathrm{XO}_{4}$ tetrahedra, and extended version on $\mathrm{M}-\mathrm{O}-\mathrm{X}$ linkage can be rewritten as -O-Fe-O-X-O-Fe-O-. Therefore, the presence of a less electronegative $\mathrm{X}$ in place of greater electronegative oxygen increases the covalency between the $\mathrm{O}-\mathrm{X}$ linkage rendering the $\mathrm{M}$ $O$ bond more ionic than earlier. Thus, the inductive effect of $X$ increases the operating voltage of the system [59]. The trends in the operating potential observed in some iron-containing $\left(\mathrm{Fe}^{+3 /+2}\right.$ couple) polyhedral compounds are depicted in Figure 4. Generally, the operating potential of several polyanionic groups runs as follows $-\mathrm{P}_{2} \mathrm{O}_{7}>\mathrm{PO}_{4}>\mathrm{BO}_{3}>\mathrm{SiO}_{4}$. A high degree of electron delocalization in the $\mathrm{P}_{2} \mathrm{O}_{7}$ moiety raises voltage slightly higher than $\mathrm{PO}_{4}$. 


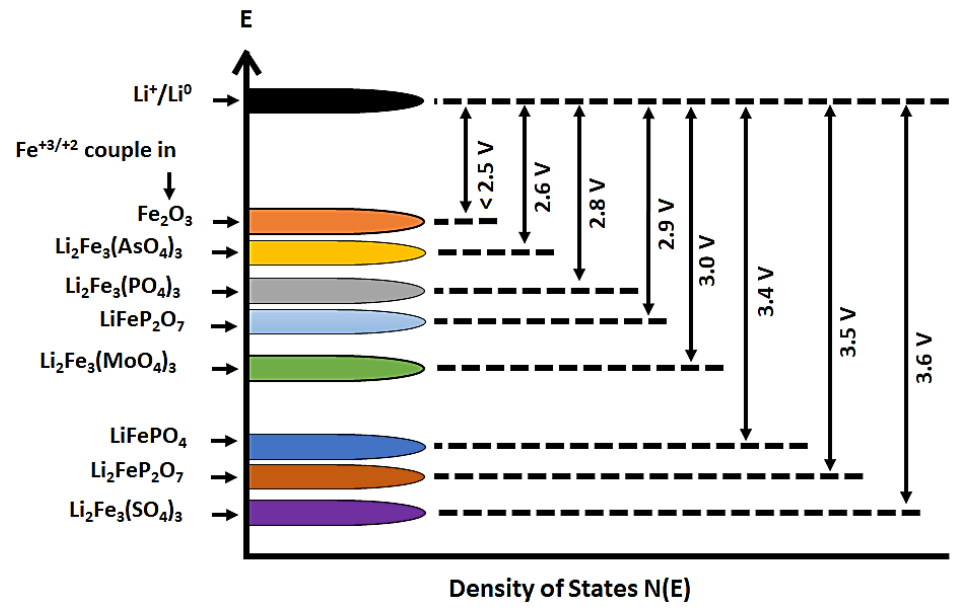

Figure 4 Relative voltage of the $\mathrm{Fe}^{+3 /+2}$ couple in various polyhedral structures.

\section{High-capacity Cathodes (Only >250 $\mathrm{mAh} \mathrm{g}^{-1}$ )}

Materials that show a capacity of $>250 \mathrm{mAh} \mathrm{g}^{-1}$ are only included in this review.

\subsection{Lithium Excess Layered Oxides}

Lithium and Manganese-rich layered oxides (LMR-LOs) is another class of cathode materials that demonstrate a high capacity of $>250 \mathrm{mAh} \mathrm{g}^{-1}$ along with high voltage to push the specific energy density beyond $1000 \mathrm{Wh} \mathrm{kg}^{-1}$. Table 1 shows the comparison of LMR-LOs first with other commercial LIB cathode materials in terms of electrochemical characteristics. The crystal structure, lithiationdelithiation mechanism, voltage fade phenomena, poor cycle life, etc., are quite distinct in LMR-LOs than the conventional class of materials. This section sheds light on these aspects.

Table 1 Relative electrochemical properties of standard LIB cathode materials.

\begin{tabular}{|c|c|c|c|c|c|c|}
\hline Properties & $\mathrm{LiCoO}_{2}$ & $\mathrm{LiFePO}_{4}$ & $\mathrm{LiMn}_{2} \mathrm{O}_{4}$ & $\begin{array}{l}\mathrm{LiNi}_{x} \mathrm{Mn}_{y} \mathrm{Co}_{z} \mathrm{O}_{2} \\
(x+y+z=1)\end{array}$ & $\begin{array}{l}\mathrm{LiNi}_{x} \mathrm{Co}_{y} \mathrm{Al}_{z} \mathrm{O}_{2} \\
(x+y+z=1)\end{array}$ & $\begin{array}{l}\mathrm{xLi}_{2} \mathrm{MnO}_{3} . \\
(1-\mathrm{x}) \mathrm{LiMO}_{2}\end{array}$ \\
\hline $\begin{array}{l}\text { Theoretical } \\
\text { capacity } \\
\left(\mathrm{mAh} \mathrm{g}^{-1}\right)\end{array}$ & 274 & 170 & 148 & $270-280$ & 274 & 280 \\
\hline $\begin{array}{l}\text { Practical } \\
\text { capacity* } \\
\left(\mathrm{mAh} \mathrm{g}{ }^{-1}\right)\end{array}$ & $140-150$ & $145-150$ & $110-120$ & $160-190^{\#}$ & $160-180$ & $250-300$ \\
\hline $\begin{array}{l}\text { Operating } \\
\text { voltage (V) }\end{array}$ & 3.7 & $\sim 3.4$ & 3.9 & $3.5-3.8^{\#}$ & $\sim 3.8$ & $\sim 3.6$ \\
\hline $\begin{array}{l}\text { Energy } \\
\text { density (Wh } \\
\mathrm{kg}^{-1} \text { ) }\end{array}$ & $520-550$ & $490-510$ & $430-470$ & $550-700^{\#}$ & $600-650$ & $900-1000$ \\
\hline Cycle life & $500-1000$ & $\begin{array}{l}2000- \\
5000\end{array}$ & $\begin{array}{l}1000- \\
2000\end{array}$ & $500-2000$ & $500-1500$ & $200-500$ \\
\hline
\end{tabular}

* depends on applied voltage range. ${ }^{*}$ depends on the value of $x, y$, and $z$. 


\subsubsection{Chemical Composition and Structure}

The concept of LMR-LO cathodes was first proposed in the 1990s [60]. The chemical formula is denoted as $x \mathrm{Li}_{2} \mathrm{MnO}_{3} \cdot(1-x) \mathrm{LiMO}_{2}$, where $\mathrm{M}$ is in the form of different metals such as $\mathrm{Co}, \mathrm{Ni}, \mathrm{Mn}, \mathrm{Cr}$, $\mathrm{Fe}, \mathrm{Mg}$, Al, etc., or a mixture of them give rise to various compositions. Classically, the crystal structure (Figure 5) comprises of two components: a rhombohedral $\mathrm{LiMO}_{2}$ phase with a space group $R \overline{3} m$ and a monoclinic $\mathrm{Li}_{2} \mathrm{MnO}_{3}$ phase with a space group $\mathrm{C} 2 / m$. The formula $\mathrm{Li}_{2} \mathrm{MnO}_{3}$ can be alternatively expressed as $\mathrm{Li}\left(\mathrm{Li}_{1 / 3} \mathrm{Mn}_{2 / 3}\right) \mathrm{O}_{2}$, i.e., lithium ions replacing one-third of the $\mathrm{Mn}$ ions in the $\mathrm{LiMO}_{2}$ phase, and the structure can be visualized to be formed by stacking alternating $\left(\mathrm{Li}_{1 / 3} \mathrm{Mn}_{2 / 3}\right)$ and Li layers [52]. A similar interlayer spacing of $0.47 \mathrm{~nm}$ among the (001) monoclinic planes and the (003) rhombohedral planes show the atomic level compatibility between the two phases in a closed-packed layered structure [61]. Therefore, all the peaks in the powder X-ray diffraction (XRD) pattern can be indexed according to the $\alpha-\mathrm{NaFeO}_{2}$ type rock-salt structure. However, the microstructural complexity has given rise to contradictory theories on whether to categorize it as a solid solution or nanocomposite [52,62]. But the several studies have revealed that the two phases could intergrow, structurally integrable, and coexist in the domain $[52,63]$. The high angle annular dark field scanning transmission electron microscopy (STEM-HAADF) image in Figure 4a and Figure $4 \mathrm{~d}$ shows that both phases can coexist even in a single nanoparticle [59, 64]. Yu et al. demonstrated the symbiosis between the two phases and the heterointerface along the $[001]_{\mathrm{rh}}$ zone axis direction through annular bright field scanning transmission electron microscopy (ABF-STEM) study [65].
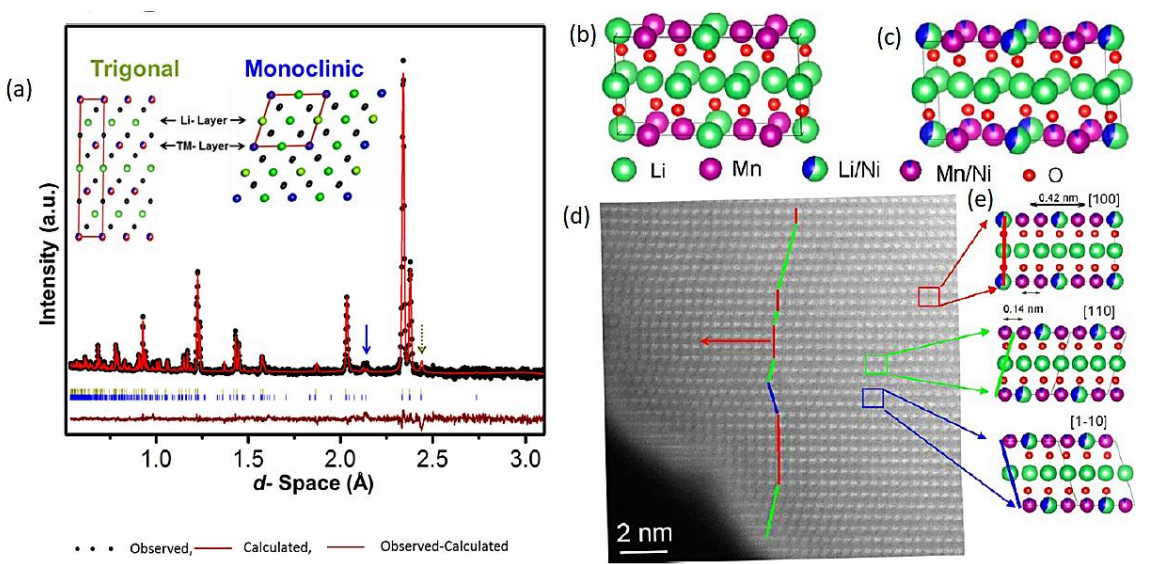

Figure 5 (a) Refined powder neutron diffraction data considering composites of monoclinic $\mathrm{Li}_{2} \mathrm{MnO}_{3}$ and trigonal $\mathrm{LiMO}_{2}(\mathrm{M}=\mathrm{Ni}, \mathrm{Co}$, and $\mathrm{Mn}$ ) unit cells. The different color of the atoms in the TM layer represents different TM ions present at the same site. The solid blue arrow shows the cation-ordering peaks exclusively from monoclinic $\mathrm{Li}_{2} \mathrm{MnO}_{3}$ unit cell, and the dotted arrow represents the (101) reflection in the trigonal phase and the $(130) /(20 \overline{1})$ reflections in the monoclinic phase. Reprinted with permission from reference [59]. Copyright 2013 American Chemical Society. Atomic model of (b) $\mathrm{Li}_{2} \mathrm{MnO}_{3}$, (c) Ni-containing $\mathrm{Li}_{2} \mathrm{MO}_{3}$, experimental Z-contrast image of the $\mathrm{C} 2 / \mathrm{m}$ phase; (d) [100], [110], [11̄0] zone projection of the $\mathrm{C} 2 / \mathrm{m}$ phase. The zone axes projection regions are labeled with different colored lines in the image $d$ and labeled in squared boxes corresponding to the atomic model in panel e. The fast Li-ion diffusion channel is marked in a red arrow in panel $\mathrm{d}$. Reprinted with permission from reference [66]. Copyright 2013 American Chemical Society. 


\subsubsection{Lithiation-delithiation Mechanism}

The lithiation-delithiation mechanism of LMR-LO cathodes are complex than conventional materials due to the coexistence of the two phases. The initial charge-discharge behavior is different - from the subsequent cycles due to several simultaneous changes in the crystal structure. The transition metal redox process is accompanied by the oxygen redox process under conditions of high voltage. The process of oxygen redox can be further divided into two steps: - a) reversible oxygen redox from the bulk and $b$ ) irreversible oxygen gas evolution from the surface. The Li-excess $\mathrm{Li}_{2} \mathrm{MnO}_{3}$ phase supplies extra lithium and triggers the oxygen redox phenomena. This section explores the details of the anomalous charge-discharge mechanism of LMR-LO cathodes.

First Charge-discharge Cycle: The upper charge cut-off voltage for galvanostatic cycling is generally extended up to $4.8 \mathrm{~V}$ starting from $2.0 \mathrm{~V}$, for the LMR-LO cathodes to include the capacity contribution at $\geq 4.5 \mathrm{~V}$ from the $\mathrm{Li}_{2} \mathrm{MnO}_{3}$ phase. The first charge and discharge proceed with two plateaus [67]. Charge up to $4.4 \mathrm{~V}$ range is dominated by transition metal redox of $\mathrm{LiMO}_{2}$ phase. The $\mathrm{Ni}^{+2 /+4}$ and $\mathrm{Co}^{+3 /+4}$ redox allow lithium deintercalation, whereas $\mathrm{Mn}^{+4}$ does not contribute like in $\mathrm{NMC}$ cathodes [68]. The $\mathrm{Li}_{2} \mathrm{MnO}_{3}$ phase remains invariant at this stage. At around $4.5 \mathrm{~V}$, the $\mathrm{Li}_{2} \mathrm{MnO}_{3}$ superlattice gets activated and results in surface oxygen evolution along with $\mathrm{Li}^{+}$extraction from the transition metal layers [69]. The charge in the higher potential region is driven by oxygen redox at bulk as seen in Figure 6a. As a result, the transition metals migrate to the interstitial oxygen defects and vacated octahedral lithium sites to maintain structural integrity after deep delithiation. It initiates the formation of the spinel phase at the surface region [70, 71]. Irreversibly blocked TMs at defect sites resist further lithium reintercalation during discharge and are responsible for large voltage hysteresis between the charge and discharge curves [72]. During discharge, high voltage lithium reintercalation into the TM layer is supported by $\mathrm{TM}\left(\mathrm{Ni}^{+4}, \mathrm{Co}^{+4}\right.$, and $\left.\mathrm{Mn}^{+4}\right)$ reduction and oxygen redox. In contrast, lithium is reinserted into the lithium layer at low voltage by further $\mathrm{Mn}^{+4}$ reduction (Figure 6b) [73, 74]. The irreversible capacity loss that accounts for a value of approximately $50-100 \mathrm{mAh} \mathrm{g}^{-1}$ is attributed to the loss of lithium in the form of $\mathrm{Li}_{2} \mathrm{O}$ from the material surface and the formation of $\mathrm{MnO}_{2}$, which takes part in lithiation-delithiation in subsequent cycles [75-77].
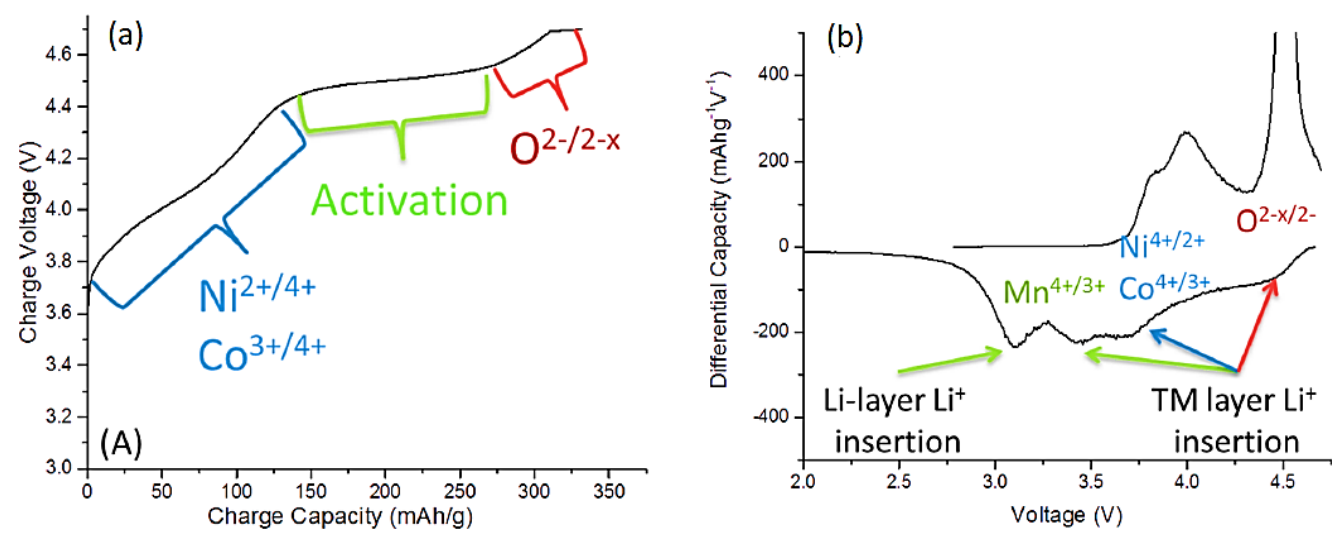

Figure 6 (a) First charge cycle and (b) first cycle dQ/dV profile recorded for Li and $\mathrm{Mn}$ rich $0.35 \mathrm{LiMn}_{2} \mathrm{O}_{3} \cdot 0.65 \mathrm{Li}\left[\mathrm{Mn}_{0.45} \mathrm{Ni}_{0.35} \mathrm{Co}_{0.20}\right] \mathrm{O}_{2}$ electrode in $\mathrm{Li}$-cell at $\mathrm{C} / 20$ rate, $30{ }^{\circ} \mathrm{C}$. Reproduced from reference [67]. 
Subsequent Charge-discharge Cycles: Following the first cycle, the charge-discharge curves evolve differently. Overall, charging and discharging occur with oxygen release, TM migration, accumulation of spinel phase at surface, and other parasitic changes in the crystal structures that drain the capacity faster. Several degradation phenomena are intertwined to complicate the mechanistic interpretation. Advanced operando techniques such as in-situ XRD, SXAS (Synchrotron X-ray absorption spectroscopy), XANES (X-ray absorption near-edge spectroscopy), X-ray tomography, in-situ Raman microscopy, mass spectrometry, HAADF-STEM (High angle annular darkfield scanning transmission electron microscopy) equipped with EELS (Electron energy loss spectroscopy), DEMS (Differential electrochemical mass spectrometry), HAXPES (Hard X-ray photoelectron spectroscopy), and multi-length scale X-ray spectroscopic imaging, etc. are employed to elucidate the underlying processes $[65,68,74,78,79]$. This section is split into a few sub-sections for a clear understanding from the readers' perspective.

(i) Anionic Redox: Abnormal high capacity of LMR-LOs cannot be provided by TM redox alone. $\mathrm{Ni}^{+2 /+4}, \mathrm{Co}^{+3 /+4}$, and $\mathrm{Mn}^{+3 /+4}$ contribute a maximum of $170-180$ mAh g $^{-1}$ capacity, whereas the bulk oxygen redox accounts for the rest of the capacity. Several theories on oxygen redox are reported in the literature $[80,81]$. Whatever way it takes part in the charge-discharge mechanism, it also brings in several adverse side effects when oxygen gas is released from the surface. Initially, the highly reactive surface oxygen attacks the organic solvent in the electrolyte to produce $\mathrm{O}_{2}$ and $\mathrm{CO}_{2}$ gases. Surface oxygen can also form electrochemically inactive $\mathrm{Li}_{2} \mathrm{O}, \mathrm{Li}_{2} \mathrm{CO}_{3}$, etc., species that accumulate on the surface to impede the lithium diffusion process $[52,64]$. The resultant oxygen vacancies at the surface lead to TM migration, dislocation, and structural changes. The release of oxygen renders the surface porous, and increased porosity obstructs the electron percolation pathway in the active material [82]. Moreover, the exothermic nature of the process of gas release inside the cell supplies the activation energy towards TM migrations and triggers phase transition [83].

(ii) TM migration and Phase Transformation: Although the processes of delithiation and surface oxygen release cause TM reorganization, there is a threshold for such migration, i.e., tri-vacancy at adjacent tetrahedral sites [84]. TM migration does not create any concentration gradient during the first cycle. During cycling, Mn migrates from the surface to the interior via lithium vacancies and occupies vacant lithium sites in the TM layer. On the other hand, the surface gets densified with nickel cations, while the bulk of the material faces a nickel deficit. Thus, a concentration gradient is established, which slows down the lithium transportation rate [85]. X-ray tomography images in Figure 7 with 3D transition metal maps and percentage concentration of the TMs in the pie charts below show the relative distribution of the TMs in the cycled particles with respect to the pristine ones. In the pristine $\mathrm{Li}_{1.2} \mathrm{Mn}_{0.525} \mathrm{Ni}_{0.175} \mathrm{CO}_{0.1} \mathrm{O}_{2}$ particles, a $76 \% \mathrm{Mn}$-Co-Ni contribution suggests a major phase to be layered NMC. Following the first cycle, surprisingly, the content of the pure Mn phase was found to be only $7.5 \%$, and the content of the Mn-Co-Ni phase decreased to $44 \%$. This suggests that $\mathrm{Mn}$ segregation begins after the first cycle and the $\mathrm{Li}_{2} \mathrm{MnO}_{3}$ phase gradually forms throughout subsequent cycles. After 200 cycles, the Mn-Co-Ni content drops down to 37.3\%, while the pure $\mathrm{Mn}$ and $\mathrm{Ni}$ phase content was $10 \%$. The stark difference in the elemental distribution with the progression of cycling is the direct evidence of TM migration [78]. 

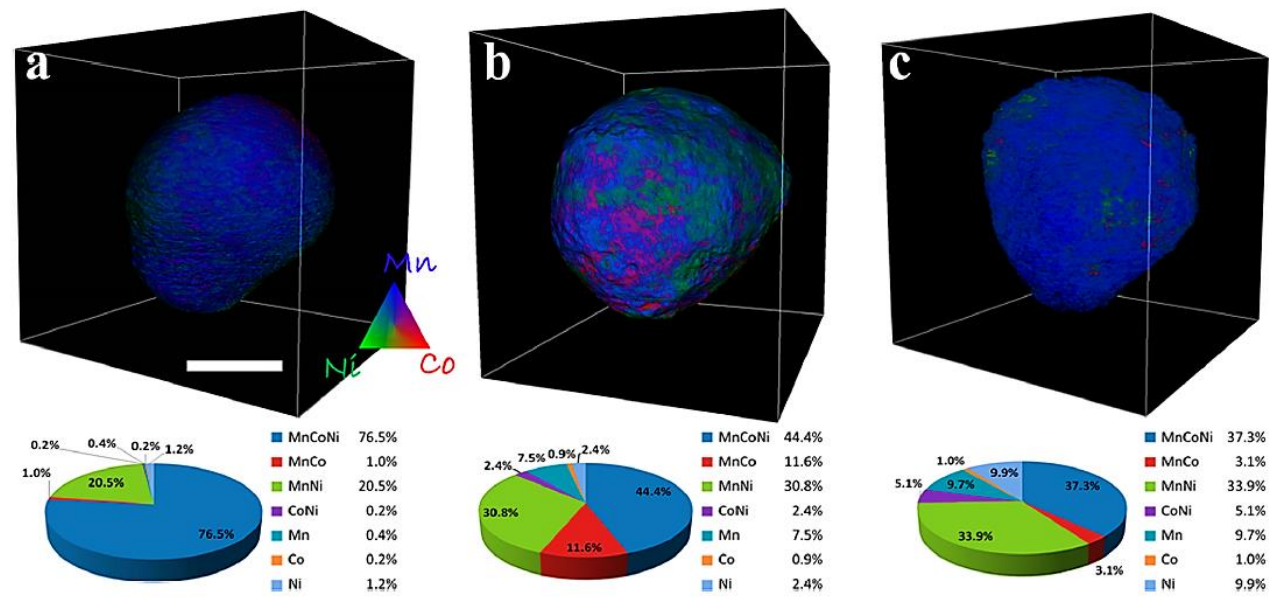

Figure 7 Distribution of transition metals in the $\mathrm{Li}_{1.2} \mathrm{Mn}_{0.525} \mathrm{Ni}_{0.175} \mathrm{Co}_{0.1} \mathrm{O}_{2}$ cathode particles after electrochemical cycling. Panel $a, b$, and c represent the selected particles at the pristine state, after $1^{\text {st }}$ cycle, and 200 cycles, respectively. Images are obtained from energy-tunable synchrotron 3D X-ray tomography. Elemental distribution data resolved from tomography above and below the K-edges of $\mathrm{Mn}, \mathrm{Co}$, and $\mathrm{Ni}$. The color legends represent the relative concentration gradient of the TM elements. Scale bar in the panel a is $5 \mu \mathrm{m}$. The corresponding pie charts were calculated using the absorption correlation tomography. Reprinted with permission from reference [78]. Copyright 2014 American Chemical Society.

Figure 8a represents a schematic illustration of the phase evolution pathways. Transformation of the pristine rhombohedral $\mathrm{LiMO}_{2}$ phase $(R \overline{3} \mathrm{~m})$ to the spinel $(F d m)$ phase is initiated at the surface during the first cycle and propagates to the bulk upon further cycling. Migration of the TMs to the $\mathrm{Li}$ sites and the migration of $\mathrm{Li}^{+}$to the tetrahedral sites leads to forming spinel grains on the surface at first and finally consuming the entire layered structure. On the other hand, the monoclinic $\mathrm{Li}_{2} \mathrm{MO}_{3}$ $(\mathrm{C} 2 / \mathrm{m})$ phase also shows a propensity towards the spinel $(\mathrm{Fdm})$ phase transition. The significant strain generated after $\mathrm{Li}$ and oxygen removal leads to lattice breakdown [66]. After few chargedischarge cycles, nanoscale spinel islands are formed and float randomly on the bulk particle. The nucleation and growth of the spinel domains eventually amorphized the material, create nanopores and thread-like cracks that widen and deepen with cycling [86].
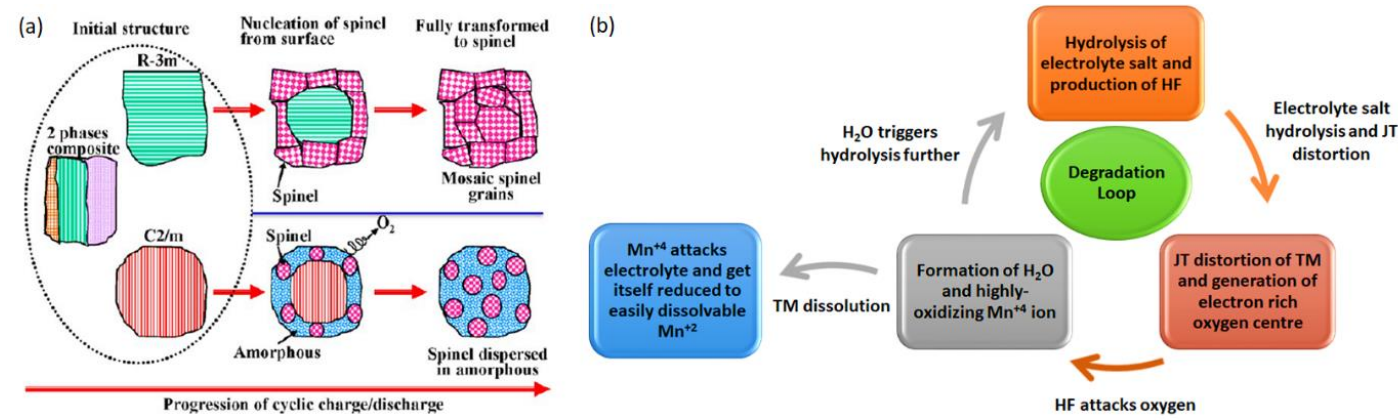

Figure 8 (a) Schematic illustration of phase evolution in LMR-LO materials during cycling finally leading to spinel structure. Reprinted with permission from reference [66]. Copyright 2013 American Chemical Society. (b) Schematic of the degradation loop resulting from JT distortion and TM dissolution. 
(iii) Modulation in Redox Contribution: Synergistic contribution from cationic and anionic redox processes helps the LMR-LO cathodes for delivering abnormally high capacity. However, the interplay between these two redox processes is not as straight forward as it might seem. Their percentage contribution to overall capacity alters upon cycling. Among all redox couples, oxygen $\mathrm{O}^{2-}$ $/ \mathrm{O}_{2}^{2-}$ and $\mathrm{Ni}^{+2 /+4}$ are the most significant contributors to capacity, whereas $\mathrm{Mn}^{+3 /+4}$ and $\mathrm{Co}^{+3 /+4}$ lie latent or contributes negligibly during the initial cycles. The loss of oxygen with cycling forces reduction of TM. This implies the formation of a surface reconstruction layer as reported in the literature. This layer having a $\mathrm{Ni}$ concentration gradient reduces the contribution of the $\mathrm{Ni}$ redox process. Moreover, a decrease in the TM valency weakens the TM-O bond covalency, and consequently, capacitive involvement of oxygen redox also decreases. However, the reduction of $\mathrm{Mn}$ and Co activates these two redox processes [82]. Thus, the overall discharge capacity remains almost the same as the sacrifice in $\mathrm{Ni}$ and oxygen redox is compensated by $\mathrm{Mn}$ and Co redox. Such a modulation in the redox contribution leads to gradual voltage decay [87]. Theoretical studies show that the Fermi level in the LMR-LO electronic structure initially lies above the $\mathrm{Ni}^{+2 /+4}$ redox. A gradual evolution of the $\mathrm{Mn}$ and Co redox processes and the decay in $\mathrm{Ni}$ and oxygen redox upshifts the Fermi level around Mn. Eventually, the differences in the relative Fermi level energies between the Li metal and TM decreases. Thus, voltage decay originates.

(iv) Voltage Hysteresis and Voltage Decay: These two terms are used interchangeably in many literatures, but they connote different senses. Voltage hysteresis refers to the voltage gap between the charge and discharge curve in a particular cycle, whereas voltage decay implies a gradual drop in the average voltage upon cycling. Their microscopic origin is different and mostly related to structural reorganization due to TM migration. However, these two phenomena are strongly correlated [88]. In the $\mathrm{LiMO}_{2}$ structure, octahedral sites are connected by interstitial tetrahedral sites. Octahedral sites are more energetically favorable positions for cations in cubic close-packed $\mathrm{LiMO}_{2}$ structures. However, tetrahedral sites may become accessible if excess energy in the form of heat or pressure is supplied externally or evolved in-situ. In stoichiometric oxides, octahedral Li and TM sites exclusively accommodate all the Li and TM cations, respectively. However, cation excess, i.e., primarily lithium excess, forces some amount of lithium to occupy octahedral TM sites. When the cell is charged beyond 4.3 or $4.4 \mathrm{~V}$, a significant amount of $\mathrm{Li}$ is removed from the Li layer, lowering the barrier for transition metal migration. TMs migrate from the octahedral TM sites to the tetrahedral Li sites under conditions of high electrode potentials. During discharge below $3.5 \mathrm{~V}$, a fraction of the TMs is forced back to the original sites. This migration is partially reversible during the initial cycles and causes voltage hysteresis during the charge and discharge processes [89]. If the TMs are irreversibly trapped in tetrahedral lithium sites in the lithium layer, they block three adjacent octahedral lithium sites due to coulombic repulsion and hinder lithium reintercalation. This results in voltage decay. On the flip side, TM migration buffers the structural collapse during excessive delithiation. Therefore, a certain extent of voltage decay is unavoidable. Voltage decay also arises from the gradual layered to spinel transition upon cycling, decreases the average voltage continuously as spinel has a redox activity around $\sim 3 \mathrm{~V} v$ s. $\mathrm{Li} / \mathrm{Li}^{+}$. Further, the modulation in redox contribution is also described in Section 5.1.2.b.iii [82].

Bettge et al. demonstrated that $\mathrm{Li}_{1.2} \mathrm{Ni}_{0.15} \mathrm{Mn}_{0.55} \mathrm{Co}_{0.1} \mathrm{O}_{2}$ under standard cycling conditions (2.0$4.7 \mathrm{~V}$ vs. $\mathrm{Li} / \mathrm{Li}^{+}, 30^{\circ} \mathrm{C}$ ) shows a drop in resistance corrected average voltage by $\sim 9 \mathrm{mV}$ per cycle during charge and $\sim 6 \mathrm{mV}$ per cycle during discharge, which accounts for $3-5 \%$ overall drop 
approximately [90]. Similar voltage fades are also common in commercial LIB cathodes (NMC, NCA, etc.), but the drop per cycle realized is lower than that realized in Li-rich chemistries. Voltage decay depends on several factors: - a) It is composition-dependent for particular chemistry. Under similar testing conditions, $\mathrm{Li}_{1.2} \mathrm{Ni}_{0.4} \mathrm{Mn}_{0.4} \mathrm{O}_{2}$ and $\mathrm{Li}_{1.2} \mathrm{Ni}_{0.2} \mathrm{Mn}_{0.6} \mathrm{O}_{2}$ show 3.8 and $7.2 \mathrm{mV}$ of voltage fade per cycle, b) voltage decay is faster at higher upper cut-off voltages due to induced side reactions, c) at elevated temperatures, the gap between the average charge and discharge voltage becomes more significant, revealing the fact that side reactions during charge override kinetics factor, and d) decay is faster during the initial cycles, but continues at a measurable rate up to several hundreds of cycle until the layered phase is completely transformed to a stable spinel structure $[90,91]$.

Voltage hysteresis reveals asymmetry between the charge and discharge profile and is caused by the metastable path of ion migration during charging-discharging. From a thermodynamics point of view, electrical work consumed during voltage hysteresis is dissipated as heat. Therefore, considerable voltage hysteresis is translated into lower energy efficiency in the case of full cells [68, 92]. Voltage decay during long-term cycling is proved to be one of the significant contributors to the energy fade mechanism of LMR-LO cathodes besides capacity loss and resistance build-up.

(v) TM Dissolution: TMs change oxidation states with lithiation-delithiation. The physio-chemical properties of a metal center differ from one oxidation state to another. Thus, with the gradual progress of charge-discharge, several asymmetries arise in the system originating from TM cations. Metal ions are symmetrically surrounded by six oxygen atoms to form the $\mathrm{MO}_{6}$ octahedra in a pristine layered oxide structure. According to crystal field theory, the electrostatic field of an octahedral ligand arrangement splits five degenerate $d$-orbitals into two sets: the triply degenerate low-energy $t_{2}$ set $\left(d_{x y}, d_{y z}\right.$, and $\left.d_{x z}\right)$ and the doubly degenerate high-energy $e_{g}$ set $\left(d_{x}{ }^{2}-y^{2}\right.$ and $\left.d_{z}{ }^{2}\right)$. Metal ions in cubical electron distribution, i.e., completely filled, half-filled, or empty orbitals $\left(t_{2}^{n}\right.$, where $n=3,6$ and $e_{g}^{m}$, where $\left.m=0,2,4\right)$ prefer such an arrangement. But if the metal ion is in a non-cubical electronic distribution, i.e., unsymmetrically filled orbitals $\left(t_{2}^{n}\right.$, where $n=1,2,4,5$ and $\mathrm{e}_{\mathrm{g}}^{\mathrm{m}}$, where $\mathrm{m}=1,3$ ) experience Jahn-Teller (JT) distortion. According to the JT theorem, unsymmetrically filled orbitals further split to remove the degeneracy and yield an additional stabilization to the system. JT splitting distorts the bond lengths of the axial and equatorial M-O bonds so that the overall energy of the system reaches the minimum value [93]. Therefore, the surface accumulation of JT active high-spin $\mathrm{Mn}^{+3}$ in the LMR-LO cathodes due to charge-discharge affects the structural stability. Local JT distortion and lattice instability increase the crystal's reactivity towards electrolytes and causes consequent TM dissolution.

The JT effect relaxes the degeneracy in the $e_{g}$ orbitals by placing an electron in the $\mathrm{d}_{\mathrm{z}}{ }^{2}$. The axial $\mathrm{M}-\mathrm{O}$ bond elongates, weakening the overlap between the TM and oxygen units. It induces more ionic character of the axial $\mathrm{M}-\mathrm{O}$ bonds than equatorial and densifies negative charge on the axial oxygens. The proton of strong acid HF originating from the hydrolysis of the $\mathrm{LiPF}_{6}$ salt readily attacks the axial oxygens at the cathode electrolyte interphase (CEI). Further, the protonation of the axial oxygen is accompanied by the metal $\left(\mathrm{TM} \mathrm{d}_{\mathrm{z}}{ }^{2}\right)$ to ligand $(\mathrm{O} 2 \mathrm{p})$ electron transfer to result in the formation of $\mathrm{H}_{2} \mathrm{O}$. Electron transfer oxidizes the metal center, i.e., $\mathrm{Mn}^{+3}$ to $\mathrm{Mn}^{+4}$ in LMR-LOs. Mn in the highest oxidation state $(+4)$ is highly oxidizing in nature. It decomposes electrolyte solvent molecules and converts itself to a JT-free $\mathrm{Mn}^{+2}$ state via a two-electron pathway. This stable low valent $\mathrm{Mn}^{+2}$ gets dissolved by electrolyte, floats towards the anode via the electrolyte, and accumulates on the anode surface to thicken the SEI [94]. Therefore, the cyclic loop of the 
degradation pathway, once get activated, damages all the interfaces, increases cell impedance, and deteriorates the electrochemical performance.

Way outs from the degradation loop, as shown in Figure $8 \mathrm{~b}$ include either surface coating at the expense of increased cell impedance or tuning uneven electron distribution of JT active centers by doping metal ions. Substituting JT active metal ions with inactive $\mathrm{Al}^{+3}$ or $\mathrm{Mg}^{+2}$ perturbs the longrange metal-metal order. The newly introduced localization effect reduces oxygen and electron mobility over the $\mathrm{M}-\mathrm{O}$ bonds, thereby suppressing TM dissolution. Other cell-level indirect measures can also be taken care of to avoid such reactions. The electrolyte salt LiPF 6 can be replaced with imide anions such as bis(trifluoromethane)sulfonimide (TFSI), bis(fluorosulfonyl)imide (FSI), bis(pentafluoroethylsulfonyl)imide (BETI), etc. More covalent C-F bonds in the linear or cyclic imide ions restricts $\mathrm{HF}$ generation than polar $\mathrm{P}-\mathrm{F}$ bonds in $\mathrm{LiPF}_{6}$. Moreover, limiting the upper charge cutoff can decrease the reactivity of oxygen at the cathode electrolyte interphase. Electrolyte additives are also used to scavenge acidic byproducts.

The extent of $\mathrm{Mn}$-dissolution depends on the crystal structure of the Mn host. Krishna Kumar et al. showed that, when pristine materials are aged inside a glove box under pure argon atmosphere at stirring condition ( $50{ }^{\circ} \mathrm{C}$ for two weeks) dissolved in $1 \mathrm{M} \mathrm{LiPF}_{6}$ in 1:2 EC/DMC, Mn dissolution decreases from $1.1 \mathrm{wt} . \%$ in $\mathrm{Li}_{1.2} \mathrm{Mn}_{0.55} \mathrm{Ni}_{0.15} \mathrm{CO}_{0.1} \mathrm{O}_{2}$ to $~ 0.5 \mathrm{wt} . \%$ when blended with carbon-coated $\mathrm{LiMnPO}_{4}$. The presence of the robust polyanionic phosphate framework hinders the reaction between the acidic proton and the basic oxygen units.

\subsubsection{Modification}

All the problems mentioned above, along with electrolyte degradation, electrolyte instability at high voltages, JT distortion, Mn dissolution, etc., are also severe shortcomings that result in various problems such as initial irreversible capacity, voltage hysteresis, and voltage decay, poor cycle life, inferior high-rate performance. Modifications can be applied to surface, bulk, or both at a time.

Composition Optimization: The chemical composition of $\mathrm{xLi}_{2} \mathrm{MnO}_{3} \cdot(1-\mathrm{x}) \mathrm{LiMO}_{2}$ varies with the value of $x$, and so the electrochemical performance. Optimizing the value $x$ is a trade-off between higher capacity and longer cycle life. When the compositional percentage of $\mathrm{Li}_{2} \mathrm{MnO}_{3}$ dominates over $\mathrm{LiMO}_{2}$, the specific capacity ( $\geq 4.5 \mathrm{~V}$ ) increases along with oxygen evolution, but cycle life and coulombic efficiency deteriorates. Increasing the concentration of $\mathrm{LiMO}_{2}$ in the composition enables to draw more capacity below $4.5 \mathrm{~V}$, especially for Ni-rich $\mathrm{LiMO}_{2}$. Manthiram and coworkers compared the charge-discharge performances of $(1-\mathrm{z}) \mathrm{Li}\left[\mathrm{Li}_{1 / 3} \mathrm{Mn}_{2 / 3}\right] \mathrm{O}_{2} \cdot(\mathrm{z}) \mathrm{Li}\left[\mathrm{Mn}_{0.5-\mathrm{y}} \mathrm{Ni}_{0.5-\mathrm{y}} \mathrm{CO}_{2 \mathrm{y}}\right] \mathrm{O}_{2}$, where $y=1 / 3$ and $0.25 \leq z \leq 0.75$ when cycled at $12.5 \mathrm{~mA} \mathrm{~g}^{-1}(\sim \mathrm{C} / 20$ rate) in the current density range of 2.0-4.8 V (Figure 9a). Except for $z=0.25$, the first discharge capacity decreases with an increase in $z$ or a decrease in the lithium content but the amount of oxygen loss increases. The highest first discharge capacity is obtained for $z=0.4$, i.e., $254 \mathrm{mAh} \mathrm{g}^{-1}$ with an irreversible loss of $80 \mathrm{mAh} \mathrm{g}^{-1}$ [95]. Moreover, the $\mathrm{Li}_{2} \mathrm{MnO}_{3}$ component can be generalized as $\mathrm{Li}_{2} \mathrm{MO}_{3}$, where $\mathrm{M}$ is the form of $\mathrm{Ru}$, $\mathrm{Sn}, \mathrm{Mo}, \mathrm{Ir}, \mathrm{Ti}$, etc. are also active and show more stable oxygen redox as non-transition and heavy transition metals ( $4 d$ and $5 d$ ) form less directional and more flexible TM-O bonds [96-98]. However, heavy atoms lower the specific capacity value and being non-abundant increases the material production cost. This design concept of the solid solution has been used to synthesize different types of combinations. Ramesha et al. showed that the solid solution $\mathrm{xLiCoO}_{2} \cdot(1-\mathrm{x}) \mathrm{Li}_{2} \mathrm{RuO}_{3}$ delivers an initial discharge capacity of $\sim 232 \mathrm{mAh} \mathrm{g}^{-1}$ and retained $85 \%$ capacity at $0.2 \mathrm{C}$ rate after $100^{\text {th }}$ 
cycles when $x=0.3$ [99]. Wang et al. demonstrated that the ternary mixture of $\mathrm{Li}_{2} \mathrm{RuO}_{3}-\mathrm{Li}_{2} \mathrm{SnO}_{3}-$ $\mathrm{Li}_{2} \mathrm{MnO}_{3}$ dramatically increases the discharge capacity from 109 to $223 \mathrm{mAh} \mathrm{g}^{-1}$ once the system goes from the composite phase to the solid-solution phase [100].
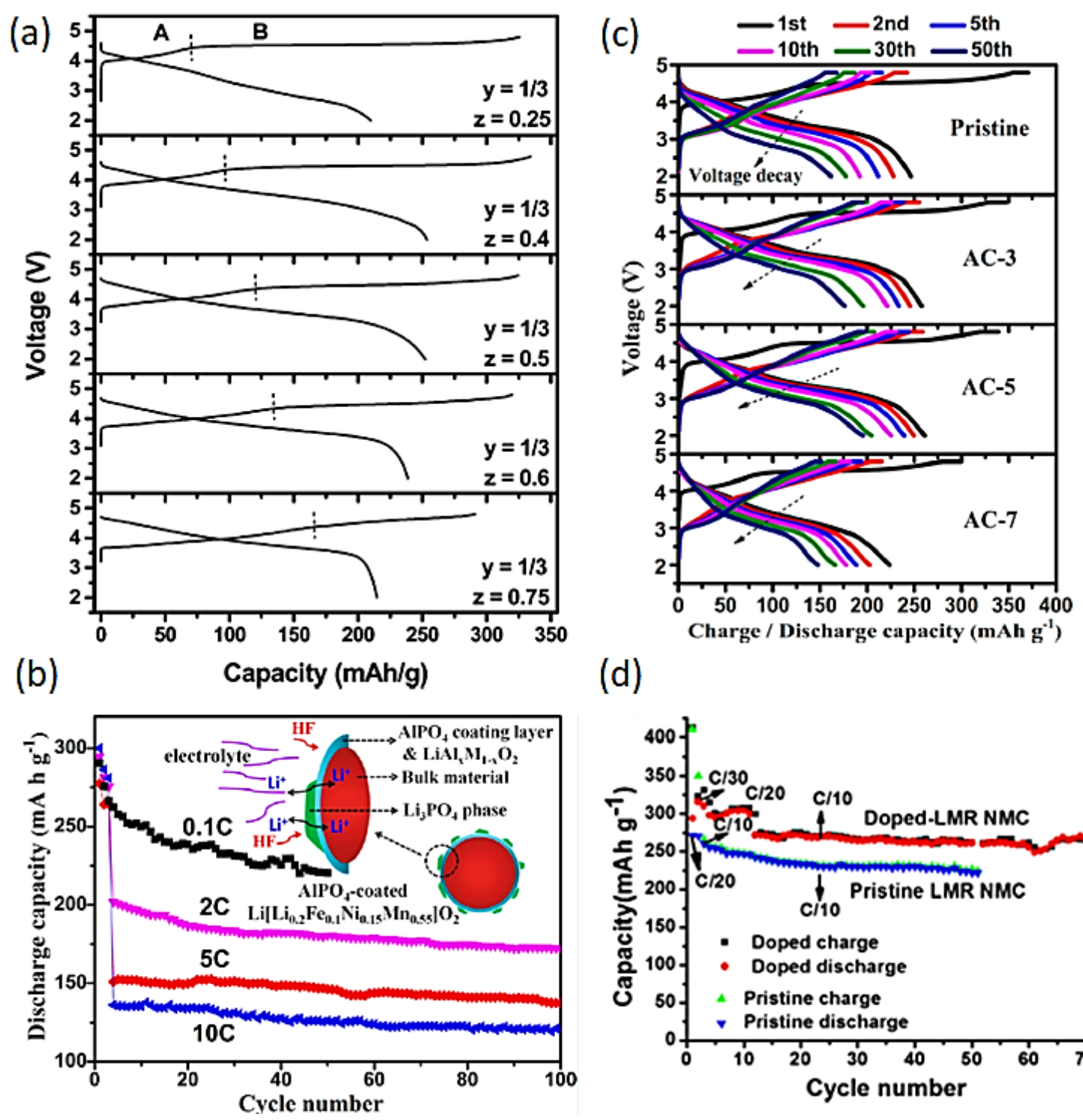

(d)

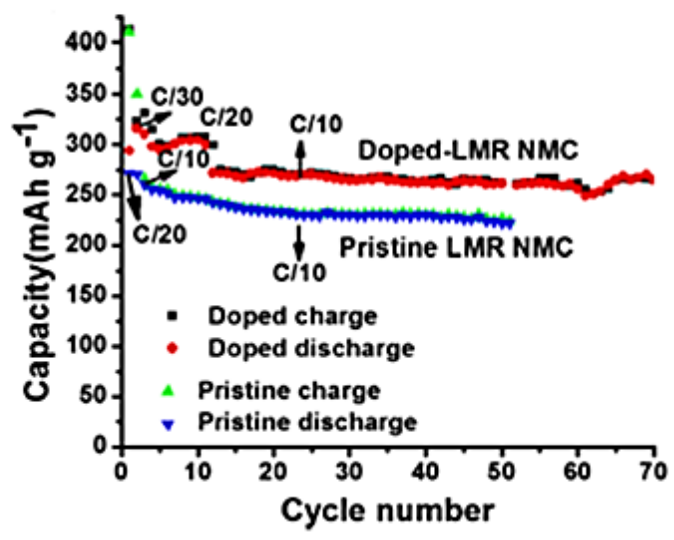

Figure 9 (a) Comparison of the first charge-discharge profiles (recorded at $12.5 \mathrm{~mA} \mathrm{~g}^{-1}$ between 2.0 and $4.8 \mathrm{~V}$ ) recorded for the (1-z) $\mathrm{Li}\left[\mathrm{Li}_{1 / 3} \mathrm{Mn}_{2 / 3}\right] \mathrm{O}_{2} \cdot(\mathrm{z}) \mathrm{Li}\left[\mathrm{Mn}_{0.5-\mathrm{y}} \mathrm{Ni}_{0.5-\mathrm{y}} \mathrm{Co}_{2 \mathrm{y}}\right] \mathrm{O}_{2}(\mathrm{y}$ $=1 / 3$ and $0.25 \leq z \leq 0.75$ ) samples. The dashed vertical lines separate the initial sloping region A from the plateau region B. Reprinted with permission from reference [95]. Copyright 2007 American Chemical Society, (b) Cycling of 5 wt.\% AlPO 4 coated $\mathrm{Li}\left[\mathrm{Li}{ }_{0.2} \mathrm{Fe}_{0.1} \mathrm{Ni}_{0.15} \mathrm{Mn}_{0.55}\right] \mathrm{O}_{2}$ sample at different current densities, (c) Charge-discharge profile recorded for pristine, $3 \mathrm{wt} . \%$ (AC-3), $5 \mathrm{wt} . \%$ (AC-5), $7 \mathrm{wt} . \%$ (AC-7) $\mathrm{AlPO}_{4}$ coated $\mathrm{Li}\left[\mathrm{Li}_{0.2} \mathrm{Fe}_{0.1} \mathrm{Ni}_{0.15} \mathrm{Mnn}_{0.55}\right] \mathrm{O}_{2}$ at $0.2 \mathrm{C}$ rate. Reprinted with permission from reference [101]. Copyright 2015 American Chemical Society, and (d) C/10 rate cycling followed by C/30 and $\mathrm{C} / 20$ rate cycling of pristine $\mathrm{Li}_{1.2} \mathrm{Ni}_{0.15} \mathrm{Mn}_{0.55} \mathrm{Co}_{0.1} \mathrm{O}_{2}$ and $\mathrm{Mg}^{+2}-\mathrm{F}^{-}$codoped samples. Reprinted by permission from Springer (reference [102]): Ionics 2017 (DOI 10.1007/s11581-017-2018-9) 
Surface Coating: Surface coating can suppress oxygen release, electrolyte corrosion, and phase transition. Coating materials require high electrochemical stability, high voltage stability, inert towards electrolyte and other cell components, surface wettability, etc. Surface coating reaches its maximum efficiency when the lattice constant of the coating material matches the host crystal; the coating is smooth, well-dispersed, covering the entire surface with optimal thickness. Mismatch of lattice constants exerts asymmetry effect to obstruct Li conduction through it and increases contact resistance. The coating material should be chosen in such a way so that it does not lithiate itself in excess as then the volume change may introduce a peel-off effect. Surface coating can minimize surface defects, and its healing function confined only to the surface. The inaccessibility of the crystal interior fails to solve bulk defects. Type of coating materials have been reported in the literature for LMR-LO cathodes includes electrochemically non-active substances such as oxides $\left(\mathrm{Al}_{2} \mathrm{O}_{3}, \mathrm{Ti}_{2} \mathrm{O}_{3}, \mathrm{Er}_{2} \mathrm{O}_{3}, \mathrm{Pr}_{6} \mathrm{O}_{11}\right.$, etc. $)$, phosphates $\left(\mathrm{AlPO}_{4}, \mathrm{COPO}_{4}\right.$, etc.), fluorides $\left(\mathrm{AlF}_{3}, \mathrm{LiF}\right)$, and solidstate fast ion conductors ( $\mathrm{LiPON}, \mathrm{LiV}_{3} \mathrm{O}_{8}, \mathrm{Li}_{x} \mathrm{La}_{y} \mathrm{TiO}_{3}$, etc.) [19, 103-109]. Wu et al. demonstrated that pristine $\mathrm{Li}\left[\mathrm{Li}_{0.2} \mathrm{Mn}_{0.54} \mathrm{Ni}_{0.13} \mathrm{Co}_{0.13}\right] \mathrm{O}_{2}$, its modified versions such as 3 wt. $\% \mathrm{Al}_{2} \mathrm{O}_{3}, \mathrm{CeO}_{2}, \mathrm{ZrO}_{2}, \mathrm{ZnO}$, $\mathrm{AlPO}_{4}$ treated, and $0.05 \mathrm{~F}^{-}$atom per formula unit provides first discharge capacity of $253,285,253$, $252,252,261$, and $270 \mathrm{mAh} \mathrm{g}^{-1}$, respectively and the first irreversible capacity of $75,41,36,48,58$, 22 , and $58 \mathrm{mAh} \mathrm{g}^{-1}$, respectively. The retention of oxide ion vacancies in the surface treated samples reduces the first cycle irreversible capacity loss and significantly modifies the first discharge capacity [110]. Optimization of coating thickness is very critical for electrochemical performance as thicker coating leads to enhanced interfacial impedance. Therefore, the weight percentage of the coating agent is a contributing factor for wet-chemical methods of coating. A report suggests that 5 wt.\% $\mathrm{AlPO}_{4}$ coatings (Figure $9 \mathrm{~b}$ and Figure $9 \mathrm{c}$ ) on $\mathrm{Li}\left[\mathrm{Li}_{0.2} \mathrm{Fe}_{0.1} \mathrm{Ni}_{0.15} \mathrm{Mn}_{0.55}\right] \mathrm{O}_{2}$ to be the optimum, showing the reversible capacity of $220.4 \mathrm{mAh} \mathrm{g}^{-1}$ after 50 cycles at $0.1 \mathrm{C}$, accounting for $74.4 \%$ retention and enhanced rate capability (175.3 $\mathrm{mAh} \mathrm{g}^{-1}$ at $1 \mathrm{C}$, and $120.2 \mathrm{mAh} \mathrm{g}^{-1}$ at $10 \mathrm{C}$ after 100 cycles) [101]. Zhang et al. coated $\mathrm{Li}_{1.2} \mathrm{Ni}_{0.13} \mathrm{Co}_{0.13} \mathrm{Mn}_{0.54} \mathrm{O}_{2}$ using different weight percentages of the Li-La-Ti-O (LLTO composite) solid-state fast ion conductor. The study shows that $5 \mathrm{wt}$.\% is the optimum coating that gives the best electrochemical performance, i.e., decay of only $\sim 35 \mathrm{mAh} \mathrm{g}^{-1}$ capacity compared to $111 \mathrm{mAh} \mathrm{g}^{-1}$ capacity loss of untreated sample over 100 cycles at $30 \mathrm{~mA} \mathrm{~g}^{-1}$ current density between 2.0-4.8 $\mathrm{V}$ range. However, all coated samples show better $\mathrm{C}$-rate performance and higher capacity retention than a pristine one. Highly conductive $\left(10^{-3} \mathrm{~S} \mathrm{~cm}^{-1}\right)$ amorphous LLTO surface layer lowers the charge transfer resistance, and the fast ionic conduction process through the thin layer results in better C-rate capability. The differential scanning calorimetry (DSC) study implies that better thermal stability provided by the coating layer helps to maintain the perfect crystalline structure even after 100 cycles [111].

lon Doping: Ions can be doped into the crystal lattice. The electronic structure is tuned in this way and may solve the fundamental voltage decay issues. Alkali metal cations $\left(\mathrm{Cs}^{+}, \mathrm{Na}^{+}, \mathrm{Al}^{+3}, \mathrm{Mg}^{+2}\right.$, etc.) normally occupy tetrahedral sites in the Li layer. The doping with larger ion than lithium increases the barrier for TM migration and exerts 'pillar effect' to maintain structural stability [112115]. Divalent and trivalent cations help increase the average positive valence to strengthen the TM-O bond. It delays the activation of the $\mathrm{Li}_{2} \mathrm{MnO}_{3}$ component and stabilizes oxygen redox. However, incorporating alkali metal ions cannot drive away from the layered to spinel transformation completely as the spinel phase is more stable than the layered in the delithiated state. Therefore, fluorine doping along with alkali metal ions is demonstrated to be an effective 
strategy. $\mathrm{Na}$ and F-doped in $\mathrm{Li}_{1.2} \mathrm{Mn}_{0.54} \mathrm{Ni}_{0.13} \mathrm{Co}_{0.13} \mathrm{O}_{2}$ to form $\mathrm{Li}_{1.15} \mathrm{Na}_{0.05} \mathrm{Mn}_{0.54} \mathrm{Ni}_{0.13} \mathrm{Co}_{0.13} \mathrm{~F}_{0.01} \mathrm{O}_{1.99}$ shows $97 \%$ capacity retention and $91 \%$ voltage retention over 100 cycles with an initial discharge capacity of $260 \mathrm{mAh} \mathrm{g}^{-1}$ at C/10 current rate. The partial substitution of Li and $\mathrm{O}$ with $\mathrm{Na}$ and F, respectively, provides structural stability and widens the Li slab to enable rapid Li-ion diffusion [116]. A Stronger $\mathrm{M}-\mathrm{F}$ bond suppresses oxygen evolution. Similar effects were also exerted when $\mathrm{Mg}$ and F were co-doped, where $10-15 \%$ excess capacity and $14-15 \%$ improvement in capacity retention was observed over 50 cycles (Figure 9d) [102]. Transition metal ions $\left(\mathrm{Cr}^{+3}, \mathrm{Ti}^{+4}, \mathrm{Nb}^{+5}\right.$, etc.) occupy the space in transition metal layers $[117,118]$. Large TM ions expand the lattice parameters and improve lithium diffusion. $\mathrm{Nb}^{+5}$ doped $\mathrm{Li}_{1.2} \mathrm{Mn}_{0.54} \mathrm{Ni}_{0.13} \mathrm{Co}_{0.13} \mathrm{O}_{2}$ demonstrates $7 \%$ improvement in capacity retention over 100 cycles than pristine sample due to increased ordering in cation distribution and delivered $\sim 20 \mathrm{mAh} \mathrm{g}^{-1}$ higher capacity than the pristine one at $5 \mathrm{C}$ rate due to lesser amplification in charge transfer resistance upon cycling [119]. Similarly, anion doping like fluorine can also stabilize cation-anion interaction, reduces oxygen loss, also increases average voltage as $\mathrm{F}^{-}$ is more electronegative than $\mathrm{O}^{2-}[120]$. Polyanionic groups have robust moieties that are able to hold TMs at even extreme voltages. Strong interactions between $\mathrm{MO}_{\mathrm{x}}$ and $\mathrm{TMs}$ can be explored by polyanionic group substitution. These groups $\left(\mathrm{XO}_{4}\right)^{\mathrm{n}-}$ or $\left(\mathrm{X}_{\mathrm{m}} \mathrm{O}_{3 \mathrm{~m}+1}\right)^{\mathrm{n}-1}(\mathrm{X}=\mathrm{B}, \mathrm{P}, \mathrm{As}, \mathrm{Mo}$, Si, etc.) also reduce the number of oxygen ions in the structure. The phosphate polyanion doped material $\mathrm{Li}_{1.17} \mathrm{Ni}_{0.2} \mathrm{Mn}_{0.58} \mathrm{Co}_{0.05} \mathrm{O}_{2-x}\left(\mathrm{PO}_{4}\right)_{x}$, where $\mathrm{x}=0.01,0.03$, and 0.05 minimizes the local structure change during cycling and also minimizes the growth in diffusion impedance during cycling. The sample with $x=0.01$ provides a very stable energy density and retains $\sim 70 \%$ of the initial value after 300 cycles at a $\mathrm{C} / 10$ rate [121]. Table 2 summarizes the modification results for the LMR-LO cathode materials. 
JEPT 2022; 4(1), doi:10.21926/jept.2201002

Table 2 Summary of surface and structural modifications carried on LMR-LO cathode materials on the electrochemical performance against lithium metal anode in coin-type half cells.

\begin{tabular}{|c|c|c|c|c|c|c|c|c|}
\hline \multirow[t]{2}{*}{ Material } & \multirow[t]{2}{*}{ Modification } & \multirow[b]{2}{*}{$\begin{array}{l}\text { Voltage } \\
\text { range } \\
\text { (V) }\end{array}$} & \multicolumn{3}{|c|}{ Electrochemical performance } & \multicolumn{3}{|c|}{ Capacity retention } \\
\hline & & & $\begin{array}{l}\text { First discharge } \\
\text { capacity } \\
\left(\mathrm{mAhg}^{-1}\right)\end{array}$ & $\begin{array}{l}\text { Current } \\
\text { rate }\end{array}$ & $\begin{array}{l}\text { Initial coulombic } \\
\text { efficiency (\%) }\end{array}$ & $\%$ & cycles & C \\
\hline $\mathrm{Li}_{1.2} \mathrm{Mn}_{0.525} \mathrm{Ni}_{0.175} \mathrm{Co}_{0.1} \mathrm{O}_{2}[\mathbf{1 2 2}]$ & 1.5 wt.\% CNF addition & $2.5-4.9$ & 280 & $\mathrm{C} / 10$ & 84 & 99 & 100 & $\mathrm{C} / 10$ \\
\hline $\mathrm{Li}_{1.2} \mathrm{Mn}_{0.54} \mathrm{Ni}_{0.13} \mathrm{Co}_{0.13} \mathrm{O}_{2}[\mathbf{1 2 3}]$ & $\mathrm{Al}_{2} \mathrm{O}_{3}$ coating & $2.0-4.8$ & 275 & $\mathrm{C} / 10$ & 84 & 98 & 30 & $\mathrm{C} / 10$ \\
\hline $\mathrm{Li}_{1.2} \mathrm{Mn}_{0.55} \mathrm{Ni}_{0.15} \mathrm{Fe}_{0.1} \mathrm{O}_{2}[\mathbf{1 0 1}]$ & $\mathrm{AlPO}_{4}$ coating & $2.0-5.0$ & 267.2 & $0.16 \mathrm{C}$ & 78.9 & 73 & 60 & $0.16 C$ \\
\hline $\mathrm{Li}_{1.2} \mathrm{Ni}_{0.15} \mathrm{Mn}_{0.55} \mathrm{Co}_{0.1} \mathrm{O}_{2}[102]$ & $\mathrm{Mg}^{+2}, \mathrm{~F}^{-}$co-doping & $2.5-4.7$ & 295 & $\mathrm{C} / 10$ & 75 & 99 & 70 & $\mathrm{C} / 10$ \\
\hline $\mathrm{Li}_{1.2} \mathrm{Ni}_{0.15} \mathrm{Mn}_{0.55} \mathrm{Co}_{0.1} \mathrm{O}_{2}[\mathbf{1 2 0}]$ & $\begin{array}{l}\text { F-doping and 3D } \\
\text { architecture }\end{array}$ & $2.5-4.7$ & 300 & $\mathrm{C} / 10$ & 95 & 98 & 50 & $\mathrm{C} / 5$ \\
\hline $\mathrm{Li}_{1.2} \mathrm{Mn}_{0.55} \mathrm{Ni}_{0.15} \mathrm{Co}_{0.1} \mathrm{O}_{2}[\mathbf{1 2 4}]$ & $\mathrm{LiMnPO}_{4}$ blend & $2.5-4.7$ & 225 & $\mathrm{C} / 10$ & 91.5 & 90 & 200 & $\mathrm{C} / 10$ \\
\hline $\mathrm{Li}_{1.2} \mathrm{Mn}_{0.54} \mathrm{Ni}_{0.13} \mathrm{Co}_{0.13} \mathrm{O}_{2}[\mathbf{1 2 5}]$ & Cs doping & $2.0-4.8$ & 280 & $\mathrm{C} / 10$ & $81 \%$ & 70 & 100 & $\mathrm{C} / 2$ \\
\hline $\mathrm{Li}_{1.2} \mathrm{Mn}_{0.54} \mathrm{Ni}_{0.13} \mathrm{Co}_{0.13} \mathrm{O}_{2}[\mathbf{1 2 5}]$ & Borate blending & $2.0-4.8$ & 319 & $0.08 \mathrm{C}$ & - & 94 & 80 & $0.08 \mathrm{C}$ \\
\hline $\mathrm{Li}_{1.2} \mathrm{Mn}_{0.525} \mathrm{Ni}_{0.175} \mathrm{Co}_{0.1} \mathrm{O}_{2}[107]$ & LiPON coating & $2.0-4.9$ & 275 & $\mathrm{C} / 10$ & - & 85 & 350 & $\mathrm{C} / 10$ \\
\hline $\mathrm{Li}_{1.19} \mathrm{Mn}_{0.54} \mathrm{Ni}_{0.13} \mathrm{Co}_{0.12} \mathrm{O}_{2}[\mathbf{1 2 6}]$ & Ru doping & $2.0-4.8$ & 277 & $C / 20$ & 75 & 79 & 50 & $\mathrm{C} / 5$ \\
\hline
\end{tabular}




\subsection{Lithium Excess Cation Disordered Rock Salt Oxides}

Commercialized cathode materials possess high theoretical capacities i.e., $\mathrm{LiCoO}_{2}\left(274 \mathrm{mAh} \mathrm{g}^{-1}\right)$, $\mathrm{LiNi}_{x} \mathrm{Mn}_{\mathrm{y}} \mathrm{Co}_{z} \mathrm{O}_{2}$, where $\mathrm{x}+\mathrm{y}+\mathrm{z}=1\left(270-280 \mathrm{mAh} \mathrm{g}^{-1}\right)$, and $\mathrm{LiNi}_{0.8} \mathrm{Co}_{0.15} \mathrm{Al}_{0.05} \mathrm{O}_{2}\left(278 \mathrm{mAh} \mathrm{g}^{-1}\right)$, but the practical useful capacity is limited to $\leq 180 \mathrm{mAh} \mathrm{g}^{-1}$. In all these materials, the Li: TM ratio is 1:1. Lithium excess cation disordered rock salt oxides have a Li: TM ratio of $>1$ can deliver $>250 \mathrm{mAh} \mathrm{g}^{-1}$ capacity. The crystallographic orientation, Li-hopping mechanism, and redox behavior of these samples differ from those of the conventional ordered layered oxides. A deep understanding of these phenomena is essential to elucidate higher obtained capacity from lithium excess cathodes.

\subsubsection{Crystal Structure and Composition}

Ordered rock salts are one of the most geologically abundant crystal structures found in nature. They crystallize in $\mathrm{Fm} \overline{3} m$ space group and generally referred to as $\mathrm{NaCl}$-like structure (Figure 10a). Common inorganic salts, such as $\mathrm{NaCl}, \mathrm{KBr}, \mathrm{NiO}, \mathrm{FeO}, \mathrm{LiF}, \mathrm{AgCl}$, etc., fall under this category. Anions occupy the $4 \mathrm{~b}$ site forming a face-centered cubic lattice in the crystal lattice, where cations fill half of the octahedral vacancies (4a site). The densely packed unit cell of the pure rock salt phase restricts the entry of the guest cations $\left(\mathrm{Li}^{+}, \mathrm{Na}^{+}, \mathrm{K}^{+}\right.$, etc.) into its lattice. Therefore, any rock salt phases are strictly avoided during battery cycling due to their electrochemical non-responsive nature towards lithiation-delithiation. The presence of $\mathrm{NiO}$ during the synthesis of the Ni-rich cathodes and its formation and surface accumulation during cycling are considered detrimental to battery performance. However, in 2014, Ceder group first showed that supplementing an extra amount of lithium beyond stoichiometry. This results in cation disordering between Li and transition metals, opening up the pathways for long-range Li-ion diffusion throughout the crystal structure (Figures 10c and d). Li and transition metal ions were randomly distributed at the 4a site in the cationic sublattice (Figure 10b) [127, 128]. 
(a)

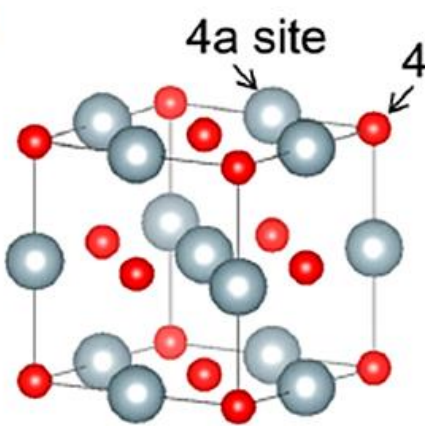

Cations $\odot$ Anions

(c)

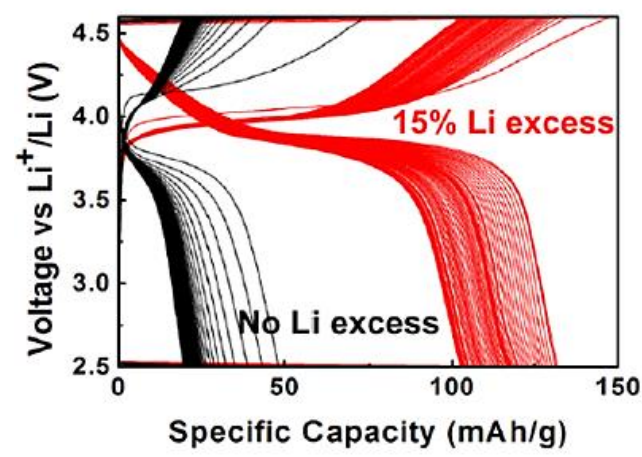

(b)

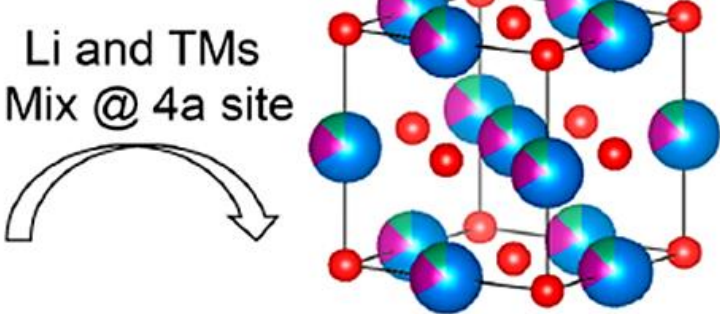

(d)

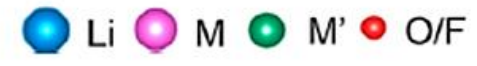

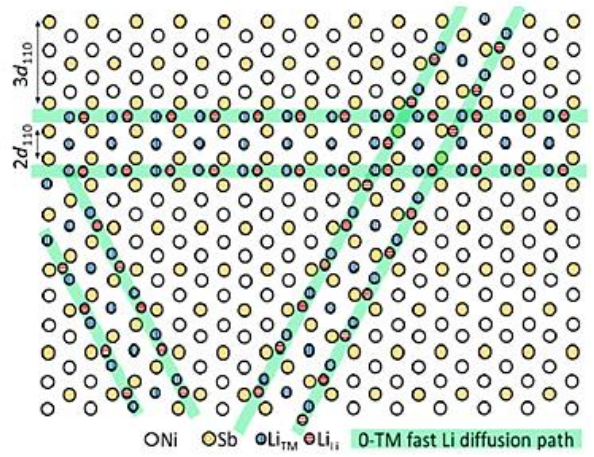

Figure 10 Crystal structure of (a) classic rock salt, (b) cation disordered rock salt. Reproduced with permission from reference [128]. Copyright 2021 American Chemical Society, (c) Galvanostatic cycling of $\mathrm{LiNi}_{0.67} \mathrm{Sb}_{0.33} \mathrm{O}_{2}$ (black curves) and $\mathrm{Li}_{1.15} \mathrm{Ni}_{0.47} \mathrm{Sb}_{0.38} \mathrm{O}_{2}$ (red curves) at $1 \mathrm{C}$ rate between 2.5-4.6 $\mathrm{V}$ range, (d) Schematic illustration demonstrating the coexistence of the two types of ordering and 0-TM diffusion channels at the domain interfaces. Reproduced with permission from reference [129]. Copyright 2014 American Chemical Society.

Unlike conventional layered oxide cathodes, cation disordered rock salts have a wide compositional range. It is mainly synthesized in the oxide or oxyfluoride form. The general chemical formula is expressed as $\mathrm{Li}_{1+x}(\mathrm{MM})_{1-x} \mathrm{O}_{2}$ or $\mathrm{Li}_{1+x}(M \underline{M})_{1-x} \mathrm{O}_{2-y} F_{y}(x, y>0)$. $\mathrm{M}$ is a redox reservoir and $\underline{M}$ is a redox inactive charge neutralizer. Both $\mathrm{M}$ and $\underline{\mathrm{M}}$ can be single or multiple transition metals. Typical redox-active $\mathrm{M}$ centers include $\mathrm{Mn}^{+2 /+4}, \mathrm{Mn}^{+3 /+4}, \mathrm{Ni}^{+2 /+4}, \mathrm{~V}^{+3 /+5}, \mathrm{~V}^{+4 /+5}, \mathrm{Fe}^{+2 /+3}, \mathrm{Cr}^{+3 /+6}, \mathrm{Mo}^{+3 /+6}$, etc., whereas it is only confined to $\mathrm{Ni}$ and $\mathrm{Mn}$ centers in the case of conventional layered oxides. The $\mathrm{Ni}^{+2 /+4}$ center provides high discharge voltage, but its overlap with oxygen redox brings instability issues due to irreversible oxygen redox. High valence $\mathrm{V}, \mathrm{Cr}$, and $\mathrm{Mo}$ center suffer from low average voltage. Fe-based systems undergo significant hysteresis during cycling. Hence, earth-abundant Mnbased systems are most explored, especially $\mathrm{Mn}^{+2 /+4}$ delivers high capacity. To stabilize the $\mathrm{Mn}$ center at the +2 state in the as-synthesized material, high valent charge neutralizers, such as $\mathrm{Mo}^{+6}$, $\mathrm{V}^{+5}, \mathrm{Sn}^{+4}, \mathrm{Ti}^{+4}$, etc., are effective [130].

\subsubsection{Lithium Percolation Theory}

The capacity of the cathode material is directly proportional to the amount of lithium that can undergo reversible intercalation-deintercalation. To support facile lithium-ion diffusion, the 
material should contain properly distributed low barrier channels throughout its structure. The low barrier channels allow microscopic lithium diffusion, whereas a well-distributed network of such channels leads to macroscopic percolation. In rock salt type oxides, lithium migration occurs via the octahedra-tetrahedra-octahedra (O-T-O) route, as the direct movement of lithium between the two edge-shared octahedra is associated with a high energy barrier. Lithium in the intermediate tetrahedral site represents the activated state of lithium migration. The lower the energy of the activated state, the more facile is the migration. The energy of the activated state depends on its interaction with the adjacent atoms. Each tetrahedron has four faces, and all faces are shared by octahedrons. The octahedral sites can accommodate lithium (or transition metals) or remain vacant. Based on the number of transition metals in the surrounding environment, the activated tetrahedral sites can be theoretically classified into the following categories: 4-TM, 3-TM, 2-TM, 1-TM, and 0TM sites. Figure 11a demonstrates 0, 1, and 2-TM channels [131]. The energy of the activated lithium site is determined by two factors: - a) electrostatic interaction between the activated lithium and transition metal, i.e., the valency of the transition metals, and b) tetrahedral height or slab distance, i.e., distance between lithium and the transition metals. Among the four face sharing sites, two sites must be occupied by lithium, e.g., one site from which lithium is coming (a-site) and another site from which lithium will migrate (b-site). Therefore, the 4-TM and 3-TM sites are inactive or dead or blocked channels through which lithium cannot diffuse. Considering that the two sites are occupied by lithium, the other two face sharing sites (also called 'gate sites') can be accommodated by the two TMs (2-TM site), one TM, one Li (1-TM site), or two lithium (0-TM site). Electrostatic repulsion exerted by the two high-valent (generally valency of +3 ) TM cations on activated $\mathrm{Li}^{+}$is too high for facile migration. Therefore, the 2-TM sites having significant energy barriers are usually inactive. Stoichiometric $\gamma$ - $\mathrm{LiFeO}_{2}$ type structures (e.g., $\mathrm{LiTiO}_{2}$ ) contain 2-TM channels and are poor lithium-ion conductors. Stoichiometric layered $\alpha-\mathrm{NaFeO}_{2}$ type oxides (examples - NMC, LCO, NCA, etc.) conduct lithium-ion via the 1-TM channel, where one of the gate sites is occupied by lithium and thus, the energy barrier for lithium migration is relatively lower. The energy barrier for 1-TM diffusion is sensitive towards the state of charge. During charge, delithiation occurs along with oxidation of TMs. The higher valence of TMs in the charged state increases electrostatic repulsion. Furthermore, the migration of TMs into the lithium layer (antisite disorder) during charge and collapse of slabs at a higher depth of delithiation hinders lithium migration. The 0 -TM channels have the minimum energy barrier. Lithium migration through it is irrespective of the size of the diffusion channel and valence of transition metals. Low-temperature (LT) spinel-like $\mathrm{LiCOO}_{2}$ structure possesses percolating networks of 0-TM channels, and macroscopic lithium percolation occurs through its bulk. On the other hand, cation disordered rock salt structures $(\alpha-$ $\mathrm{LiFeO}_{2}$ ) contain 0-TM, 1-TM, and 2-TM channels. As described earlier, the 2-TM channels are inactive [132]. Due to the disordered arrangements of the cations, the average height of the tetrahedron sites is lower than that of the ordered rock salt structure. It results in a higher energy barrier for lithium migration via a 1-TM channel. Therefore, only 0-TM channels sustain lithium percolation in the case of disordered rock salt structures. 0-TM channels, i.e., activated tetrahedral site surrounded by four lithium atoms, demand a lithium-rich environment. Their concentration increases with increasing lithium content in the composition. There is a threshold value of lithium content for different structures beyond which the 0-TM channels form a percolating network to enable facile macroscopic diffusion. Monte-Carlo simulations suggest that approximately $10 \%$ excess of lithium is required for layered and disordered rock salt structure, $>30 \%$ for $\gamma$ - $\mathrm{LiFeO}_{2}$ type 
structure, while $\sim 23 \%$ deficiency is enough for low-temperature $\mathrm{LiCoO}_{2}$. Therefore, spinel-like lithium oxide is the ideal situation for 0-TM percolation. It is not only capable of acting as a cathode but also as a lithium insertion anode in partially delithiated form.

(a) o-t-o diffusion

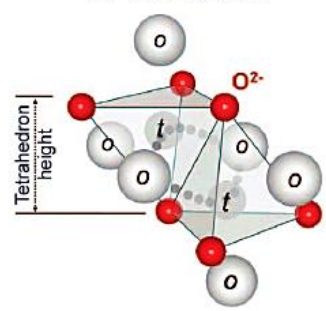

1-TM channel

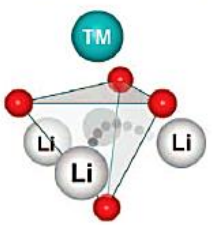

0-TM channel

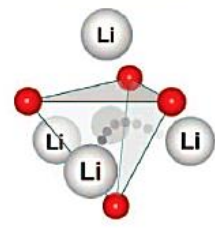

2-TM channel

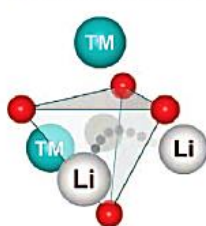

(b) $E$

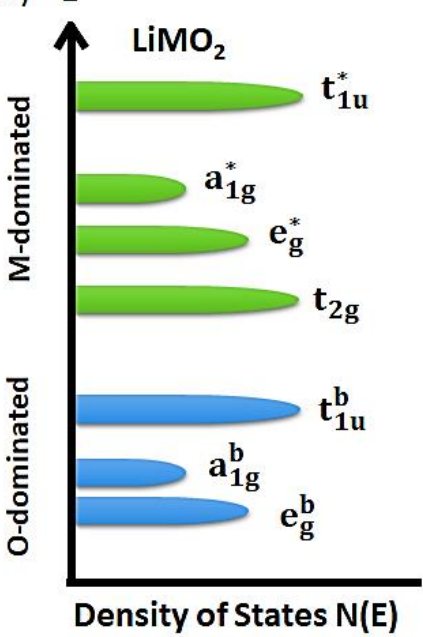

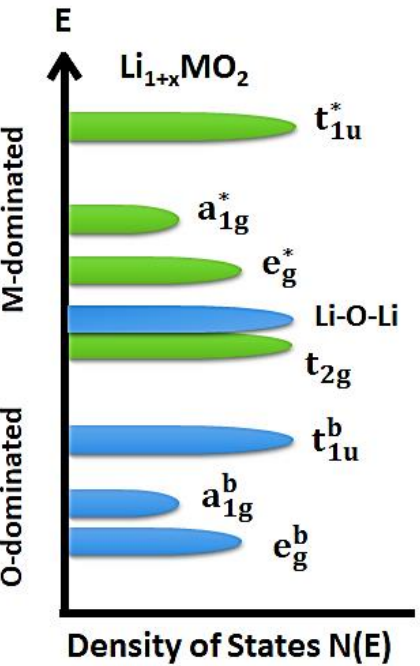

Figure 11 (a) Possible environments within Li-rich cation disordered layered oxide cathodes. O-T-O diffusion route and activated states of Li migration. Reproduced with permission from reference [131]. Copyright 2014 AAAS, and (b) Schematic band structure of stoichiometric lithium layered oxide and lithium-rich layered oxides.

\subsubsection{Contribution of Anionic Redox}

$\mathrm{Li}^{+}$and charge-compensating electrons are simultaneously generated from layered oxide cathodes during charge. Both move towards the anode, the former via the inner circuit, while the latter via the outer circuit and return during discharge to complete a cycle. In stoichiometric layered oxides, the amount of extractable lithium is balanced with available transition metal redox, which supplies the electrons. Transition metal redox is the only source of capacity here as each lithiumion extraction must be balanced by one electron ejection to maintain charge neutrality. In lithium excess oxides, the extra capacity is attributed to the fact that oxide ions can also take part in a reversible redox reaction. The assistance of oxygen redox pushes the capacity beyond the transition metal redox. This section discusses the aspects of oxygen redox in lithium excess materials.

If we consider the case of an oxygen atom, it is surrounded by three metal atoms (M) and three lithium (3M-O-3Li) in the stoichiometric layered $\mathrm{LiMO}_{2}$ [133]. Oxygen is in a symmetric Li-O-M local environment. However, in lithium excess oxides, the presence of extra lithium can distort the local oxygen environment, where oxygen is coordinated to four lithium atoms and two metal atoms (4Li$\mathrm{O}-2 \mathrm{M}$ ) and gives rise to liner $\mathrm{Li}-\mathrm{O}-\mathrm{Li}$ configuration. Advanced density function theory (DFT) calculation demonstrates increased charge density around oxygen in such configuration. It indicates labile electrons (also denoted as oxygen holes), the extraction of which is the origin of oxygen redox. Reversibility of oxygen redox $\left(\mathrm{O}^{2-} / \mathrm{O}_{2}^{\mathrm{n}-}\right)$ is critical as it competes with irreversible oxygen $\left(\mathrm{O}_{2}\right)$ gas evolution. Formation of peroxo $\left(\mathrm{O}_{2}^{\mathrm{n}-}, \mathrm{n}=2\right)$ species require $\mathrm{O}-\mathrm{O} \sigma$-interaction [134]. It is only possible when two neighboring oxidized oxygen in the Li-O-Li configuration rotates and hybridizes 
without sacrificing much $\mathrm{M}-\mathrm{O}$ bonding. Rotation and subsequent interaction of the metastable oxygen holes enable the formation of a peroxide network avoiding the oxygen gas evolution pathway. Therefore, the rotation of the Li-O-Li configuration is the key step in the mechanism, which depends on adjacent Li-O-M configuration or, more precisely, on the nature of $\mathrm{M}-\mathrm{O}$ bonding. The material cannot afford the loss in $\mathrm{M}-\mathrm{O}$ bonding to a large extent as it may affect the structural integrity and probable collapse of the $\left(\mathrm{MO}_{2}\right)_{\mathrm{n}}$ slabs. Therefore, the flexibility of the $\mathrm{M}-\mathrm{O}$ bond governs the energy barrier of Li-O-Li rotation. Transition metals with partially filled d-orbitals form directional M-O bonds, which poses a difficulty in rotation, whereas metals in their $d^{0}$ and $d^{10}$ configuration form much weaker bonds and facilitates the rotation. Moreover, in the transition metal series, $4 \mathrm{~d}$ and $5 \mathrm{~d}$ metals form more flexible bonds than the $3 \mathrm{~d}$ metals and lower the energy barrier for rotation [135]. Another important factor worth mentioning is the competition between transition metals and anionic redox. Maximum capacity can be obtained when this two redox does not overlap. O2p in Li-O-Li configuration cannot hybridize with Li2s due to the large gap in energy. This unhybridized $02 p$ state has higher energy than the hybridized $02 p$ bonding states. That is why oxygen oxidation occurs preferentially from the Li-O-Li configuration. On the other hand, the unhybridized $02 p$ state lies in a lower position than the metal antibonding state in the $\mathrm{LiMO}_{2}$ molecular orbital diagram (Figure 11b) [81]. Overlap between these two indicates initiation of oxygen redox at partial completion of TM redox leading to lower extractable capacity. Early transition metals ( $\mathrm{V}, \mathrm{Cr}, \mathrm{Mn}$, etc.), having high energy $3 \mathrm{~d}$ orbitals raise the energy of the metal antibonding states preventing the overlap with unhybridized $02 p$ states. Lithium excess oxides containing late $3 \mathrm{~d}$ transition metals ( $\mathrm{Ni}, \mathrm{Fe}, \mathrm{Co}$, etc.) do not allow the full utilization of $\mathrm{TM}$ redox in some cases.

Although anionic redox is a significant step in the capacity generation mechanism of lithium excess materials, Li-O-Li configuration also occurs in stoichiometric layered oxides following cationic disorder at a high depth of delithiation $\geq 4.5 \mathrm{~V}$, especially observed in the case of $\mathrm{LiNiO}_{2}$. However, oxygen oxidation is substantial at $\sim 4.3 \mathrm{~V}$ for lithium excess materials [136].

\subsubsection{High Capacity vs. Better Reversibility}

Lithium excess cathode materials are able to show $\geq 250 \mathrm{mAh} \mathrm{g}^{-1}$ capacity, but stability is confined to only a hundred galvanostatic charge-discharge cycles for most of the materials. They particularly suffered from capacity fade and increased polarization under conditions of chargedischarge upon cycling. The poor electrochemical reversibility can be ascribed to a high degree of oxygen redox utilization leading to oxygen gas evolution, metal dissolution, and consequent structural deterioration. Oxygen gas release leaves behind cations on the surface, and the cationdensified surface blocks the passage of lithium migration into the bulk, increasing the impedance of the cell [137]. The evolved gas can trigger side reactions with the electrolyte. Protective surface coating and doping improve the cycling performance $[138,139]$. One of the most followed modification approaches is fluorine doping that provides multifaceted benefits. Substitution of $\mathrm{O}^{2-}$ with $\mathrm{F}^{-}$lowers the average anion valence so that the pristine material can accommodate a more significant number of metals at their lower oxidation states ( $\mathrm{Mn}$ and $\mathrm{Ni}$ in their +2 states) [140]. Incorporating low valent metals widens the capacity obtained from transition metal redox. The decreased dependency on oxygen redox to draw more capacity reduces the probability of 
irreversible oxygen deposition. F-substitution also hinders asymmetric structural distortion during cycling for Jahn-Teller active redox sites [141].

\subsubsection{Enhanced C-rate Performance}

C-rate performance is the measure of how fast lithium can migrate during galvanostatic cycles. Although the movement of $\mathrm{Li}^{+}$is fast enough through liquid electrolytes, it is impeded by a solidstate diffusion barrier. If delithiation is accompanied by a shift of other atoms in the host, the lithium transport pathway becomes crowded, resulting in kinetic complexities. Polyanionic frameworks $\left(\mathrm{LiFePO}_{4}, \mathrm{LiMn}_{2} \mathrm{O}_{4}\right)$ are the ideal examples where atomic rearrangements during delithiation are minimal and show superior rate capability. In contrast, the high current rate performance of $\mathrm{LiCrO}_{2}$ is severely hampered by $\mathrm{Cr}$ migration [142]. Therefore, the traditional view supports the fact that these non-topotactic movements are detrimental to the fast lithium-ion migration. But a recent study suggests an opposite trend for Li-rich cation disordered rock salt oxides. $\mathrm{Cr}$-doped $\mathrm{Li}_{1.2} \mathrm{Mn}_{0.2} \mathrm{Ti}_{0.4} \mathrm{Cr}_{0.2} \mathrm{O}_{2}$ shows a $40 \%$ capacity reduction when current density increases from $20 \mathrm{~mA} \mathrm{~g}$ ${ }^{1}$ to $1 \mathrm{~A} \mathrm{~g} \mathrm{~g}^{-1}$ with respect to a $57 \%$ decrease in $\mathrm{Li}_{1.2} \mathrm{Mn}_{0.4} \mathrm{Ti}_{0.4} \mathrm{O}_{2}$. Theoretical studies identified the movement of $\mathrm{Cr}$ (from octahedral to the tetrahedral site) as the reason for high capacity retention. Non-topotactic migration of $\mathrm{Cr}$ generates additional 0-TM sites, and the resulting expansion in the lithium percolating network improves the kinetics. One necessary condition for such octahedral to tetrahedral site migration is that the metal ion must prefer tetrahedral coordination under conditions of a high oxidation state. According to the theory of coordination complexes, metal ions in $\mathrm{d}^{0}, \mathrm{~d}^{10}$, and $\mathrm{d}^{5}\left(\mathrm{~V}^{+5}, \mathrm{Mo}^{+6}, \mathrm{Fe}^{+3}, \mathrm{Mn}^{+2}\right.$, etc. $)$ configuration gather no gain in octahedral site stabilization energy. They may undergo similar movement towards adjacent tetrahedral sites if their size matches the tetrahedron height [143].

Figure 12 depicts the contribution from each atom in lithium excess cation-disordered rock salt oxide materials. The choice of elements is critical, and many inter-related factors must be taken into consideration to reach the optimized composition. Table 3 is a collection of some literaturereported compounds and their electrochemical performances. 

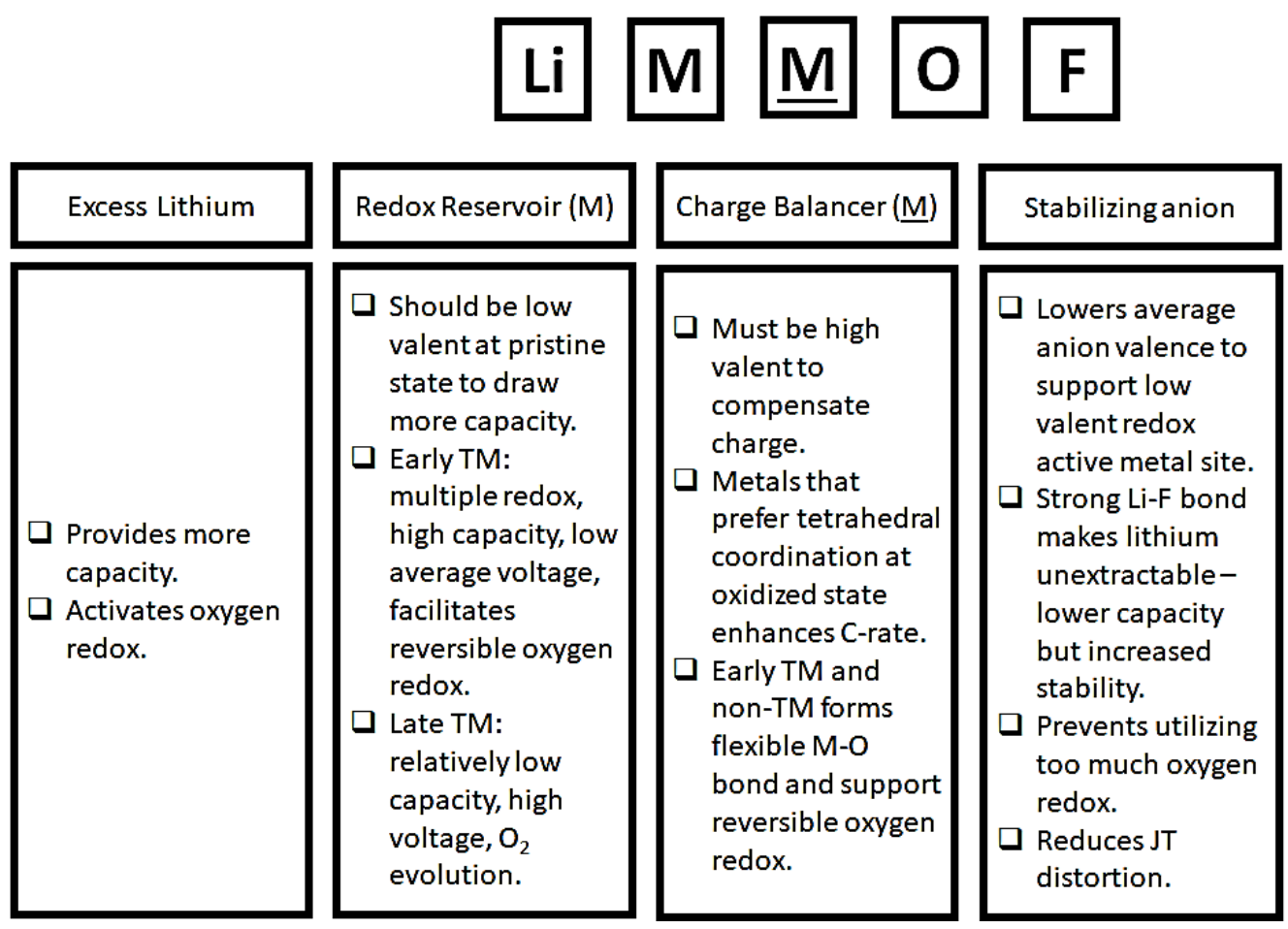

Additional Points

- Early TM multiredox centres: $\mathrm{V}^{+3 /+5}, \mathrm{Mo}^{+3 /+6}$, $\mathrm{Cr}^{+3 /+5}$

Conventional redox couples: $\mathrm{Mn}^{+3 /+4}, \mathrm{Ni}^{+2 /+4}$, $\mathrm{Fe}^{+3 /+4}, \mathrm{Co}^{+3 /+4}$

Redox active charge balancer$\mathrm{V}^{+4 /+5}, \mathrm{Mo}^{+5 /+6}$

- Redox inactive charge balancer $\mathrm{V}^{+5}, \mathrm{Cr}^{+6}, \mathrm{Ru}^{+5}$, $\mathrm{Nb}^{+5}, \mathrm{Mo}^{+6}, \mathrm{Sn}^{+4}$, $\mathrm{Ti}^{+4}, \mathrm{Sb}^{+5}$, etc.

Figure 12 Summary of design principles for lithium excess cation-disordered rock salt oxide materials.

Table 3 Electrochemical performances of selected lithium-rich cathode materials.

\begin{tabular}{|c|c|c|c|c|c|c|}
\hline \multirow[t]{2}{*}{ Material composition } & \multicolumn{4}{|c|}{ Electrochemical testing conditions } & \multirow{2}{*}{$\begin{array}{l}\text { First } \\
\text { discharge } \\
\text { capacity } \\
\left(\mathrm{mAh} \mathrm{g}{ }^{-1}\right)\end{array}$} & \multirow{2}{*}{$\begin{array}{l}\text { Capacity } \\
\text { retention } \\
(\%), \\
\text { number } \\
\text { of cycles }\end{array}$} \\
\hline & $\begin{array}{l}\text { Active } \\
\text { material } \\
\text { loading } \\
(\%)\end{array}$ & $\begin{array}{l}\text { Voltage } \\
\text { range } \\
\text { (V) }\end{array}$ & $\begin{array}{l}\text { Current } \\
\text { density } \\
\left(\mathrm{mA} \mathrm{g}^{-1}\right) \\
\text { or } \\
\text { C-rate }\end{array}$ & $\begin{array}{l}\text { Temp. } \\
\left({ }^{\circ} \mathrm{C}\right)\end{array}$ & & \\
\hline $\mathrm{Li}_{2} \mathrm{VO}_{2} \mathrm{~F}[144]$ & 72 & $1.3-4.1$ & $1 \mathrm{C}$ & 40 & 300 & 80,20 \\
\hline $\mathrm{Li}_{2} \mathrm{~V}_{0.2} \mathrm{Cr}_{0.8} \mathrm{O}_{2} \mathrm{~F}[145]$ & 60 & $1.3-4.7$ & $13(C / 35)$ & 25 & 409 & 58,60 \\
\hline $\mathrm{Li}_{1.25} \mathrm{Nb}_{0.25} \mathrm{Mn}_{0.5} \mathrm{O}_{2}[146]$ & 70 & $1.5-4.8$ & 10 & 55 & 287 & 70,20 \\
\hline $\mathrm{Li}_{9 / 7} \mathrm{Nb}_{2 / 7} \mathrm{Mo}_{3 / 7} \mathrm{O}_{2}[147]$ & 76.5 & $1.0-4.0$ & 100 & RT & 240 & 83,60 \\
\hline $\mathrm{Li}_{1.42} \mathrm{Mo}_{0.29} \mathrm{Fe}_{0.29} \mathrm{O}_{2}[148]$ & 76.5 & $1.5-4.8$ & 10 & RT & 350 & 35,15 \\
\hline $\mathrm{Li}_{1.15} \mathrm{Ni}_{0.47} \mathrm{Sb}_{0.38} \mathrm{O}_{2}[129]$ & 80 & $2.5-4.6$ & $1 \mathrm{C}$ & - & 131 & 78,50 \\
\hline $\mathrm{Li}_{2} \mathrm{Ru}_{0.75} \mathrm{Sn}_{0.25} \mathrm{O}_{3}[149]$ & - & $2.0-4.6$ & $C / 10$ & 20 & 230 & 95,60 \\
\hline $\mathrm{Li}_{1.23} \mathrm{Ni}_{0.155} \mathrm{Ru}_{0.615} \mathrm{O}_{2}[150]$ & 70 & $2.2-4.3$ & $\mathrm{C} / 10$ & RT & 295.3 & 67,50 \\
\hline $\mathrm{Li}_{1.2} \mathrm{Ni}_{1 / 3} \mathrm{Ti}_{1 / 3} \mathrm{Mo}_{2 / 15} \mathrm{O}_{2}[151]$ & 70 & $1.5-4.5$ & 20 & RT & 230 & 75,20 \\
\hline $\mathrm{Al}_{2} \mathrm{O}_{3} \quad$ modified & 70 & $1.5-4.8$ & 10 & $\mathrm{RT}$ & 286 to 293 & 79.7-91, \\
\hline $\mathrm{Li}_{1.2} \mathrm{Ti}_{0.4} \mathrm{Mn}_{0.4} \mathrm{O}_{2}[152]$ & & & & & & 15 \\
\hline
\end{tabular}

\subsection{Conversion Cathodes}

Conversion type cathodes involve chemical reactions with Li-ion through bond breaking and bond formation. Thus, more energy can be stored and transformed using these types of reactions. 
The Li-ion storage capacity in these cathodes is not site-limited. Therefore, more capacity can be achieved and hence, higher energy can be recorded. Conversion electrode reactions involve two to six electron transfer processes. The conversion reactions result in considerable structural changes of the host matrix, unlike insertion-type ones. The disadvantage with these types of cathodes is the inherent low conductivity leading to low active mass utilization, low reversibility of the conversion phases, and high hysteresis. These also involve high volume expansion during cycling. As a consequence of these shortcomings, the reversibility of the redox reaction decreases rapidly under conditions of repeated cycling, and hence, the energy conversion efficiency also becomes inferior. The redox reactions occurring in the conversion cathodes during the lithiation-delithiation process is given below $[10,153,154]$

Type 1: $\mathrm{MX}_{\mathrm{Z}}+\mathrm{yLi} \leftrightarrow \mathrm{M}+\mathrm{zLiy}_{\mathrm{z}} \mathrm{X}, \mathrm{M}=$ transition metal $(\mathrm{Fe}, \mathrm{Ni}, \mathrm{Mn}, \mathrm{Cu}) ; \mathrm{X}=\mathrm{F}, \mathrm{Cl}, \mathrm{Br}, \mathrm{I}$

Type 2: $y \mathrm{Li}+\mathrm{X} \leftrightarrow \mathrm{Li}_{\mathrm{y}} \mathrm{X}, \mathrm{X}=\mathrm{O}, \mathrm{S}, \mathrm{Se}, \mathrm{Te}$

\subsubsection{Type 1-Category Conversion Cathodes}

This category of conversion cathodes includes $\mathrm{MX}_{\mathrm{z}}$ type of compounds, where $\mathrm{M}$ represents transition metals such as $\mathrm{Fe}, \mathrm{Ni}, \mathrm{Mn}, \mathrm{Cu}$, and $\mathrm{X}$ represent $\mathrm{F}, \mathrm{Cl}, \mathrm{Br}$, I. For instance, Iron trifluoride $\left(\mathrm{FeF}_{3}\right.$ ), which has a high theoretical capacity of $712 \mathrm{mAh} \mathrm{g}^{-1}$ (involving 3 electrons) and a working voltage of $2.7 \mathrm{~V}$, has been studied as a LIB cathode [155]. FeF 3 reacts with three Li-ions during lithiation, i.e., $\mathrm{F}^{-}$ions diffuse to form $\mathrm{LiF}$ and Fe. The structure appears to be Fe metals scattered in a pool of LiF [17]. The reaction for the above process is denoted as below.

$$
\mathrm{FeF}_{3}+3 \mathrm{Li}^{+}+3 \mathrm{e}^{-} \leftrightarrow 3 \mathrm{LiF}+\mathrm{Fe}
$$

Similarly, metal fluorides, including nickel (II) fluoride $\left(\mathrm{NiF}_{2}\right)$, cobalt (II) fluoride $\left(\mathrm{CoF}_{2}\right)$, $\mathrm{FeF}_{2}$, etc., have also been explored as LIB cathodes. Some common Type 1-category conversion cathodes are summarized in Table $4[10,153]$.

Table 4 Properties of some typical Type-1 conversion-type cathodes [17].

\begin{tabular}{lllll}
\hline Materials & $\begin{array}{l}\text { Relative electronic } \\
\text { conductivity }\end{array}$ & $\begin{array}{l}\text { Theoretical } \\
\text { potential }(\mathrm{V})\end{array}$ & $\begin{array}{l}\text { Theoretical } \\
\text { capacity }\left(\mathrm{mAh} \mathrm{g}^{-1}\right)\end{array}$ & $\begin{array}{l}\text { Volume expansion } \\
\text { fraction (\%) }\end{array}$ \\
\hline $\mathrm{FeF}_{3}$ & Insulator & 2.74 & 712 & 25.6 \\
$\mathrm{FeF}_{2}$ & Insulator & 2.66 & 512 & 16.7 \\
$\mathrm{FeCl}_{3}$ & Poor & 2.83 & 495.7 & 22.6 \\
$\mathrm{FeCl}_{2}$ & Poor & 2.41 & 422.9 & 19.9 \\
$\mathrm{CoF}_{2}$ & Poor & 2.85 & 553 & 21 \\
$\mathrm{CoCl}_{2}$ & Poor & 2.59 & 412,8 & 23 \\
$\mathrm{CuF}_{2}$ & Insulator & 3.55 & 527.8 & 11.6 \\
$\mathrm{NiF}_{2}$ & Poor & 2.96 & 554.3 & 28.3 \\
\hline
\end{tabular}

The feasibility of reversible electrode reaction in these electrodes is questionable due to the added limitations like poor ion transport kinetics, lesser structural stability, and metal cluster 
formations at a fully delithiated state, which catalyzes the electrolyte decomposition. Electrode engineering, nano-structuring, conductive coating, and composite formation using conductive additives like carbon and conducting polymers can significantly improve their electrochemical performance [10, 153]. A 3-dimensional (3D) carbon fiber electrode architecture with nano-size active iron fluorides and multilayer graphene (MLG) as connectors can deliver capacities of $595 \mathrm{mAh}$ $\mathrm{g}^{-1}$ and $445 \mathrm{mAh} \mathrm{g}^{-1}$ in the operating voltage range of 4.5-1.0 $\mathrm{V}$ and 4.5-1.5 V, respectively. Besides, the hysteresis voltage is reduced from $2 \mathrm{~V}$ for pristine $\mathrm{FeF}_{3}$ to about $0.9 \mathrm{~V}$ for the $3 \mathrm{D}$ carbon fiber

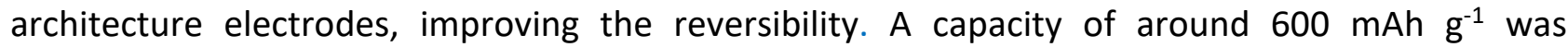
maintained till 25 cycles even when the electrodes were cycled at an elevated temperature of $60^{\circ} \mathrm{C}$ due to the enabling of reversible 3 electron kinetics [156]. But the cycle life and $C$ rate performances reported were still lower compared to conventional insertion cathodes (Figure 13).
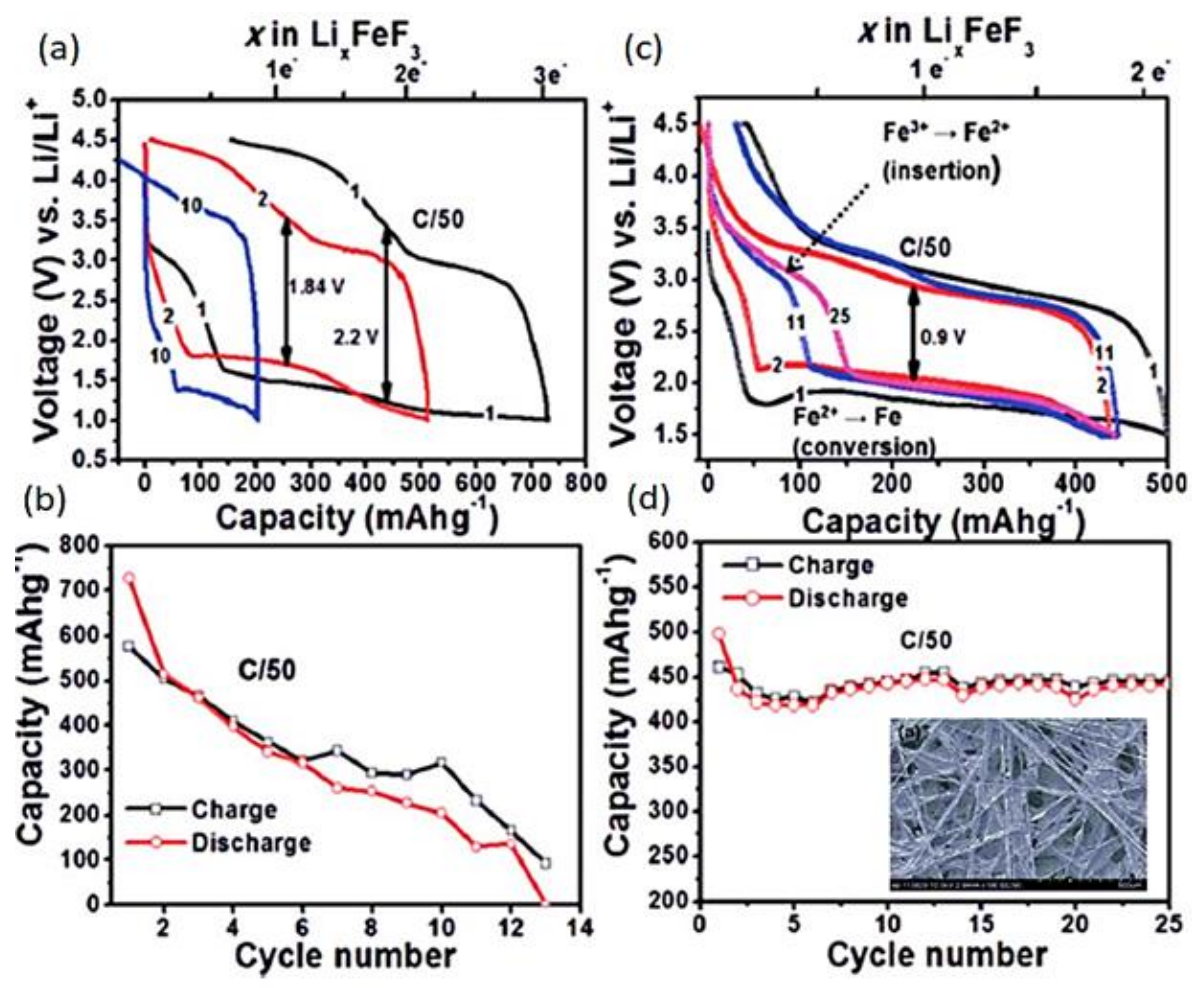

Figure 13 Slurry coated on Al-foil by conventional method (a) Voltage profiles of $\mathrm{Li} / \mathrm{FeF}_{3}$ cell at $25^{\circ} \mathrm{C}$ and (b) Capacity plotted as a function of cycle number for the Li/FeF 3 cell. $\mathrm{FeF}_{3}$ on carbon fiber 3D electrode. (c) Voltage profile ( $\mathrm{C} / 50$ rate) between 1.5-4.5 $\mathrm{V}$ at $25{ }^{\circ} \mathrm{C}$ and (d) Capacity plotted as a function of the cycle number. The inset of figure $\mathrm{d}$ represents a scanning electron microscopy image of $\mathrm{FeF}_{3} /$ carbon fiber electrode. Adapted from reference [156] with permission from the Royal Society of Chemistry.

\subsubsection{Type 2-Category Conversion Cathodes}

This type of conversion electrodes includes $X=0, S, S e, T e$, etc. The most extensively studied conversion cathodes of this category include the oxygen cathode in the lithium-air battery and the sulfur cathode in the lithium-sulfur battery.

Lithium-sulfur battery utilizes sulfur as a cathode and lithium metal as the anode material. The common electrolyte used is $1 \mathrm{M}$ LiTFSI in a $1: 1$ volume ratio of DOL: DME with $1 \% \mathrm{w} / \mathrm{w} \mathrm{LiNO}_{3}$ as an 
additive for lithium surface passivation [157]. Sulfur has a high theoretical capacity of $\sim 1600 \mathrm{mAh} \mathrm{g}^{-}$ ${ }^{1}$ and high abundance in the earth's crust, but it has poor electronic conductivity $\left(10^{-30} \mathrm{~S} \mathrm{~cm}^{-1}\right)$. High volume expansion ( $\sim 80 \%$ ), dissolution of intermediate polysulfides in the electrolyte with effective loss of active $\mathrm{S}, \mathrm{Li}_{2} \mathrm{~S}$ deposition, and dendrite formation on $\mathrm{Li}$ anode during cycling results in capacity fading and cycling instability, which limit the practical application [158-160]. The electrochemical cell reaction involved during the charge-discharge process is as follows [10]:

$$
\begin{aligned}
& \text { Cathode reaction: } \mathrm{S}+2 \mathrm{Li}^{+}+2 \mathrm{e}^{-} \leftrightarrow \mathrm{Li}_{2} \mathrm{~S} \\
& \text { Anode reaction: } 2 \mathrm{Li} \leftrightarrow 2 \mathrm{Li}^{+}+2 \mathrm{e}^{-} \\
& \text {Overall reaction: } 2 \mathrm{Li}+\mathrm{S} \leftrightarrow \mathrm{Li}_{2} \mathrm{~S} \quad \mathrm{E}^{0}=2 \mathrm{~V}
\end{aligned}
$$

During charge-discharge, irreversible by-products such as methanol, ethanol, thiocarbonates, and ethylene glycol are formed as a result of intermediate polysulfide formation. The formation of polysulfides through the intermediates can be represented as follows:

$$
\mathrm{Li}_{2} \mathrm{~S} \rightarrow \mathrm{Li}_{2} \mathrm{~S}_{2} \rightarrow \mathrm{Li}_{2} \mathrm{~S}_{4} \rightarrow \mathrm{Li}_{2} \mathrm{~S}_{6} \rightarrow \mathrm{Li}_{2} \mathrm{~S}_{8} \rightarrow \mathrm{S}_{8}
$$

Due to polysulfide formation and resulting low cycle life, instead of taking bare $S$, the $\mathrm{Li}_{2} \mathrm{~S}$ cathodes are also reported. $\mathrm{Li}_{2} \mathrm{~S}$ nanoparticles embedded with conductive carbon show little structural change after 400 cycles. Self-standing 3D printed sulfur/carbon composite cathodes with high sulfur loading were found to deliver a stable capacity of $564 \mathrm{mAh} \mathrm{g}^{-1}$ within 200 cycles at a $3 \mathrm{C}$ current rate by facilitating $\mathrm{Li}^{+} / \mathrm{e}^{-}$transport [161-164].

Se and Ti-based conversion cathodes have high electronic conductivity compared to $\mathrm{S}$ and show higher rate capability. But they also suffer from issues similar to S-based conversion reactions.

The Li-air battery is one of the most promising Li-based batteries with regard to the ultrahigh specific energy density of $11,650 \mathrm{Wh} \mathrm{kg}^{-1}$ that is much higher than conventional LIBs (150-200 Wh $\mathrm{kg}^{-1}$ ) [165]. The electrochemical cell reaction of $\mathrm{Li} / \mathrm{O}_{2}$ (air) in an organic electrolyte (Li salts such as $\mathrm{LiPF}_{6}$ in ether-based solvents such as dimethyl ether, DMSO, acetonitrile, pyrrolidone, ionic liquids, etc) [166] is as follows [167]:

$$
\begin{aligned}
& \text { Cathode reaction: } \mathrm{O}_{2}+2 \mathrm{Li}^{+}+2 \mathrm{e}^{-} \leftrightarrow \mathrm{Li}_{2} \mathrm{O}_{2} \text { (solid) } \\
& \text { Anode reaction: } 2 \mathrm{Li} \leftrightarrow 2 \mathrm{Li}^{+}+2 \mathrm{e}^{-} \\
& \text {Overall reaction: } 2 \mathrm{Li}+\mathrm{O}_{2} \leftrightarrow \mathrm{Li}_{2} \mathrm{O}_{2} \text { (solid) } \mathrm{E}^{0}=2.96 \mathrm{~V}
\end{aligned}
$$

The major drawback of a $\mathrm{Li}-\mathrm{O}_{2}$ battery is air cathode and electrolyte decomposition on reaction with $\mathrm{O}_{2}$. The deposition of solid $\mathrm{Li}_{2} \mathrm{O}_{2}$ at the electrolyte- air interface that further converts into $\mathrm{Li}_{2} \mathrm{O}$ complicates the oxygen reduction reaction (ORR) and results in a steep decrease in the cell capacity on cycling. Research is dedicated to the ORR mechanism in an organic electrolytic medium and ORR catalysts for the cathode. The major types of catalysts include conventional metal catalysts (e.g., Pt, $\mathrm{Pd}, \mathrm{Au}, \mathrm{Co}$ ), metal oxides (various crystallographic phases of $\mathrm{MnO}_{\mathrm{x}}, \mathrm{CoO}_{\mathrm{x}}$ ), composites of metal and metal oxides (e.g., the composites of $\mathrm{Ag}, \mathrm{Ni}$, and $\mathrm{MnO}_{\mathrm{x}}, \mathrm{CoO}_{\mathrm{x}}$ ), metal carbide, nitrides, sulfides, or organo-C/N/S composites with metal (e.g., Fe/N/C, TiN/C) [167]. Also, nano-structuring of the metal 
oxides and metal components is reported to enhance the performance. Moreover, nanostructured, high surface area, porous carbon has also been reported as catalysts and supporters for ORR in Li$\mathrm{O}_{2}$ batteries. But the carbon surface suffers from instability due to the oxidative environment and the reaction with the discharge product $\left(\mathrm{Li}_{2} \mathrm{O}_{2}\right)$, resulting in the formation of $\mathrm{Li}_{2} \mathrm{CO}_{3}$. Thus, passivated carbon nanostructures using metal oxides such as $\mathrm{Al}_{2} \mathrm{O}_{3}, \mathrm{Ru}_{2} \mathrm{O}$ are utilized to avoid direct contact with the carbon surface $[165,166,168,169]$.

Conversion cathodes are the next-generation cathodes for lithium-ion-based batteries. Still, the limitations of the lower cycling stability and reversibility are being resolved by researchers using various above-mentioned methodologies.

\section{High Voltage Materials (Only >4 V)}

Materials that show either an average voltage greater than $4 \mathrm{~V}$ or demonstrate a significant plateau capacity beyond $4 \mathrm{~V}$ are only included in the review. $\mathrm{LiFePO}_{4}$ is the only material in the polyanionic phosphate group that is still reigning in the commercial market since its first introduction in 1995. Polyanionic frameworks provide robust lattice which undergoes minimal atomic arrangements upon lithiation-delithiation. It shows $150-160 \mathrm{mAh} \mathrm{g}^{-1}$ capacity at more comprehensive current ranges with an average voltage of approximately $3.45 \mathrm{~V}$ and easily cyclable up to 5000 cycles with good capacity retention [23]. It is also regarded as one of the stable cathodes (air, thermal and cyclic stability) and, coupled with the LTO anode, results in an ultrasafe LFP-LTO battery pack, that can power electric buses, trains, etc. However, due to low voltage and capacity, the overall energy density is lower than that of oxide cathodes. Hence, LFP analogs having higher voltages can mitigate the energy density issue and worth consideration for commercial applications. Several other polyanionic frameworks such as sulfate, silicate, fluorophosphate, pyrophosphate, etc., that crystallize in a variety of polymorphs have also been studied as high voltage LIB cathodes. Table 5 compares the electrochemical properties of the various classes of polyanionic materials.

Table 5 Electrochemical properties pristine polyanionic materials without modification.

\begin{tabular}{|c|c|c|c|c|c|}
\hline Class & Materials (ref) & $\begin{array}{l}\text { Redox } \\
\text { couple }\end{array}$ & $\begin{array}{l}\text { Average } \\
\text { voltage } \\
\left(\mathrm{V} \text { vs. } \mathrm{Li}^{+} / \mathrm{Li}\right)\end{array}$ & $\begin{array}{l}\text { Reversible } \\
\text { capacity } \\
\left(\mathrm{mAh} \mathrm{g}^{-1}\right) \\
\end{array}$ & $\begin{array}{l}\text { Theoretical } \\
\text { capacity } \\
\left(\mathrm{mAh} \mathrm{g}^{-1}\right)\end{array}$ \\
\hline Phosphate & $\mathrm{LiMnPO}_{4}[170]$ & $\mathrm{Mn}^{+2 /+3}$ & $\sim 4.1$ & 160 & 171 \\
\hline \multirow[t]{2}{*}{$\mathrm{LiMPO}_{4}$} & $\mathrm{LiCoPO}_{4}[171]$ & $\mathrm{Co}^{+2 /+3}$ & $\sim 4.8$ & 120 & 167 \\
\hline & $\mathrm{LiNiPO}_{4}[172]$ & $\mathrm{Ni}^{+2 /+3}$ & $\sim 5.1$ & 75 & 169 \\
\hline Phosphate & $\alpha-\mathrm{Li}_{3} \mathrm{~V}_{2}\left(\mathrm{PO}_{4}\right)_{3}$ & $\mathrm{~V}^{+3 /+5}$ & $\sim 4.0$ & 170 & 197 \\
\hline $\mathrm{Li}_{3} \mathrm{M}_{2}\left(\mathrm{PO}_{4}\right)_{3}$ & [173] & & & & \\
\hline Tavorite & $\mathrm{LiVOPO}_{4}[174]$ & $\mathrm{V}^{+3 /+5}$ & $\sim 3.2$ & 240 & 318 \\
\hline \multicolumn{6}{|l|}{ Oxyphosphate } \\
\hline \multicolumn{6}{|l|}{$\mathrm{LiMOPO}_{4}$} \\
\hline Tavorite & $\mathrm{LiVPO}_{4} \mathrm{~F}[175]$ & $\mathrm{V}^{+2 /+4}$ & $\sim 3.2$ & 260 & 312 \\
\hline Fluorophosphate & $\mathrm{Li}_{2} \mathrm{CoPO}_{4} \mathrm{~F}[176]$ & $\mathrm{Co}^{+2 /+3}$ & $\sim 5.0$ & 120 & 143 \\
\hline $\begin{array}{l}\mathrm{LiMPO}_{4} \mathrm{~F} \\
\text { or }\end{array}$ & $\mathrm{Li}_{2} \mathrm{NiPO}_{4} \mathrm{~F}[177]$ & $\mathrm{Ni}^{+2 /+3}$ & $\sim 5.3$ & NF & 144 \\
\hline
\end{tabular}




\begin{tabular}{llllll}
\hline $\mathrm{Li}_{2} \mathrm{MPO}_{4} \mathrm{~F}$ & & & & & \\
Pyrophosphate & $\mathrm{Li}_{2} \mathrm{MnP}_{2} \mathrm{O}_{7}[178]$ & $\mathrm{Mn}^{+2 /+3}$ & $\sim 4.4$ & 60 & 110 \\
$\mathrm{Li}_{2} \mathrm{MP}_{2} \mathrm{O}_{7}$ & $\mathrm{Li}_{2} \mathrm{CoP}_{2} \mathrm{O}_{7}[179]$ & $\mathrm{Co}^{+2 /+3}$ & $\sim 5.0$ & 90 & 109 \\
& $\mathrm{Li}_{2} \mathrm{VOP}_{2} \mathrm{O}_{7}[180]$ & $\mathrm{V}^{+4 /+5}$ & $\sim 4.1$ & 30 & 105 \\
Silicate & $\mathrm{Li}_{2} \mathrm{MnSiO}_{4}[181]$ & $\mathrm{Mn}^{+2 /+4}$ & $\sim 4.1^{*}$ & 200 & $333^{\#}$ \\
$\mathrm{Li}_{2} \mathrm{MSiO}_{4}$ & $\mathrm{Li}_{2} \mathrm{CoSiO}_{4}[181]$ & $\mathrm{Co}^{+2 /+3}$ & $\sim 4.2^{*}$ & 40 & 163 \\
\hline
\end{tabular}

* based on computational calculation, NF refers to data Not Found in literature, " calculated based on two-electron transfer

\subsection{Polyanionic Oxides}

\subsubsection{Phosphate Group}

The structure of polyanionic cathodes is described in the previous section (4.2.2.b.). The inductive effect of the polyanionic framework alters the iono-covalency of the $\mathrm{M}-\mathrm{O}$ bond and results in good structural stability. The stronger $\mathrm{X}-\mathrm{O}$ bond decreases orbital overlap between $\mathrm{M}-\mathrm{O}$ bonds, increasing the ionic character of the $\mathrm{M}-\mathrm{O}$ bond and the electrochemical potential. The stronger $\mathrm{M}$ O-X linkage holds the oxygen very tightly and does not release oxygen during abusing conditions (under overcharging, overheating, short circuit, etc. conditions). Therefore, the system is intrinsically safer than layered oxides. The more ionic or less covalent $\mathrm{M}-\mathrm{O}$ bond stabilizes the $\mathrm{M}^{+\mathrm{n} /+(\mathrm{n}+1)}$ redox. The stabilization in redox energy allows faster ion migration and generates higher C-rate benefits over layered oxides. $\mathrm{LiCoO}_{2}$ undergoes non-linear expansion after $50 \%$ delithiation during the charge [182]. On the contrary, polyanionic frameworks maintain structural integrity and can be cycled for more than 5000 cycles. Overall, polyanionic frameworks have advantages like safety, fast charge-discharge, long-term cycling, and high voltage, but the capacity is limited (170 $\mathrm{mAh}^{-1}$ for phosphates, $\sim 325 \mathrm{mAh} \mathrm{g}^{-1}$ for silicates).

High Voltage Phospho-olivines: The high voltage phosphate olivines are described as $\mathrm{LiMPO}_{4}(\mathrm{M}$ $=\mathrm{Mn}, \mathrm{Co}, \mathrm{Ni})$. In the lattice, oxygen atoms are distributed in a hexagonal closed packed (hcp) array, where $\mathrm{Li}^{+}$and $\mathrm{M}^{+2}$ occupy half of the octahedral sites and phosphorous takes one-eighth of the tetrahedral sites. The structure is crystallized in the orthorhombic phase, either in Pmnb or in the Pnma space group (Figure 14a) [183]. The electrochemical profiles are flat over a large Licomposition range revealing framework stability upon lithiation/delithiation as shown in Figure 14c [184]. Influence of the $\mathrm{PO}_{4}^{3-}$ anion tunes the redox energy of the $\mathrm{M}^{+3 /+2}$ couple and increases the operating potential of $\mathrm{LiMPO}_{4}$, such as $\sim 4.1 \mathrm{~V}$ for $\mathrm{Mn}^{+3 /+2}, 4.8 \mathrm{~V}$ for $\mathrm{Co}^{+3 /+2}$, and $\sim 5.1 \mathrm{~V}$ for $\mathrm{Ni}^{+3 /+2}$. Still, surprisingly, $\mathrm{Fe}^{+2 /+3}$ stands at $\sim 3.4 \mathrm{~V}$. Higher electronegativity of Fe ( compared to $\mathrm{Mn}$ ) should result in the higher operating potential of $\mathrm{LiFePO}_{4}$ (compared to $\mathrm{LiMnPO}_{4}$ ), but the trend is opposite. $\mathrm{Fe}^{+2}\left(3 \mathrm{~d}^{6}\right)$ requires extra energy to pair the sixth electron in the $\mathrm{t}_{2} \mathrm{~g}$ orbital, while $\mathrm{Mn}^{+2}\left(3 \mathrm{~d}^{5}\right)$ does not. Thus, pairing energy increases the redox energy of the $\mathrm{Fe}^{+2 /+3}$ couple. Hence, more energy could be released or consumed during the redox process of $\mathrm{Mn}^{+2 /+3}$, and $\mathrm{LiMnPO}_{4}$ shows higher operating potential [185]. However, the associated problems are plenty. $\mathrm{LiMPO}_{4}$ has intrinsic lower electrical and ionic conductivity issues. Electrical conductivities of $\mathrm{LiFePO}_{4}, \mathrm{LiMnPO}_{4}$ and $\mathrm{LiCoPO}_{4}$ are $\sim 10^{-9}, \sim$ $10^{-11}$, and $\sim 10^{-9} \mathrm{~S} \mathrm{~cm}^{-1}$, respectively, which are much lower than commercial LCO cathode $\left(\sim 10^{-3} \mathrm{~S}\right.$ $\mathrm{cm}^{-1}$ ). $\mathrm{LiMnPO}_{4}$ shows Jahn-Teller distortion of $\mathrm{Mn}^{+3}$. On the other hand, $\mathrm{LiNiPO}_{4}$ and $\mathrm{LiCOPO}_{4}$ suffer 
from major electrolyte degradation during high voltage cycling [186]. In addition, the pure phase synthesis of $\mathrm{LiNiPO}_{4}$ is difficult due to the segregation of the $\mathrm{Li}_{4} \mathrm{P}_{2} \mathrm{O}_{7}$ and $\mathrm{Ni}_{3} \mathrm{P}$ impurity phases [187]. Several ways of coating and doping are reported in the literature for the performance enhancement of $\mathrm{LiMPO}_{4}$ [188].
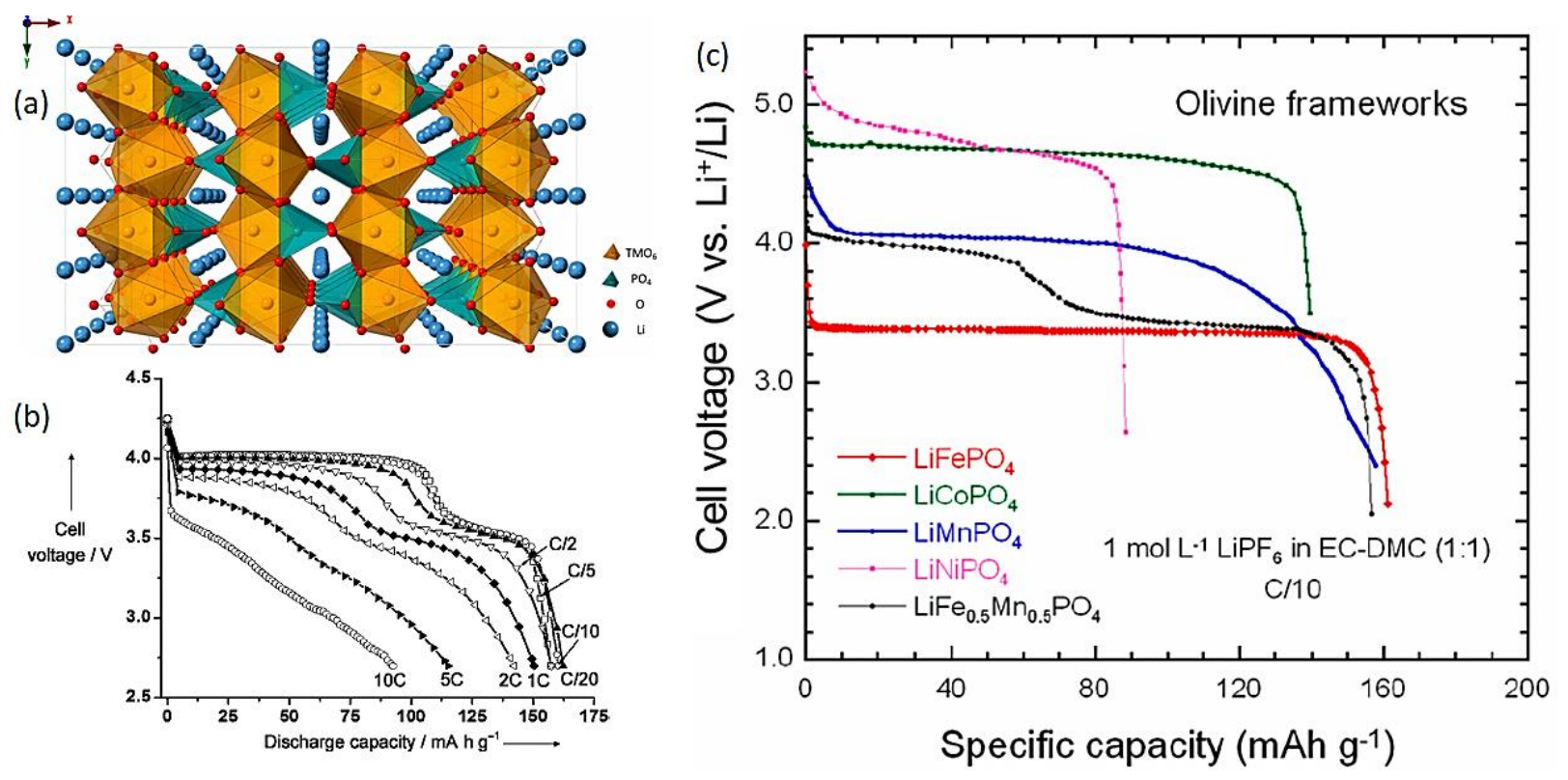

Figure 14 (a) Crystal structure of $\mathrm{LiMPO}_{4}(\mathrm{M}=\mathrm{Mn}, \mathrm{Fe}, \mathrm{Co}$, and Ni). Reproduced from reference [183]. Copyright 2021 IOP Publishing Ltd, (b) Typical voltage profiles of Carbon coated $\mathrm{LiMn}_{0.8} \mathrm{Fe}_{0.2} \mathrm{PO}_{4}$ composite electrodes measured galvanostatically at various discharge rates at $30{ }^{\circ} \mathrm{C}$ in the standard electrolyte solution considering theoretical capacity of $165 \mathrm{mAh} \mathrm{g}^{-1}$. Reproduced with permission from reference [189]. Copyright 2021 Wiley-VCH Verlag GmbH \& Co. KGaA, Weinheim and (c) Discharge profile of $\mathrm{LiMPO}_{4}\left(\mathrm{M}=\mathrm{Mn}, \mathrm{Fe}, \mathrm{Co}\right.$, and $\mathrm{Ni}$ ) olivines and $\mathrm{LiFe}_{0.5} \mathrm{Mn}_{0.5} \mathrm{PO}_{4}$. Reproduced from reference [184].

Carbon-coated $\mathrm{LiMnPO}_{4}$ shows a flat voltage plateau around $4.1 \mathrm{~V}$ vs. $\mathrm{Li}^{+} / \mathrm{Li}$ and shows a reversible capacity of $140 \mathrm{mAh} \mathrm{g}^{-1}$ at a $\mathrm{C} / 10$ rate in the range of $2.7-4.4 \mathrm{~V}$. The material can sustain hundreds of charge-discharge cycles at elevated temperatures without significant capacity fade. Carbon coating increases the electronic conductivity of the pristine sample and stabilizes the cathode-electrolyte interphase. However, $\mathrm{LiMnPO}_{4}$ suffers from a shortage of specific capacity and rate capability [190]. $10 \%$ carbon-coated $\mathrm{LiMn}_{0.8} \mathrm{Fe}_{0.2} \mathrm{PO}_{4}$, where $20 \% \mathrm{Mn}$ sites are substituted with $\mathrm{Fe}$, can mitigate the issues mentioned above. Fe doping pushes the specific capacity beyond 150 $\mathrm{mAh} \mathrm{g}^{-1}$. The composite electrode delivers $\sim 100 \mathrm{mAh} \mathrm{g}^{-1}$ capacity at a $10 \mathrm{C}$ rate, whereas the undoped composite electrode delivers only $60 \mathrm{mAh} \mathrm{g}^{-1}$ (Figure 14b). The performance improvement is attributed to fewer defects in transition metal sites after Fe doping, which maintains the open space for Li-ion conduction even after long-term cycling [189].

On the other hand, due to low electrical conductivity, high voltage cycling, structural instability, etc., $\mathrm{LiCoPO}_{4}$ losses almost $50 \%$ capacity below 100 cycles at C/10 rate [191]. Modification strategies include nanoparticle synthesis, carbon coating, metal-ion doping, use of electrolyte additives, etc. Xing et al. showed that carbon-coated $\mathrm{LiCoPO}_{4}$ nanograins synthesized via the sol-gel method deliver an initial discharge capacity of $137 \mathrm{mAh} \mathrm{g}^{-1}$ at $\mathrm{C} / 10$ rate and retains $68 \%$ after 30 cycles when 
cycled between 3.0-5.1 V using $1 \mathrm{M}^{\mathrm{LiPF}} 6$ in 1:1:1 ratio of EC-DMC-EMC along with 0.1 wt.\% thiophene additive [192]. Literature reports on $\mathrm{LiNiPO}_{4}$ are rare due to difficulty in pure phase synthesis. $\mathrm{LiNiPO}_{4}$ soaked in Graphitic carbon foam delivers a stable discharge capacity of $\sim 80 \mathrm{mAh}$ $\mathrm{g}^{-1}$ with $8 \%$ fade after the $10^{\text {th }}$ cycle when cycled at a $\mathrm{C} / 10$ rate between 3.5-5.4 V. One vital point to note here is that the discharge voltage profile is unexpectedly sloping, unlike the flat voltage region in other phospho-olivines. Other drawbacks are electrolyte decomposition and inferior highrate performance (almost no capacity at C/2 rate) [193].

Rhombohedral or Monoclinic $\mathrm{Li}_{3} \underline{\mathrm{M}}_{2}\left(\mathrm{PO}_{4}\right)_{3}$ : The vanadium analog, i.e., $\mathrm{Li}_{3} \mathrm{~V}_{2}\left(\mathrm{PO}_{4}\right)_{3}$, shows two room temperature polymorphs: $\alpha$-monoclinic and $\beta$-rhombohedral (NASICON - Sodium superionic conductor). The monoclinic phase is isotypic with the $\alpha$-form of the monoclinic $\mathrm{Li}_{3} \mathrm{Fe}_{2}\left(\mathrm{PO}_{4}\right)_{3}$, whereas the rhombohedral form is isotypic with the NASICON framework. The $\alpha$-form is thermodynamically more stable and can be directly synthesized via the chemical reaction route, while $\beta$-form is synthesized from $\mathrm{Na}_{3} \mathrm{~V}_{2}\left(\mathrm{PO}_{4}\right)_{3}$ through the ion-exchange method [194]. Conversion of the rhombohedral $\mathrm{Li}_{3} \mathrm{~V}_{2}\left(\mathrm{PO}_{4}\right)_{3}$ from the $\mathrm{Na}_{3} \mathrm{~V}_{2}\left(\mathrm{PO}_{4}\right)_{3}$ crystals via the ion-exchange method can be seen in Figure 15a [195]. The main structural difference between the two polymorphs is that the 'lantern unit $\left[\mathrm{V}_{2}\left(\mathrm{PO}_{4}\right)_{3}\right]^{\prime}$ is interconnected in the $\beta$-form, while in the $\alpha$-form, they are alternatively oriented in a perpendicular fashion leading to more closed packed structure than the $\beta$-form [196]. All the three lithium can be electrochemically extracted from the monoclinic phase, while deinsertion of only two lithium is possible from the rhombohedral phase. Rhombohedral $\mathrm{Li}_{3} \mathrm{~V}_{2}\left(\mathrm{PO}_{4}\right)_{3}$ under potentiodynamic testing conditions $(10 \mathrm{mV} / 1.5 \mathrm{~h}$ followed by equilibration) between 3.0-4.5 V range shows two lithium extraction accompanied by the oxidation of $\mathrm{V}^{+3}$ to $\mathrm{V}^{+4}$ and occurs via a biphasic process with an average voltage of $3.77 \mathrm{~V}$ vs. Li+/Li (Figure 15b). On the contrary, the monoclinic phase undergoes three lithium extraction in the voltage range of 3.0-4.8 $\mathrm{V}$ due to $\mathrm{V}^{+4 /+5}$ redox at $\sim 4.5 \mathrm{~V}$. It occurs via a multiphasic process with an average voltage of $3.85 \mathrm{~V} \mathrm{vs.} \mathrm{Li}^{+} / \mathrm{Li}$ [197]. Figure $15 \mathrm{c}$ shows the Li-ion migration pathway in the monoclinic structure [198]. The obtained capacity of $200 \mathrm{mAh} \mathrm{g}^{-1}$ and high voltage pushes the specific energy density to $2330 \mathrm{mWh} \mathrm{cm}^{-3}$, which is comparable to that of other commercial materials such as $\mathrm{LiCoO}_{2}\left(2750 \mathrm{mWh} \mathrm{cm}^{-3}\right)$ and $\mathrm{LiFePO}_{4}\left(2065 \mathrm{mWh} \mathrm{cm}^{-3}\right)$ [196]. However, both the phases suffer from similar poor electronic and ionic conductivity issues like other phospho-olivines (electronic conductivity is lying in the range of $10^{-8}-10^{-9} \mathrm{~S} \mathrm{~cm}^{-1}$ ). Carbon coating can enhance electronic conductivity. Ding et al. performed dual carbon coating as an effective strategy and achieved high-rate performance in aqueous electrolytes [199]. Metal-ion doping can address the challenge of bulk ionic conductivity. Doped $\mathrm{Li}_{3} \mathrm{~V}_{2-}$ ${ }_{x} \mathrm{M}_{\mathrm{x}}\left(\mathrm{PO}_{4}\right)_{3} / \mathrm{C}\left(\mathrm{M}=\mathrm{Cr}^{+3}, \mathrm{Co}^{+2}, \mathrm{Na}^{+}, \mathrm{Nb}^{+5}\right.$, etc. $)$ have been studied where electrochemical performances have been upgraded as a result of doping [200-203]. One special mention is high valent $\mathrm{Mo}^{+6}$ doping. The $\mathrm{Li}_{3} \mathrm{~V}_{1.97} \mathrm{Mo}_{0.03}\left(\mathrm{PO}_{4}\right)_{3} / \mathrm{C}$ composite retains $98.3 \%$ of the initial capacity $\left(122.8 \mathrm{mAh} \mathrm{g}^{-1}\right)$ after 150 cycles at $20 \mathrm{C}$ current rate compared to $<70 \%$ retention for the pristine material. Substitution of low valent $\mathrm{V}^{+3}$ with $\mathrm{Mo}^{+6}$ strengthens the $\mathrm{Mo}-\mathrm{O}$ bond to stabilize the structure. It also weakens the $\mathrm{Li}-\mathrm{O}$ interaction to increase Li-ion diffusivity. Moreover, Mo-doping leads to Li-deficient holeconducting material, and the donor effect increases ionic conductivity [204]. $\mathrm{SiO}_{2}$ modification on monoclinic $\mathrm{Li}_{3} \mathrm{~V}_{2}\left(\mathrm{PO}_{4}\right)_{3} / \mathrm{C}$ improves the cycling performance, although multiple plateaus were still visible (Figure 15d). The transmission electron microscopy (TEM) image in Figure 15e confirms that the $\mathrm{Li}_{3} \mathrm{~V}_{2}\left(\mathrm{PO}_{4}\right)_{3}$ particles were wrapped in amorphous silica and carbon layers having a 3-5 $\mathrm{nm}$ thickness [205]. 
(a)

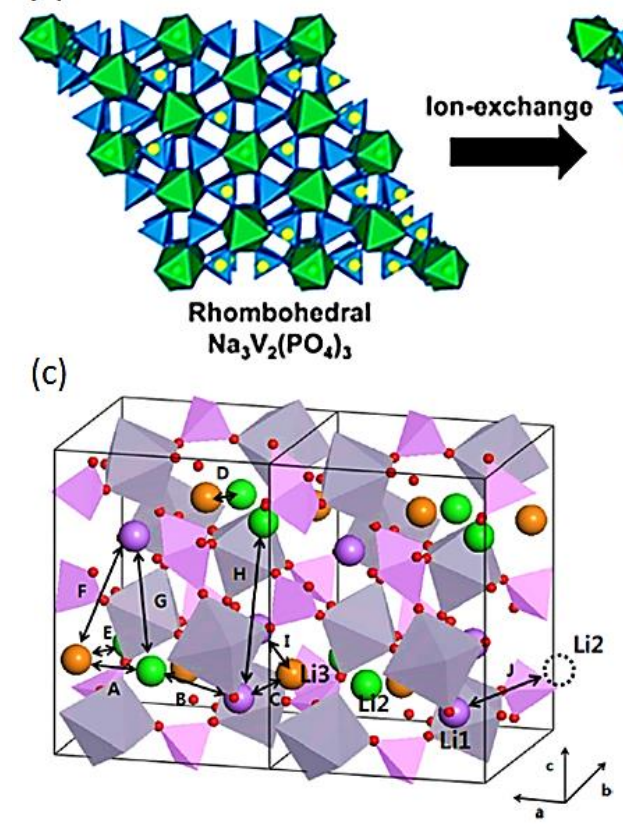

(b)

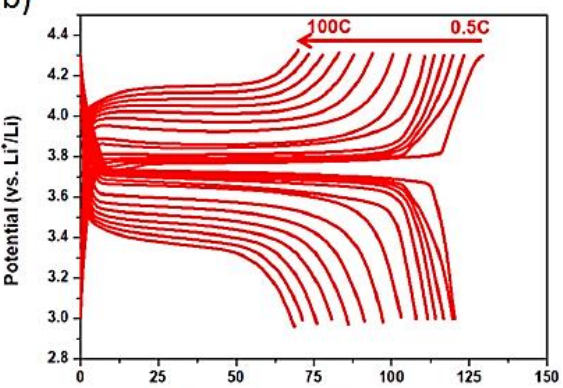

(e) Specific capacity (mAh/g) (d)

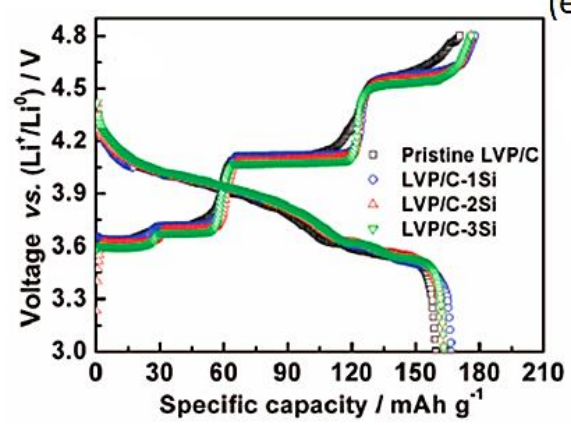

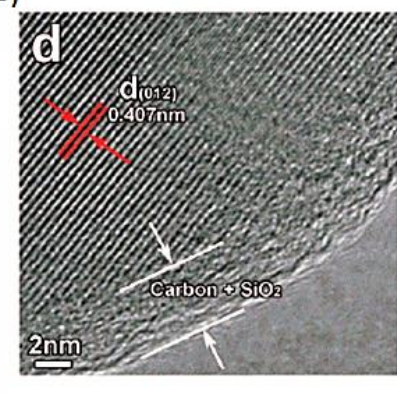

Figure 15 (a) Conversion of the rhombohedral $\mathrm{Na}_{3} \mathrm{~V}_{2}\left(\mathrm{PO}_{4}\right)_{3}$ crystal structure to the rhombohedral $\mathrm{Li}_{3} \mathrm{~V}_{2}\left(\mathrm{PO}_{4}\right)_{3}$ crystal structure via the ion-exchange method, (b) Chargedischarge curves of the rhombohedral $\mathrm{Li}_{3} \mathrm{~V}_{2}\left(\mathrm{PO}_{4}\right)_{3} /$ carbon nanofiber (CNF) composite at various current rates ranging from $0.5 \mathrm{C}$ to $100 \mathrm{C}$. Reprinted with permission from reference [195]. Copyright 2020 American Chemical Society, (c) Schematic illustration of the possible Li-ion migration pathways in monoclinic $\mathrm{Li}_{3} \mathrm{~V}_{2}\left(\mathrm{PO}_{4}\right)_{3}$ crystal structure. Reprinted with permission from reference [198]. Copyright 2012 American Chemical Society, (d) Charge-discharge voltage profiles of monoclinic $\mathrm{Li}_{3} \mathrm{~V}_{2}\left(\mathrm{PO}_{4}\right)_{3} / \mathrm{C}$ and $1,2,3$ wt.\% $\mathrm{SiO}_{2}$ coated samples at $\mathrm{C} / 10$ current rate in between 3.0-4.8 $\mathrm{V}$ range and (e) Transmission electron microscopy (TEM) image of $2 \mathrm{wt} . \% \mathrm{SiO}_{2}$ coated $\mathrm{Li}_{3} \mathrm{~V}_{2}\left(\mathrm{PO}_{4}\right)_{3} / \mathrm{C}$. The lattice fringes of pristine material and coating region are clearly visible. Reprinted with permission from reference [205]. Copyright 2012 American Chemical Society.

\subsubsection{Tavorite Compounds and Derivatives}

The tavorite phase generally defines a large class of phosphates and sulfates of the general formula $\mathrm{Li}_{y} \mathrm{MXO}_{4} \mathrm{Z}$, where $\mathrm{y}=0,1,2 ; \mathrm{M}=\mathrm{Co}, \mathrm{Ni}, \mathrm{Mn}, \mathrm{V}, \mathrm{Fe} ; \mathrm{X}=\mathrm{P}, \mathrm{S} ; \mathrm{Z}=\mathrm{F}, \mathrm{O}, \mathrm{OH}$. The presence of ' $\mathrm{Z}$ ' helps the two lithium and two electrons exchange per formula unit theoretically. However, practically only one electron exchange is observed in most cases [206].

Vanadium-based fluorophosphate $\left(\mathrm{LiVPO}_{4} \mathrm{~F}\right)$ and oxyphosphate $\left(\mathrm{LiVOPO}_{4}\right)$ are examples that can exchange two electrons per formula unit. However, besides their high voltage redox, e.g., at $4.2 \mathrm{~V}$ for $\mathrm{V}^{+3 /+4}$ in $\mathrm{LiVPO}_{4} \mathrm{~F}$ and $4.0 \mathrm{~V}$ for $\mathrm{V}^{+4 /+5}$ in $\mathrm{LiVOPO}_{4}$, the low voltage redox at $2.2 \mathrm{~V}$ for $\mathrm{V}^{+3 /+4}$ in $\mathrm{LiVOPO}_{4}$, and $1.8 \mathrm{~V}$ for $\mathrm{V}^{+2 /+3}$ in $\mathrm{LiVPO}_{4} \mathrm{~F}$ lowers the average voltage down to $~ 2.4 \mathrm{~V}$ for LiVPO${ }_{4} \mathrm{~F}$ and $\sim 1.8 \mathrm{~V}$ for $\mathrm{LiVOPO}_{4}$ [207-209]. Due to this fact, proper attention was not provided on these materials like insertion and other polyanionic cathodes, although having high theoretical capacity. LiVPO $\mathrm{F}_{4}$ can show reversible capacity around $120-150 \mathrm{mAh} \mathrm{g}^{-1}$ when cycled within $\mathrm{C} / 2$ to $10 \mathrm{C}$ current rate. Further optimization is needed to scale up vanadium phosphates to reach the level of $\mathrm{LiFePO}_{4}$. 
Fluorophosphates $\left(\mathrm{Li}_{2} \mathrm{MPO}_{4} \mathrm{~F}\right)$ is a fluorine substituted phosphate analog and comes under the category of the tavorite phase. The edge shared $\mathrm{MO}_{4} \mathrm{~F}_{2}$ infinite chains interconnected by $\mathrm{PO}_{4}$ tetrahedra opens two sites for Li, out of which only one is electrochemically mobile [176]. The presence of fluorine upshifts the average voltage to $\sim 5 \mathrm{~V}$ for $\mathrm{Co}^{+3 /+2}$ and $\sim 5.3 \mathrm{~V}$ for $\mathrm{Ni}^{+3 /+2}$, i.e., approximately $200 \mathrm{mV}$ is gained due to fluorination. $\mathrm{Li}_{2} \mathrm{CoPO}_{4} \mathrm{~F}$ is reported to show a capacity of $110 \mathrm{mAh} \mathrm{g}^{-1}$ in a sulfone-based electrolyte with an upper cut-off voltage of $\sim 5.5 \mathrm{~V}$ [210]. $\mathrm{Li}_{2} \mathrm{NiPO}_{4} \mathrm{~F}$ is hard to synthesize in the pure phase, and related reports are scarce in the literature [177]. The study on these materials is mainly limited due to the electrode-electrolyte instability at high voltages.

\subsubsection{Pyrophosphates}

Pyrophosphate $\left(\mathrm{Li}_{2} \mathrm{MP}_{2} \mathrm{O}_{7}\right)$ combines a high theoretical capacity of $220 \mathrm{mAh} \mathrm{g}^{-1}$ due to the twoelectron transfer per metal cation along with high average voltage $(>4 \mathrm{~V})$. As mentioned earlier, pyrophosphate moiety has more resonance structures arising from its extended P-O backbone, and the resulting covalence is the reason behind higher average voltage than phosphates. The crystal structure can be described as 3D frameworks with $\mathrm{MO}_{5}$ square pyramids sharing an edge with the $\mathrm{MO}_{6}$ octahedra, which further interlinked via $\mathrm{P}_{2} \mathrm{O}_{7}$ groups (Figure $16 \mathrm{a}$ and Figure 16b). The electrochemical performance of $\mathrm{Li}_{2} \mathrm{FeP}_{2} \mathrm{O}_{7}$ is comparatively inferior to that of $\mathrm{LiFePO}_{4}$. The average voltage is almost similar, i.e., $3.5 \mathrm{~V}$ vs. $\mathrm{Li}^{+} / \mathrm{Li}$. But the higher atomic weight of the $\mathrm{P}_{2} \mathrm{O}_{7}$ moiety lowers the capacity down to $110 \mathrm{mAh} \mathrm{g}^{-1}$ (Figure 14d) [211]. Similar specific capacity lowering effect due to higher molar mass per formula unit is also obvious for $\mathrm{Li}_{2} \mathrm{MP}_{2} \mathrm{O}_{7}$ other than Fe. Other analogs such as $\mathrm{Li}_{2} \mathrm{VOP}_{2} \mathrm{O}_{7}, \mathrm{Li}_{2} \mathrm{CoP}_{2} \mathrm{O}_{7}$, and $\mathrm{Li}_{2} \mathrm{MnP}_{2} \mathrm{O}_{7}$ draw attention due to the high average discharge potentials of $4.1 \mathrm{~V}, 5.0 \mathrm{~V}$, and $4.4 \mathrm{~V}$, respectively, but the reversible capacity lies around $100 \mathrm{mAh} \mathrm{g}^{-1}$ (Figure 16c and Figure 16d) [212-214]. Ng et al. showed by first-principles calculations that lithium diffusion and the charge capacity of lithium cobalt phosphate depends on the intrinsic defects. Doping $\mathrm{Si}$ in place of $\mathrm{P}$ improves charge carrier mobility without altering other electronic properties of the pristine material [215]. However, cyclic stability is also inferior resulting from poor stability of the electrolytes at $\sim 5 \mathrm{~V}$. Moreover, difficulty in extracting lithium due to sluggish kinetics is the other reason behind these materials' poor cycling performance. Whittingham and coworkers synthesized molybdenum (oxy) pyrophosphate $\left[\delta-\left(\mathrm{MoO}_{2}\right)_{2} \mathrm{P}_{2} \mathrm{O}_{7}\right]$ that can accommodate four lithium ions upon discharge to $2 \mathrm{~V}$ based on $\mathrm{Mo}^{+6 /+4}$ redox accounting for a capacity of $\sim 250 \mathrm{mAh} \mathrm{g}^{-1}$. Intercalation of more than two lithium ions is not electrochemically reversible and leads to a loss in crystallinity. The reversible two lithium intercalation capacity of $\sim 110 \mathrm{mAh} \mathrm{g}^{-1}$ between 4.0-2.3 V have been achieved for this material [216]. 

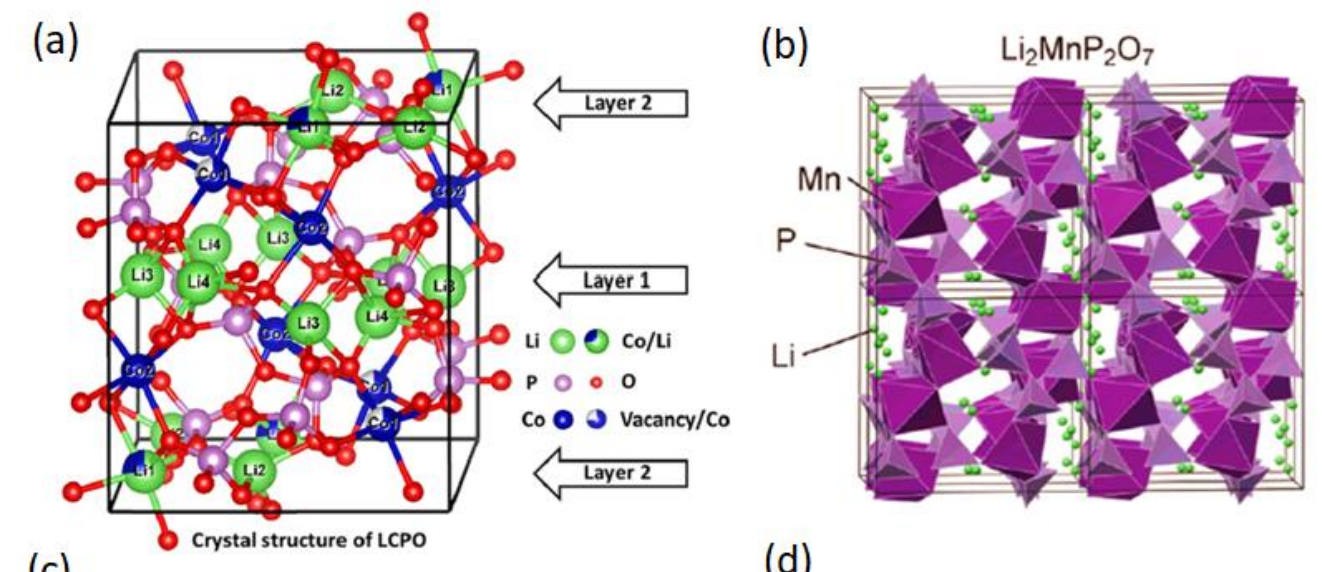

(c)

(d)
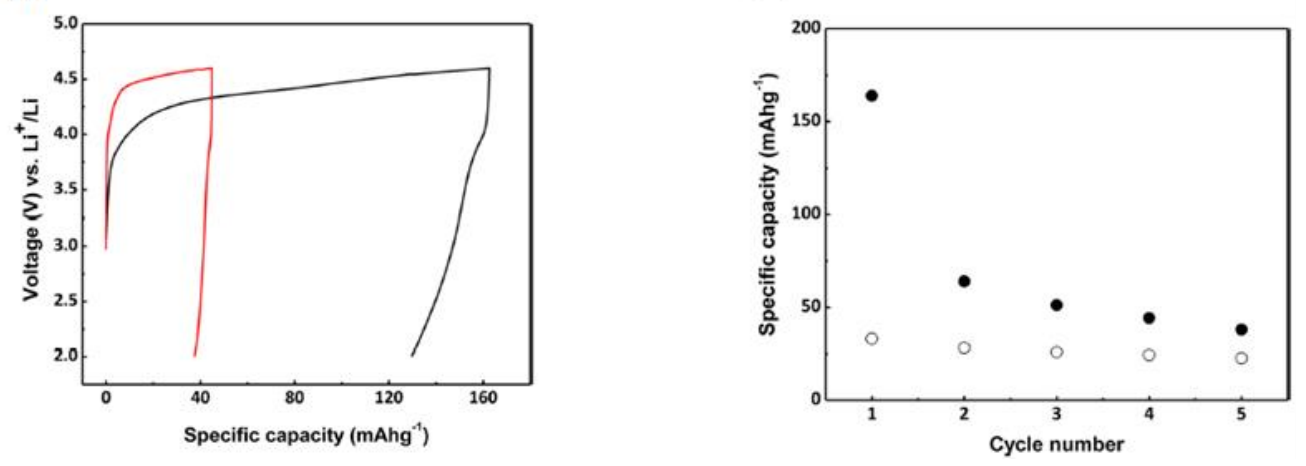

Figure 16 (a) Crystal structure of $\mathrm{Li}_{2-x} \mathrm{CoP}_{2} \mathrm{O}_{7}$. Reprinted with permission from reference [215]. Copyright 2019 American Chemical Society, (b) crystal structure of $\mathrm{Li}_{2} \mathrm{MnP}_{2} \mathrm{O}_{7}$. Reprinted with permission from reference [211]. Copyright 2010 American Chemical Society, (c) Initial voltage profiles of $\mathrm{Li}_{2} \mathrm{CoSiO}_{4}$ (red curve) and $\mathrm{Li}_{2} \mathrm{CoSiO}_{4} / \mathrm{C}$ (black curve), (d) Charge-discharge capacity as a function of cycle number for $\mathrm{Li}_{2} \mathrm{CoSiO}_{4} / \mathrm{C}$. Reprinted with permission from reference [217]. Copyright 2013 American Chemical Society.

\subsubsection{Silicates and Fluorosilicates}

Silicates or orthosilicates $\mathrm{Li}_{2} \mathrm{MSiO}_{4}$ (where $\mathrm{M}=\mathrm{Mn}^{2+}, \mathrm{Fe}^{2+}$ and $\mathrm{Co}^{2+}$ is a class of poly-oxyanion cathodes that have attracted much attention after the first proposal in 2005 by Nyten et al. [218]. It was reported as a phase pure $\mathrm{Li}_{2} \mathrm{FeSiO}_{4}$, with an orthorhombic structure that showed an initial discharge capacity of $130 \mathrm{mAh} \mathrm{g}^{-1}$. $\mathrm{Li}_{2} \mathrm{MnSiO}_{4}$ is another extensively studied silicate cathode that shows a high voltage of $\sim 4.1 \mathrm{~V}$ and a high theoretical capacity of $333 \mathrm{mAh} \mathrm{g}^{-1}$ as the extraction of two lithium ions is possible, which is accompanied by the $\mathrm{Mn}^{+2} / \mathrm{Mn}^{+3}$ and $\mathrm{Mn}^{+3} / \mathrm{Mn}^{+4}$ redox couple. But practically it shows only $120 \mathrm{mAh} \mathrm{g}^{-1}$ capacity [219]. Fe and Si are among the most abundant and low-cost elements in the earth's crust. This is also one of the lying reasons behind quick popularity gain after the first report [218]. Other features of the silicate materials are as follows: a) unlike the olivine phosphate materials (where at most only one lithium can be extracted), silicates can undergo two lithium ions per formula unit extraction accompanied by a two-electron redox process (i.e., resulting from both $\mathrm{M}^{2+} \mathrm{M}^{3+}$ and $\mathrm{M}^{3+} \mathrm{M}^{4+}$ redox couples) leading to the higher theoretical specific capacity of this type of materials (300-330 mAh g-1), b) due to strong Si-O bond this material shows high thermal stability and exhibits good safety under extreme testing conditions. However, low electronic conductivity $\left(10^{-14} \mathrm{~S} \mathrm{~cm}^{-1}\right)$, thereby slow lithium-ion kinetics; 
amorphization of the active material, and structural reversibility are the major drawbacks of these types of materials.

Among silicates, $\mathrm{Li}_{2} \mathrm{CoSiO}_{4}$ has a high voltage of $\sim 4.5 \mathrm{~V}$ and a capacity of about $~ 325 \mathrm{mAh} \mathrm{g}^{-1}$, which leads to a high energy density of $\sim 1463 \mathrm{Wh} \mathrm{kg}^{-1}$. The $2^{\text {nd }} \mathrm{Li}$-ion deintercalation voltage plateau at around $5 \mathrm{~V}$ is difficult to achieve [220]. Co is expensive and environmentally toxic. Therefore, the material lost commercial interest as the battery industry is seeking to reach a Co-free zone. However, there are some excellent reports on this material. Gong et al. have reported a charge capacity of $234 \mathrm{mAh} \mathrm{g}^{-1}$ for the $\mathrm{Li}_{2} \mathrm{CoSiO}_{4} / \mathrm{C}$ composite, which corresponds to 0.46 lithium per formula unit. They have used the hydrothermal route for synthesis and found the reversible $\mathrm{Li}$ extraction and insertion at $4.1 \mathrm{~V}$ vs. Li. [220]. Lyness et al. synthesized all three polymorphs of $\mathrm{Li}_{2} \mathrm{CoSiO}_{4}$ and showed that the $\beta \mathrm{I}$ polymorph exhibits electrochemical activity. They reported a charge capacity of $170 \mathrm{mAh} \mathrm{g}^{-1}$, which is equivalent to $1.1 \mathrm{Li}$ per formula unit for the $\beta$ I polymorph of $\mathrm{Li}_{2} \mathrm{CoSiO}_{4}$ coated with carbon [221]. Linda Nazar and coworkers synthesized the $\mathrm{Li}_{2} \mathrm{CoSiO}_{4} / \mathrm{C}$ nanocomposite via hydrothermal method using highly ordered mesoporous carbon/silica (MCS) framework as both carbon and silica precursors. However, the electrochemical performance is very poor, as shown in Figure 15c and Figure 15d [217].

\subsection{Spinel Oxides}

Spinel oxide as cathode for lithium-ion battery is primarily limited to $\mathrm{LiMn}_{2} \mathrm{O}_{4}$ (LMO). This compound has a spinel-like structure with anionic lattice having an $\alpha-\mathrm{NaFeO}_{2}$ type structure in which $\mathrm{Li}$ and $\mathrm{Mn}$ reside in the tetrahedral and octahedral sites, respectively [222]. In LMO, lithium-ion shuttles between the tetrahedral sites by hopping via the intermediate octahedral site. Due to this spinel structure and diffusion behavior, the lithium diffusion pathway is three-dimensional. This type of stable 3D geometry helps in the Li-ion diffusivity and offers high-rate capability. The material shows a theoretical capacity of $148 \mathrm{mAh} \mathrm{g}^{-1}$ and a discharge potential of $4 \mathrm{~V}$ [223]. But $\mathrm{LiMn}_{2} \mathrm{O}_{4}$ cathode has a significant issue of $\mathrm{Mn}$ dissolution [224]. The insertion of $\mathrm{Ni}$ into the spinel structure of $\mathrm{LiMn}_{2} \mathrm{O}_{4}$ forming $\mathrm{LiNi}_{0.5} \mathrm{Mn}_{1.5} \mathrm{O}_{4}$ (LNMO) leads to an increased operating voltage of $4.7 \mathrm{~V} \mathrm{vs}$. $\mathrm{Li}^{+} / \mathrm{Li}$. LNMO has gained much more attention than LMO because of its high operating potential, low cost of synthesis, and Co-free nature. It shows a reversible specific capacity of $148 \mathrm{mAh} \mathrm{g}^{-1}$ [225]. The compound crystallizes in an ordered and disordered configuration depending on the synthetic condition (Figure 17a) [226]. The disordered configuration exhibits a more stable cycling performance due to its better ionic and electronic conductivities. But the practical application of LNMO is hampered due to electrolyte instability at such a high working potential of $\sim 4.7 \mathrm{Vvs}$. $\mathrm{Li}^{+} / \mathrm{Li}$. 

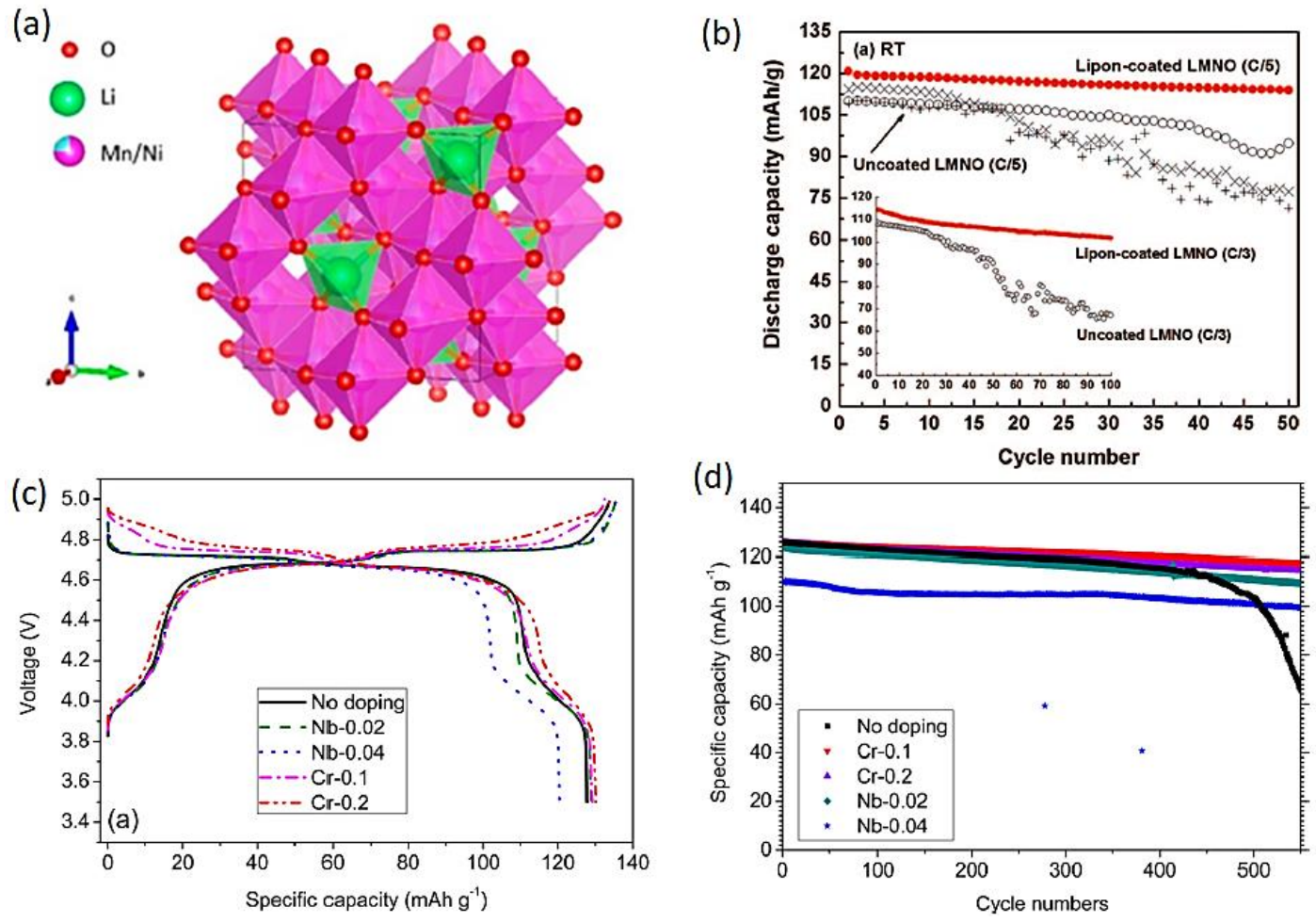

Figure 17 Crystal structure of $\mathrm{LiNi}_{1.5} \mathrm{Mn}_{0.5} \mathrm{O}_{4}$. Reprinted with permission from reference [226]. Copyright 2020 American Chemical Society, (b) Discharge capacities of uncoated and LiPON coated LNMO at $\mathrm{C} / 5$ and $\mathrm{C} / 3$ current rates. Reprinted with permission from reference [227]. Copyright 2013 The Electrochemical Society, (c) Charge-discharge profiles of undoped, $\mathrm{Cr}$-doped, and $\mathrm{Nb}$-doped $\mathrm{LNMO}$ at $\mathrm{C} / 5$ rate, and (d) Cycling performance of undoped, $\mathrm{Cr}$-doped, and Nb-doped LNMO up to 500 cycles. Reprinted with permission from reference [228]. Copyright 2016 American Chemical Society.

\subsubsection{Metal Cation Doping}

One of the most effective methods is the partial replacement of $\mathrm{Ni}$ or $\mathrm{O}$ in LNMO with a metal cation or anion. Mg doping into LNMO confers structural stability and improves the voltage profile (4.70-4.75 V vs. $\mathrm{Li}^{+} / \mathrm{Li}$ ) [229]. The nanosized $\mathrm{LiMg}_{0.05} \mathrm{Ni}_{0.45} \mathrm{Mn}_{1.5} \mathrm{O}_{4}$ material is synthesized by a modified solid-state synthesis with an ordered cubic spinel structure that shows good capacity retention upon cycling (131 $\mathrm{mAh} \mathrm{g}^{-1}$ at $\mathrm{C} / 10$ and $117 \mathrm{mAh} \mathrm{g}^{-1}$ at $1 \mathrm{C}$ ) [230]. There are also some essential outcomes being obtained by $\mathrm{Cr}$-doping. The strong oxygen affinity of the $\mathrm{Cr}$ atom helps to form strong $\mathrm{Cr}-\mathrm{O}$ bonds favoring good stability of the spinel structure during cycling. A single-phase $\mathrm{LiMn}_{1.4} \mathrm{Cr}_{0.2} \mathrm{Ni}_{0.4} \mathrm{O}_{4}$ spinel synthesized by simple sucrose assisted combustion method exhibits the maximum rate capability with capacity retention of $92 \%$ at $60 \mathrm{C}\left(1 \mathrm{C}=147.5 \mathrm{~mA} \mathrm{~g}^{-1}\right.$ or $0.260 \mathrm{~mA}$ $\mathrm{cm}^{-2}$ ) discharge rate among $\mathrm{LiNi}_{0.5} \mathrm{Mn}_{1.5} \mathrm{O}_{4}$ - type cathodes [231]. Mao et al. synthesized $\mathrm{Cr}$-and $\mathrm{Nb}$ doped LNMO via a polyvinylpyrrolidone (PVP) combustion method. The $\mathrm{Cr}$ doped sample $\mathrm{LiCr}_{0.1} \mathrm{Ni}_{0.45} \mathrm{Mn}_{1.45} \mathrm{O}_{4}$ retains $94.1 \%$ capacity after 500 cycles at $1 \mathrm{C}$, the coulombic and energy efficiencies remain at over 99.7\%, and 97.5\%, respectively. The $\mathrm{Nb}$-doped sample $\mathrm{LiNb}_{0.02} \mathrm{Ni}_{0.49} \mathrm{Mn}_{1.49} \mathrm{O}_{4}$ shows slightly higher capacity but lesser retention (Figure $17 \mathrm{c}$ and Figure $17 \mathrm{~d}$ ) than other materials. The performance improvement is ascribed to the fact that $\mathrm{Cr}$ doping sharpens 
the edges and decreases particle size, while $\mathrm{Nb}$ doping results in smoother surface and more rounded large particles [228].

\subsubsection{Surface Coating}

The presence of ppm level HF produced due to reaction of salt $\mathrm{LiPF}_{6}$ and trace level water in the organic electrolyte (e.g., $1 \mathrm{M} \mathrm{LiPF}_{6}$ in 1:1 ratio of EC: $\mathrm{DEC}$ ) causes unavoidable side reactions. The steps of the reaction mechanism are discussed below:

1) $\mathrm{LiPF}_{6}$ decomposes at $>4.4 \mathrm{~V}$ and forms $\mathrm{PF}_{5}$, which reacts with water leading to the formation of $\mathrm{HF}$ according to the reaction:

$$
\mathrm{LiPF}_{6} \rightarrow \mathrm{LiF}+\mathrm{PF}_{5} ; \mathrm{PF}_{5}+\mathrm{H}_{2} \mathrm{O} \rightarrow 2 \mathrm{HF}+\mathrm{PF}_{3} \mathrm{O}
$$

2) The resulting HF causes high voltage LNMO to dissolve in the electrolyte solvent through the following reaction:

$$
4 \mathrm{HF}+2 \mathrm{LiNi}_{0.5} \mathrm{Mn}_{1.5} \mathrm{O}_{4} \rightarrow 3 \mathrm{Ni}_{0.25} \mathrm{Mn}_{0.75} \mathrm{O}_{2}+0.25 \mathrm{NiF}_{2}+0.75 \mathrm{MnF}_{2}+2 \mathrm{LiF}+2 \mathrm{H}_{2} \mathrm{O}[232]
$$

Therefore, capacity fade is observed over cycling due to the loss of the active materials following the reactions mentioned above. The surface coatings have been proven to be the effective materials to mitigate this HF corrosion. In this regard, some oxide and fluoride materials draw special attention as surface coating materials for $\mathrm{LNMO}$ [233]. $\mathrm{SiO}_{2}$ is known as an $\mathrm{HF}$ scavenger. Therefore, $\mathrm{SiO}_{2}$ helps to protect $\mathrm{LNMO}$ electrode materials by neutralizing the $\mathrm{HF}$ in the electrolyte. Wei Pang et al. have studied the effect of $\mathrm{SiO}_{2}$ coatings on $\mathrm{LNMO} \mathrm{SiO}_{2}$ coating layer lowers the capacity decay rate by $45 \%$ and $65 \%$, at $25 \mathrm{C}$ and $55 \mathrm{C}$, respectively, and enhances the Li diffusivity by $15 \%$ [234]. Tao et al. reported $\mathrm{TiO}_{2}$ coated $\mathrm{LNMO}$ synthesized by simple wet chemical method. The coated material shows better cycling stability, about $88.5 \%$ of the capacity was retained at a $2 \mathrm{C}$ rate at the

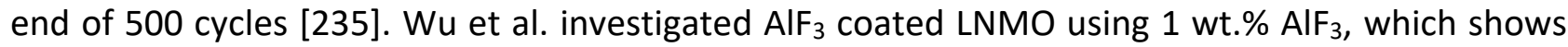
good reversibility, with $93.6 \%$ retention after 50 cycles [236]. Sub-nanometer LiPON coating also improves the high voltage $(\sim 4.9 \mathrm{~V})$ cycling stability of the LNMO cathodes in conventional carbonate electrolytes, as shown in Figure 17b [227].

\subsubsection{Rare Earth Metal Doping}

Partial substitution of $\mathrm{Mn}$ by rare-earth elements, such as $\mathrm{La}, \mathrm{Nd}$, and $\mathrm{Ce}$, have also been investigated to improve the electrochemical performance of LNMO. Ce substituted $\mathrm{LiNi}_{0.495} \mathrm{Ce}_{0.005} \mathrm{Mn}_{1.5} \mathrm{O}_{4}$ delivers better $\mathrm{C}$ rate performance than $\mathrm{LiNi} \mathrm{N}_{.5} \mathrm{Mn}_{1.5} \mathrm{O}_{4}$ [237]. This is due to the synergistic effects of the decrease in the extent of mixing between lithium ions and transition metal ions, an increase in the lattice parameter, and $\mathrm{Ni} / \mathrm{Mn}$ disordering degree after an appropriate amount of Ce doping. The doped materials exhibit a specific capacity of $123 \mathrm{mAh} \mathrm{g}^{-1}$ at $1 \mathrm{C}$ rate, capacity retention of $94.51 \%$ after 100 cycles, and $115.4 \mathrm{mAh} \mathrm{g}^{-1}$ capacity at $10 \mathrm{C}$ rate, indicating good rate capability. Besides, it has been observed that Ce substitution decreases the formation of $\mathrm{Mn}^{3+}$ and stabilizes the structure, and improves the electrical conductivity. The $\mathrm{LiNi}_{0.495} \mathrm{Mn}_{1.495} \mathrm{Ce}_{0.02} \mathrm{O}_{4} /$ graphite full-cell can deliver a capacity of $113 \mathrm{mAh} \mathrm{g}{ }^{-1}$ and capacity retention of $98 \%$ after 100 cycles at $1 \mathrm{C}$ rate and $25^{\circ} \mathrm{C}$ [238]. Nb doping also improves performance, as described in Figure $16 \mathrm{c}$ and Figure $16 \mathrm{~d}$ [228]. 


\subsubsection{Anion Doping}

Similar to cation doping, few reports of anion doping, e.g., F-doping, replace some of the oxygen with fluorine and thereby helps suppress the formation of $\mathrm{NiO}$ impurity, improves the tap density of the material, and simultaneously reduces the voltage polarization. Moreover, the dissolution of the particles into the electrolyte can be mitigated by fluorine coating (Figure 6). Xu et al. reported the sol-gel synthesis of $\mathrm{LiNi}_{0.5} \mathrm{Mn}_{1.5} \mathrm{O}_{3.975} \mathrm{~F}_{0.05}$. Electrochemical performance shows that fluorine doping enhances the initial capacity from $130 \mathrm{mAh} \mathrm{g}^{-1}$ to over $140 \mathrm{mAh} \mathrm{g}^{-1}$ in the voltage range of 3.5- 5.2 $\mathrm{V}$ compared with pristine $\mathrm{LiNi}_{0.5} \mathrm{Mn}_{1.5} \mathrm{O}_{4}$ [239].

Table 6 Electrochemical performance of LNMO modified by surface coating and dopings.

\begin{tabular}{|c|c|c|c|c|c|}
\hline $\begin{array}{l}\text { Type of } \\
\text { modification }\end{array}$ & $\begin{array}{l}\text { Synthesis } \\
\text { process }\end{array}$ & $\begin{array}{l}\text { Voltage } \\
\text { range } \\
\text { (V) }\end{array}$ & $\begin{array}{l}\text { Current density } \\
\left(\mathrm{mA} \mathrm{g}^{-1}\right) \\
\text { or } \\
\text { Current rate (C) }\end{array}$ & $\begin{array}{l}\text { First } \\
\text { discharge } \\
\text { capacity } \\
\left(\mathrm{mAh} \mathrm{g}^{-1}\right) \\
\end{array}$ & $\begin{array}{l}\text { Capacity } \\
\text { retention } \\
(\%) \\
\text { @ No. of cycles }\end{array}$ \\
\hline $\begin{array}{l}\text { Nanosized } \\
\text { LNMO [240] }\end{array}$ & $\begin{array}{l}\text { One-pot } \\
\text { resorcinol- } \\
\text { formaldehyde } \\
\text { synthesis }\end{array}$ & $3.5-5.0$ & $10 C$ & 129 & 99.97\% @ 200 \\
\hline $\begin{array}{l}\text { LNMO } \\
\text { nanorods } \\
{[241]}\end{array}$ & $\begin{array}{l}\text { Using } \mathrm{MnO}_{2} \\
\text { nanorods as a } \\
\text { Mn source }\end{array}$ & $3.4-5.0$ & $1 C$ & 125 & 95.7\% @ 200 \\
\hline $\begin{array}{l}\text { LNMO } \\
\text { nanofibers } \\
{[242]}\end{array}$ & & $3.5-4.8$ & 27 & 130 & \\
\hline $\begin{array}{l}\text { LNMO } \\
\text { nanoplates } \\
{[243]}\end{array}$ & $\begin{array}{l}\text { hydrothermal } \\
\text { method and } \\
\text { subsequent } \\
\text { solid-state } \\
\text { reaction }\end{array}$ & $3.5-5.0$ & $1 C$ & 148 & 86.4\%@1000 \\
\hline $\begin{array}{ll}\mathrm{Cr} & \text { doping } \\
{[244]} & \end{array}$ & Sol-gel method & $3.5-5.0$ & $0.5 \mathrm{C}$ & 137 & 97.5\%@ @ 50 \\
\hline $\begin{array}{l}\mathrm{Na} \text { doping } \\
{[245]}\end{array}$ & $\begin{array}{l}\text { Solid-state } \\
\text { synthesis }\end{array}$ & $3.5-4.9$ & $1 C$ & 125 & 92.96\%@ @ 100 \\
\hline LNMO/C [246] & Sol-gel method & $3.0-5.0$ & $1 C$ & 130 & 92\% @ 100 \\
\hline $\begin{array}{l}\mathrm{Li}_{3} \mathrm{PO}_{4} \\
\text { coating [247] }\end{array}$ & $\begin{array}{l}\text { Solid-state } \\
\text { method }\end{array}$ & $3.0-5.0$ & $0.5 \mathrm{C}$ & 122 & 80\%@650 \\
\hline $\begin{array}{l}\mathrm{Al}_{2} \mathrm{O}_{3} \\
\text { coating [248] }\end{array}$ & $\begin{array}{l}\text { Atomic layer } \\
\text { deposition }\end{array}$ & $3.5-4.8$ & $0.1 \mathrm{C}$ & & $\begin{array}{l}105 \mathrm{mAh} \mathrm{g}^{-1} \text { after } \\
150 \text { cycles at } \\
0.1 \mathrm{C}\end{array}$ \\
\hline $\begin{array}{l}\text { ZnO } \\
\text { coating [249] }\end{array}$ & $\begin{array}{l}\text { Wet-chemistry } \\
\text { method }\end{array}$ & $3.0-5.0$ & $2 C$ & & $\begin{array}{l}102 \text { mAh g }^{-1} \text { after } \\
50 \text { cycles at } 2 \mathrm{C}\end{array}$ \\
\hline
\end{tabular}




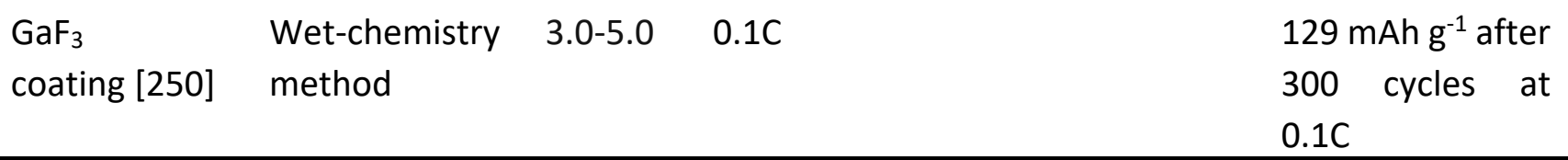

Spinel $\mathrm{LiNi}_{0.5} \mathrm{Mn}_{1.5} \mathrm{O}_{4}$ (LNMO) is a promising cathode material due to its high operating voltage of $\sim 4.7 \mathrm{~V} \mathrm{vs}$. $\mathrm{Li}^{+} / \mathrm{Li}$, leading to a specific energy of $650 \mathrm{Wh} \mathrm{kg}^{-1}$, which is $162.5 \%$ and $131.3 \%$ higher than that of $\mathrm{LiMn}_{2} \mathrm{O}_{4}$ and LiFePO4, respectively. Moreover, these materials exhibit good cycling stability, excellent rate performance, superior thermal stability, and high ionic conductivity. However, the high operating voltage, which is beyond the oxidation potential of the carbonate solvents, limits its practical applications. Therefore, large irreversible capacity and low coulombic efficiency are observed for these materials with conventional LIB electrolytes. In addition, electrolytes with high voltage additives can enhance the long-term electrochemical performances of this material.

\section{Conclusion and Outlook}

This review focuses on LIB cathode materials which show either capacity $\geq 250 \mathrm{mAh} \mathrm{g}^{-1}$ or voltage $\geq 4 \mathrm{~V}$. The crystal structure, performance comparison among various compositions, Li-ion storing mechanism, shortcomings of the materials, capacity, voltage fading mechanisms, and the reported methods to overcome these problems have been systematically described.

1. The concept of lithium-rich layered oxide cathodes is based on the solid solution of $\mathrm{Li}_{2} \mathrm{MO}_{3}(\mathrm{M}$ $=\mathrm{Mn}, \mathrm{Ru}, \mathrm{Ti}, \mathrm{Sn}$, etc.) and $\mathrm{LiMO}_{2}(\mathrm{M}=\mathrm{Ni}, \mathrm{Co}, \mathrm{Mn}$, etc.). Incorporating oxygen redox beyond the transition metal redox opened up the gateway to achieve high capacity that was beyond conventional layered oxides. But irreversible oxygen redox causes transition metal migration, voltage hysteresis, voltage decay, severe capacity fade, and poor rate performance during charge-discharge cycles. Based on the reported theories, coating, doping, and composition optimization effectively hinder oxygen gas release, thereby balancing high capacity and longterm cyclability.

2. Lithium-rich disordered rock salts are another class of oxide materials that show capacity beyond $250 \mathrm{mAh} \mathrm{g}^{-1}$ utilizing the benefit from oxygen redox. It has a wide compositional range that provides the opportunity to use metals ( $\mathrm{Ru}, \mathrm{Mo}, \mathrm{Nb}, \mathrm{V}, \mathrm{Cr}$, etc.) that are not commonly used to synthesize conventional layered oxides. The ease of synthesis via simple solid-state and mechanical route and earth-abundant $\mathrm{Mn}$-rich compositions is desirable for commercial applications. However, it also suffers from similar problems that appear in lithium-rich layered oxides. Cycling stability in most of the literature reports was confined to $100 \mathrm{cycles}$, and the performance of those 100 cycles significantly relied on the amount of carbon in the coating slurry. Therefore, further optimization of electrode fabrication, slurry composition, and testing protocols are required.

3. On the other hand, conversion cathodes can yield a capacity of $>300 \mathrm{mAh} \mathrm{g}^{-1}$ through non-site limited chemical reactions with lithium. However, the performance is limited by the vast volume expansion and low electrical conductivity. The commercialization of silicon-based anodes was made possible due to extensive research to synthesize unique morphology, robust binders, and optimization of carbon contents. Similar studies are also needed for the further development of conversion cathodes. 
4. Phosphate frameworks are extensively studied in this category after the commercial success of $\mathrm{LiFePO}_{4}$. Fe-based systems primarily offer $<4 \mathrm{~V}$ of average voltage. On the other hand, $\mathrm{V}$ based materials such as $\mathrm{Li}_{3} \mathrm{~V}_{2}\left(\mathrm{PO}_{4}\right)_{3}$, $\mathrm{LiVOPO}_{4}, \mathrm{LiVPO}_{4} \mathrm{~F}$ demonstrate $\geq 4 \mathrm{~V}$ plateau and stable capacity. Their electrochemical performance mainly depends on the uniform and welldistributed carbon coating as the hindrance of electron conduction is the major shortcoming. Remaining challenges include further optimization of carbon coating, size and shape of the synthesized nanoparticles, and the synthetic conditions. Ni-and Co-based phosphates, pyrophosphates, and silicate moieties can provide 4.8-5.0 V of discharge voltage. However, most reports are only computationally realized because of the difficulty in synthesizing the pure phase material and the instability of the conventional carbonate electrolytes. The development of the solid-state electrolyte or high voltage ionic-liquid electrolytes may broaden the scope of investigating these materials in the future.

5. High voltage spinel oxides, especially LNMO, also deliver $4.7 \mathrm{~V}$ vs. $\mathrm{Li}^{\mathrm{Li}} \mathrm{Li}^{+}$. But improving electrolyte stability by using additives, formation of artificial interphase, thin and uniform carbon coating is essential for its electrochemical performance. Areas, where LNMO lacks are long-term cycling stability and coulombic efficiency. Therefore, research in high-voltage electrolyte and cathode-electrolyte interphase are the keys to future progress.

In summary, high-capacity materials mainly suffer from the inaccessibility of reversible lithium sites after a few cycles, whereas high voltage materials experience cathode-electrolyte incompatibility at elevated voltages. Tuning the electronic structure of the host crystals through doping, protective coating on the surface of active materials to hinder the attack of reactive electrolyte, synthesis with suitable morphology for facile ion migration, manufacturing electrode architecture to buffer the volume change, and the use of high voltage electrolytes or electrolyte additive salts are the exploited tactics to improve the electrochemical performance. An important point to note here is that high capacity and high voltage are not the only criteria to judge the commercial suitability of material.

Batteries, being energy storage devices, must meet all the long-term storage requirements. Apart from the energy density, other criteria like power density, cost, safety, recyclability, ease of operation, life span, etc., are also equally vital for a LIB performance matrix. Based on the commercial demand, the performance comparison of the materials is discussed here by considering the parameters mentioned above. It is also shown that how does one material surpasses the other in a particular electrochemical property.

1. From the point of view of energy density, LMR-LO cathodes can reach beyond $1000 \mathrm{Wh} \mathrm{kg}^{-1}$, whereas the current LIB technology stands at $~ 300 \mathrm{Wh} \mathrm{kg}^{-1}$. To shrug off the complete dependence on fossil fuel, LIBs at some point should be used to substitute gasoline. Still, the inadequate energy storing capability of the currently used LIBs is a major obstacle behind electric aviation. The energy density of gasoline is $\sim 13 \mathrm{kWh} \mathrm{kg}^{-1}$, more than 40 times higher than that of LIBs. Considering 12.6\% of the average gasoline tank-to-wheel efficiency of the US fleet, the practical energy density becomes $\sim 1700 \mathrm{Wh} \mathrm{kg}^{-1}$, which is also approximately ten times higher than that of the stated system. A lithium-air battery, where oxygen is used as a cathode, is the only system that can theoretically satisfy the energy density demand $\left(11,640 \mathrm{Wh} \mathrm{kg}^{-1}\right.$ for a nominal voltage of $\left.3 \mathrm{~V}\right)$. 
2. The power density is another important factor that must be kept in balance with the energy density. Although supercapacitors, hybrid ultracapacitors, etc., are specially designed devices to achieve high power output, a battery should possess a threshold value of power at the time of quick energy supply. The robust structural moiety of the polyanionic materials supports fast lithium-ion migration and is thereby used in high-power commercial tools. Next-generation high voltage polyanionic frameworks coupled with the $\mathrm{Li}_{4} \mathrm{Ti}_{5} \mathrm{O}_{12}$ (LTO) anode is the best choice in terms of power output. Cationic reorganization in high-capacity layered cathodes and irreversible phase formation in conversion materials are problematic towards power delivery.

3. Cost is an essential criterion for any material to gain wide acceptability in the mass market. The lower the cost or lesser the $\$ / \mathrm{kWh}$ for an electric vehicle, the more attractive it is to the customers. Due to uneven geological distribution, geopolitical tensions, and unethical exploitation of child labor, Co and Li have been considered under the critical element category for the last few years. Mainly, the fluctuation in the cobalt price results in a sudden upsurge or rapid downfall in the stock market price. On the other hand, too much reliance on $\mathrm{Ni}$ for NMC-811 in EVs may cause a vast Ni deficit in the no-distant future. Mn-rich disordered rock salt materials and $\mathrm{Ni}$-Co free polyanionic frameworks can be a viable option. However, if lithium-oxygen comes into the picture, the worries about cathode cost can be relived as oxygen is ubiquitous. Another way to regain the material value is to reuse or recycle spent LIBs. But the consideration of recycling comes from a commercialized material. Materials discussed here are still being studied at a laboratory scale, and literature reports on recycling are rare. On a general note, polyanionic frameworks are resistant to chemical attacks and are difficult to recycle due to the covalently bonded network. Moreover, it will not be attentionworthy from an industrial perspective if it does not contain any critical metals. Therefore, the recycling of oxide materials is only industry-relevant.

4. Safety must be given the utmost priority for designing a device. Customers do not embrace any unsafe gadget at all for any type of use. Heat generation is a common phenomenon in the case of LIB-run devices. Ni-rich content of current commercial cathodes may cause massive heat evolution, and Li-plating at graphite during fast charging, at low state-of-charge $(<20 \%)$, and low-temperature may pose a potential threat. From a chemistry point of view, a polyanionic cathode coupled with an LTO anode is the most reliable system. However, the future commercialization of solid-state batteries may solve the problem.

5. Finally, the durability is an essential factor for commercial success. For example, LIBs in the mobile phone can sustain 3-5 years, and the threshold is a minimum of 10 years for batteryrun electric vehicles. Polyanionic materials can perform for a long time but at the expense of low energy density, which means adding more weight or putting excess volume in the battery of equivalent energy-power rating. On the contrary, irreversible lithium loss from lithium cathodes, parasitic side reactions in conversion cathodes, polysulfide shuttling in the Li-S system, and overvoltage and polarization during ORR, OER, etc., in the case of $\mathrm{Li}^{-} \mathrm{O}_{2}$ raise a question mark in terms of reversibility. Overall, the high energy materials need to cover the far distance before it becomes a commercial reality. But the scientific concept, electrochemical mechanism, failure processes corresponding to these materials are worth consideration. 


\section{Author contribution}

SG, UB, and SB has written the various parts of the review. Dr. Surendra K. Martha has conceptualized, planned, and coordinated the work.

\section{Funding}

SG acknowledges CSIR, Govt. of India (File No: 09/1001(0067)/2019-EMR-I) for fellowship. UB and SKM acknowledge DST-SERB Sanction Order: CRG/2018/003543 for the fellowship and financial support to this work. SB acknowledges DST-IISc Energy Storage Platform on Supercapacitors and Power Dense Devices through the MECSP-2K17 program under grant no. DST/TMD/MECSP/2K17/20, Government of India for fellowship.

\section{Competing Interest}

The authors declare no competing interest.

\section{References}

1. Armand M, Tarascon JM. Building better batteries. Nature. 2008; 451: 652-657.

2. Dunn B, Kamath H, Tarascon JM. Electrical energy storage for the grid: A battery of choices. Science. 2011; 334: 928-935.

3. Scrosati B, Hassoun J, Sun YK. Lithium-ion batteries. A look into the future. Energy Environ Sci. 2011; 4: 3287-3295.

4. Whittingham MS. Lithium batteries and cathode materials. Chem Rev. 2004; 104: 4271-4302.

5. Chen W, Liang J, Yang Z, Li G. A review of lithium-ion battery for electric vehicle applications and beyond. Energy Procedia. 2019; 158: 4363-4368.

6. Sripad S, Bills A, Viswanathan $V$. A review of safety considerations for batteries in aircraft with electric propulsion. MRS Bull. 2021; 46: 435-442.

7. Akhoundzadeh MH, Panchal S, Samadani E, Raahemifar K, Fowler M, Fraser R. Investigation and simulation of electric train utilizing hydrogen fuel cell and lithium-ion battery. Sustain Energy Technol Assess. 2021; 46: 101234.

8. Beard KW. Linden's Handbook of Batteries. 5th ed. New York: McGraw-Hill Education; 2019.

9. Martha SK, Elias L. Nanostructured anode materials for batteries (lithium ion, Ni-MH, lead-acid, and thermal batteries). In: Nanomaterials for Electrochemical Energy Storage Devices. Hoboken: Scrivener Publishing LLC; 2019. pp.145-229.

10. Singh S. Energy storage systems: An Introduction. Hauppauge: Nova Science Publishers; 2021.

11. Nazri GA, Pistoia G. Lithium batteries: Science and technology. New York: Springer Science \& Business Media; 2008.

12. Li B, Wang $Y$, Lin $H$, Liu J, Xing L, Xu M, et al. Improving high voltage stability of lithium cobalt oxide/graphite battery via forming protective films simultaneously on anode and cathode by using electrolyte additive. Electrochim Acta. 2014; 141: 263-270.

13. Reimers JN, Dahn JR. Electrochemical and in situ X-ray diffraction studies of lithium intercalation in $\mathrm{Li}_{x} \mathrm{CoO}_{2}$. J Electrochem Soc. 1992; 139: 2091.

14. Doh $\mathrm{CH}$, Kim DH, Kim HS, Shin HM, Jeong YD, Moon SI, et al. Thermal and electrochemical behaviour of $\mathrm{C} / \mathrm{Li}_{x} \mathrm{CoO}_{2}$ cell during safety test. J Power Sources. 2008; 175: 881-885. 
15. Yamada S, Fujiwara M, Kanda M. Synthesis and properties of $\mathrm{LiNiO}_{2}$ as cathode material for secondary batteries. J Power Sources. 1995; 54: 209-213.

16. Chen $\mathrm{CH}$, Liu J, Stoll ME, Henriksen G, Vissers DR, Amine K. Aluminum-doped lithium nickel cobalt oxide electrodes for high-power lithium-ion batteries. J Power Sources. 2004; 128: 278285.

17. Nitta N, Wu F, Lee JT, Yushin G. Li-ion battery materials: Present and future. Mater Today. 2015; 18: 252-264.

18. Martha SK, Sclar H, Framowitz ZS, Kovacheva D, Saliyski N, Gofer Y, et al. A comparative study of electrodes comprising nanometric and submicron particles of $\mathrm{LiNi}_{0.50} \mathrm{Mn}_{0.50} \mathrm{O}_{2}$, $\mathrm{LiNi}_{0.33} \mathrm{Mn}_{0.33} \mathrm{Co}_{0.33} \mathrm{O}_{2}$, and $\mathrm{LiNi}_{0.40} \mathrm{Mn}_{0.40} \mathrm{Co}_{0.20} \mathrm{O}_{2}$ layered compounds. J Power Sources. 2009; 189: 248-255.

19. Martha SK, Nanda J, Veith GM, Dudney NJ. Surface studies of high voltage lithium rich composition: $\mathrm{Li}_{1.2} \mathrm{Mn}_{0.525} \mathrm{Ni}_{0.175} \mathrm{Co}_{0.1} \mathrm{O}_{2}$. J Power Sources. 2012; 216: 179-186.

20. Gummow RJ, De Kock A, Thackeray MM. Improved capacity retention in rechargeable $4 \mathrm{~V}$ lithium/lithium-manganese oxide (spinel) cells. Solid State Ion. 1994; 69: 59-67.

21. Thackeray MM, David WI, Bruce PG, Goodenough JB. Lithium insertion into manganese spinels. Mater Res Bull. 1983; 18: 461-472.

22. Tarascon JM, McKinnon WR, Coowar F, Bowmer TN, Amatucci G, Guyomard D. Synthesis conditions and oxygen stoichiometry effects on $\mathrm{Li}$ insertion into the spinel $\mathrm{LiMn}_{2} \mathrm{O}_{4}$. J Electrochem Soc. 1994; 141: 1421.

23. Padhi AK, Nanjundaswamy KS, Goodenough JB. Phospho-olivines as positive-electrode materials for rechargeable lithium batteries. J Electrochem Soc. 1997; 144: 1188.

24. Kim SW, Kim J, Gwon H, Kang K. Phase stability study of $\mathrm{Li}_{1-x} \mathrm{MnPO}_{4}(0 \leqslant x \leqslant 1)$ cathode for Li rechargeable battery. J Electrochem Soc. 2009; 156: A635.

25. Bloom I, Jones SA, Battaglia VS, Henriksen GL, Christophersen JP, Wright RB, et al. Effect of cathode composition on capacity fade, impedance rise and power fade in high-power, lithiumion cells. J Power Sources. 2003; 124: 538-550.

26. Du W, Gupta A, Zhang X, Sastry AM, Shyy W. Effect of cycling rate, particle size and transport properties on lithium-ion cathode performance. Int J Heat Mass Transf. 2010; 53: 3552-3561.

27. Li T, Yuan XZ, Zhang L, Song D, Shi K, Bock C. Degradation mechanisms and mitigation strategies of nickel-rich NMC-based lithium-ion batteries. Electrochem Energ Rev. 2020; 3: 43-80.

28. Tian C, Lin F, Doeff MM. Electrochemical characteristics of layered transition metal oxide cathode materials for lithium ion batteries: Surface, bulk behavior, and thermal properties. Acc Chem Res. 2017; 51: 89-96.

29. Zhang WJ. Structure and performance of $\mathrm{LiFePO}_{4}$ cathode materials: A review. J Power Sources. 2011; 196: 2962-2970.

30. Kim J, Lee $H$, Cha $H$, Yoon M, Park M, Cho J. Prospect and reality of Ni-rich cathode for commercialization. Adv Energy Mater. 2018; 8: 1702028.

31. Wang $X$, Ding YL, Deng YP, Chen Z. Ni-rich/Co-poor layered cathode for automotive Li-ion batteries: Promises and challenges. Adv Energy Mater. 2020; 10: 1903864.

32. Sarma DD, Shukla AK. Building better batteries: A travel back in time. ACS Energy Lett. 2018; 3 : 2841-2845.

33. Whittingham MS. History, evolution, and future status of energy storage. Proc IEEE Inst Electr Electron Eng. 2012; 100: 1518-1534. 
34. Armand MB. Intercalation Electrodes. In: Materials for Advanced Batteries. Boston: Springer; 1980. pp.145-161.

35. Armand MB, Whittingham MS, Huggins RA. The iron cyanide bronzes. Mate Res Bull. 1972; 7: 101-107.

36. Dines MB. Intercalation of metallocenes in the layered transition-metal dichalcogenides. Science. 1975; 188: 1210-1211.

37. Gamble FR, Osiecki JH, Cais M, Pisharody R, DiSalvo FJ, Geballe TH. Intercalation complexes of Lewis bases and layered sulfides: A large class of new superconductors. Science. 1971; 174: $493-$ 497.

38. Murphy DW, Broadhead J, Steele BC. Materials for advanced batteries. NASA STI Recon Tech Rep A. 1980; 82: 18112.

39. van Gool W, Yue DD. Fast ion transport in solids, solid state batteries and devices. J Electrochem Soc. 1974; 121: 154Ca.

40. Rao GS, Tsang JC. Electrolysis method of intercalation of layered transition metal dichalcogenides. Mater Res Bull. 1974; 9: 921-926.

41. Leblanc-Soreau $A$, Danot $M$, Trichet $L$, Rouxel J. Les intercalaires $A_{x} T i S_{2}$ et $A_{x} Z r S_{2}$. Structure et liaisons. (A = Li, Na, K, Rb, Cs). Mater Res Bull. 1974; 9: 191-197.

42. Whittingham MS. Electrical energy storage and intercalation chemistry. Science. 1976; 192: 1126-1127.

43. Godshall NA. Electrochemical and thermodynamic investigation of ternary lithium-transition metal-oxygen cathode materials. Stanford: Stanford University; 1980.

44. Mizushima K, Jones PC, Wiseman PJ, Goodenough JB. $\mathrm{Li}_{x} \mathrm{CoO}_{2}(0$, materials research. Bulletin. 1980; 15: 783-789.

45. Thackeray MM, Johnson PJ, De Picciotto LA, Bruce PG, Goodenough JB. Electrochemical extraction of lithium from $\mathrm{LiMn}_{2} \mathrm{O}_{4}$. Mater Res Bull. 1984; 19: 179-187.

46. Zanini M, Basu S, Fischer JE. Alternate synthesis and reflectivity spectrum of stage 1 lithiumgraphite intercalation compound. Carbon. 1978; 16: 211-212.

47. Yazami R, Touzain P. A reversible graphite-lithium negative electrode for electrochemical generators. J Power Sources. 1983; 9: 365-371.

48. Yoshino A, Sanechika K, Nakajima T. Secondary battery. Alexandria: United States Patent and Trademark Office; 1987; US4668595A.

49. Fouchard D, Taylor JB. The molicel ${ }^{\circledR}$ rechargeable lithium system: Multicell aspects. J Power Sources. 1987; 21: 195-205.

50. Ozawa K. Lithium-ion rechargeable batteries with $\mathrm{LiCoO}_{2}$ and carbon electrodes: The $\mathrm{LiCoO}_{2} / \mathrm{C}$ system. Solid State Ion. 1994; 69: 212-221.

51. Thackeray MM. Manganese oxides for lithium batteries. Prog Solid State Ch. 1997; 25: 1-71.

52. Thackeray MM, Kang SH, Johnson CS, Vaughey JT, Benedek R, Hackney SA. $\mathrm{Li}_{2} \mathrm{MnO}_{3}$-Stabilized $\mathrm{LiMO}_{2}(\mathrm{M}=\mathrm{Mn}, \mathrm{Ni}, \mathrm{Co})$ electrodes for lithium-ion batteries. J Mater Chem. 2007; 17: 31123125.

53. Reddy MV, Mauger A, Julien CM, Paolella A, Zaghib K. Brief history of early lithium-battery development. Materials. 2020; 13: 1884.

54. Li M, Lu J, Chen Z, Amine K. 30 years of lithium-ion batteries. Adv Mater. 2018; 30: 1800561.

55. Goodenough JB, Kim Y. Challenges for rechargeable Li batteries. Chem Mater. 2010; 22: 587603. 
56. Peled E. Film forming reaction at the lithium/electrolyte interface. J Power Sources. 1983; 9: 253-266.

57. Manthiram A. An outlook on lithium ion battery technology. ACS Cent Sci. 2017; 3: 1063-1069.

58. Liu C, Neale ZG, Cao G. Understanding electrochemical potentials of cathode materials in rechargeable batteries. Mater Today. 2016; 19: 109-123.

59. Manthiram A. A reflection on lithium-ion battery cathode chemistry. Nat Commun. 2020; 11: 1550.

60. Rossouw $\mathrm{MH}$, Thackeray $\mathrm{MM}$. Lithium manganese oxides from $\mathrm{Li}_{2} \mathrm{MnO}_{3}$ for rechargeable lithium battery applications. Mater Res Bull. 1991; 26: 463-473.

61. Thackeray MM, Kang SH, Johnson CS, Vaughey JT, Hackney SA. Comments on the structural complexity of lithium-rich $\mathrm{Li}_{1+x} \mathrm{M}_{1-\mathrm{x}} \mathrm{O}_{2}$ electrodes $(\mathrm{M}=\mathrm{Mn}, \mathrm{Ni}, \mathrm{Co})$ for lithium batteries. Electrochem Commun. 2006; 8: 1531-1538.

62. Jarvis KA, Deng Z, Allard LF, Manthiram A, Ferreira PJ. Atomic structure of a lithium-rich layered oxide material for lithium-ion batteries: Evidence of a solid solution. Chem Mater. 2011; 23: 3614-3621.

63. Shukla AK, Ramasse QM, Ophus C, Duncan H, Hage F, Chen G. Unravelling structural ambiguities in lithium-and manganese-rich transition metal oxides. Nat Commun. 2015; 6: 8711.

64. Hy S, Felix F, Rick J, Su WN, Hwang BJ. Direct In situ observation of $\mathrm{Li}_{2} \mathrm{O}$ evolution on Li-rich highcapacity cathode material, $\mathrm{Li}_{[}\left[\mathrm{Ni}_{x} \mathrm{Li}_{(1-2 x) / 3} \mathrm{Mn}_{(2-\mathrm{x}) / 3}\right] \mathrm{O}_{2}(0 \leq x \leq 0.5)$. J Am Chem Soc. 2014; 136: 9991007.

65. Yu H, Ishikawa R, So YG, Shibata N, Kudo T, Zhou H, et al. Direct atomic-resolution observation of two phases in the $\mathrm{Li}_{1.2} \mathrm{Mn}_{0.567} \mathrm{Ni}_{0.166} \mathrm{Co}_{0.067} \mathrm{O}_{2}$ cathode material for lithium-ion batteries. Angew Chem Int Ed. 2013; 52: 5969-5973.

66. Gu M, Belharouak I, Zheng J, Wu H, Xiao J, Genc A, et al. Formation of the spinel phase in the layered composite cathode used in Li-ion batteries. ACS Nano. 2013; 7: 760-767.

67. Schipper F, Nayak PK, Erickson EM, Amalraj SF, Srur-Lavi O, Penki TR, et al. Study of cathode materials for lithium-ion batteries: Recent progress and new challenges. Inorganics. 2017; 5: 32.

68. Assat G, Foix D, Delacourt C, ladecola A, Dedryvère R, Tarascon JM. Fundamental interplay between anionic/cationic redox governing the kinetics and thermodynamics of lithium-rich cathodes. Nat Commun. 2017; 8: 2219.

69. Kalyani $\mathrm{P}$, Chitra S, Mohan T, Gopukumar S. Lithium metal rechargeable cells using $\mathrm{Li}_{2} \mathrm{MnO}_{3}$ as the positive electrode. J Power Sources. 1999; 80: 103-106.

70. Abe M, Matsumoto F, Saito M, Yamamura H, Kobayashi G, Ito A, et al. Activation of a Li-rich solid-solution layered $\mathrm{Li}\left[\mathrm{Ni}_{0.18} \mathrm{Li}_{0.20} \mathrm{Co}_{0.03} \mathrm{Mn}_{0.58}\right] \mathrm{O}_{2}$ cathode and retention of high capacities via an electrochemical pretreatment with a low discharge voltage limit. Chem Lett. 2012; 41: 418419.

71. Yu X, Lyu Y, Gu L, Wu H, Bak SM, Zhou Y, et al. Understanding the rate capability of high-energydensity Li-rich layered $\mathrm{Li}_{1.2} \mathrm{Ni}_{0.15} \mathrm{Co}_{0.1} \mathrm{Mn}_{0.55} \mathrm{O}_{2}$ cathode materials. Adv Energy Mater. 2014; 4: 1300950.

72. Armstrong AR, Dupre N, Paterson AJ, Grey CP, Bruce PG. Combined neutron diffraction, NMR, and electrochemical investigation of the layered-to-spinel transformation in $\mathrm{LiMnO}_{2}$. Chem Mater. 2004; 16: 3106-3118. 
73. Schipper F, Erickson EM, Erk C, Shin JY, Chesneau FF, Aurbach D. Recent advances and remaining challenges for lithium ion battery cathodes. J Electrochem Soc. 2016; 164: A6220.

74. Mohanty D, Kalnaus S, Meisner RA, Rhodes KJ, Li J, Payzant EA, et al. Structural transformation of a lithium-rich $\mathrm{Li}_{1.2} \mathrm{Co}_{0.1} \mathrm{Mn}_{0.55} \mathrm{Ni}_{0.15} \mathrm{O}_{2}$ cathode during high voltage cycling resolved by in situ X-ray diffraction. J Power Sources. 2013; 229: 239-248.

75. Armstrong AR, Holzapfel M, Novák P, Johnson CS, Kang SH, Thackeray MM, et al. Demonstrating oxygen loss and associated structural reorganization in the lithium battery cathode $\mathrm{Li}\left[\mathrm{Ni}_{0.2} \mathrm{Li}_{0.2} \mathrm{Mn}_{0.6}\right] \mathrm{O}_{2}$. J Am Chem Soc. 2006; 128: 8694-8698.

76. Armstrong AR, Bruce PG. Electrochemistry Beyond $\mathrm{Mn}^{4+}$ in $\mathrm{Li}_{x} \mathrm{Mn}_{1-y} \mathrm{Li}_{y} \mathrm{O}_{2}$. Electrochem Solid State Lett. 2003; 7: A1.

77. Thackeray MM, Johnson CS, Vaughey JT, Li N, Hackney SA. Advances in manganese-oxide 'composite'electrodes for lithium-ion batteries. J Mater Chem. 2005; 15: 2257-2267.

78. Yang F, Liu Y, Martha SK, Wu Z, Andrews JC, Ice GE, et al. Nanoscale morphological and chemical changes of high voltage lithium-manganese rich NMC composite cathodes with cycling. Nano Lett. 2014; 14: 4334-4341.

79. Ruther RE, Callender AF, Zhou H, Martha SK, Nanda J. Raman microscopy of lithium-manganeserich transition metal oxide cathodes. J Electrochem Soc. 2014; 162: A98.

80. Li Q, Ning $D$, Zhou $D$, An K, Wong $D$, Zhang $L$, et al. The effect of oxygen vacancy and spinel phase integration on both anionic and cationic redox in Li-rich cathode materials. J Mater Chem A. 2020; 8: 7733-7745.

81. Seo DH, Lee J, Urban A, Malik R, Kang S, Ceder G. The structural and chemical origin of the oxygen redox activity in layered and cation-disordered Li-excess cathode materials. Nat Chem. 2016; 8: 692-697.

82. Hu E, Yu X, Lin R, Bi X, Lu J, Bak S, et al. Evolution of redox couples in Li-and Mn-rich cathode materials and mitigation of voltage fade by reducing oxygen release. Nat Energy. 2018; 3: 690698.

83. Nakamura T, Gao H, Ohta K, Kimura Y, Tamenori Y, Nitta K, et al. Defect chemical studies on oxygen release from the Li-rich cathode material $\mathrm{Li}_{1.2} \mathrm{Mn}_{0.6} \mathrm{Ni}_{0.2} \mathrm{O}_{2-\delta}$. J Mater Chem A. 2019; 7: 5009-5019.

84. Reed J, Ceder G, Van Der Ven A. Layered-to-spinel phase transition in $\mathrm{Li}_{x} \mathrm{MnO}_{2}$. Electrochem Solid State Lett. 2001; 4: A78.

85. Boulineau A, Simonin L, Colin JF, Bourbon C, Patoux S. First evidence of manganese-nickel segregation and densification upon cycling in Li-rich layered oxides for lithium batteries. Nano Lett. 2013; 13: 3857-3863.

86. Yan P, Zheng J, Gu M, Xiao J, Zhang JG, Wang CM. Intragranular cracking as a critical barrier for high-voltage usage of layer-structured cathode for lithium-ion batteries. Nat Commun. 2017; 8: 14101.

87. Zheng J, Gu M, Genc A, Xiao J, Xu P, Chen X, et al. Mitigating voltage fade in cathode materials by improving the atomic level uniformity of elemental distribution. Nano Lett. 2014; 14: 2628 2635.

88. Croy JR, Gallagher KG, Balasubramanian M, Long BR, Thackeray MM. Quantifying hysteresis and voltage fade in $\mathrm{xLi}_{2} \mathrm{MnO}_{3} \bullet(1-\mathrm{x}) \mathrm{LiMn}_{0.5} \mathrm{Ni}_{0.5} \mathrm{O}_{2}$ electrodes as a function of $\mathrm{Li}_{2} \mathrm{MnO}_{3}$ content. J Electrochem Soc. 2013; 161: A318. 
89. Gallagher KG, Croy JR, Balasubramanian M, Bettge M, Abraham DP, Burrell AK, et al. Correlating hysteresis and voltage fade in lithium-and manganese-rich layered transition-metal oxide electrodes. Electrochem Commun. 2013; 33: 96-98.

90. Bettge M, Li Y, Gallagher K, Zhu Y, Wu Q, Lu W, et al. Voltage fade of layered oxides: Its measurement and impact on energy density. J Electrochem Soc. 2013; 160: A2046.

91. Gent WE, Lim K, Liang Y, Li Q, Barnes T, Ahn SJ, et al. Coupling between oxygen redox and cation migration explains unusual electrochemistry in lithium-rich layered oxides. Nat Commun. 2017; 8: 2091.

92. Li Y, Bareno J, Bettge M, Abraham DP. Unexpected voltage fade in LMR-NMC oxides cycled below the "activation" plateau. J Electrochem Soc. 2014; 162: A155.

93. Burdett JK. Use of the Jahn-Teller theorem in inorganic chemistry. Inorg Chem. 1981; 20: 19591962.

94. Asl HY, Manthiram A. Reining in dissolved transition-metal ions. Science. 2020; 369: 140-141.

95. Arunkumar TA, Wu Y, Manthiram A. Factors influencing the irreversible oxygen loss and reversible capacity in layered $\mathrm{Li}\left[\mathrm{Li}_{1 / 3} \mathrm{Mn}_{2 / 3}\right] \mathrm{O}_{2}-\mathrm{Li}[\mathrm{M}] \mathrm{O}_{2}\left(\mathrm{M}=\mathrm{Mn}_{0.5-\mathrm{y}} \mathrm{Ni}_{0.5-\mathrm{y}} \mathrm{Co}_{2 y}\right.$ and $\left.\mathrm{Ni}_{1-y} \mathrm{Co}_{\mathrm{y}}\right)$ solid solutions. Chem Mater. 2007; 19: 3067-3073.

96. Han M, Jiao J, Liu Z, Shen X, Zhang Q, Lin HJ, et al. Eliminating transition metal migration and anionic redox to understand voltage hysteresis of lithium-rich layered oxides. Adv Energy Mater. 2020; 10: 1903634.

97. Pearce $P E$, Perez AJ, Rousse $G$, Saubanère $M$, Batuk $D$, Foix $D$, et al. Evidence for anionic redox activity in a tridimensional-ordered Li-rich positive electrode $\beta-\mathrm{Li}_{2} \mid \mathrm{IO}_{3}$. Nat Mater. 2017; 16: 580-586.

98. Sarkar $\mathrm{S}$, Mahale $\mathrm{P}$, Mitra S. Lithium rich composition of $\mathrm{Li}_{2} \mathrm{RuO}_{3}$ and $\mathrm{Li}_{2} \mathrm{Ru}_{1-\mathrm{x}} \mathrm{I} \mathrm{r}_{\mathrm{x}} \mathrm{O}_{3}$ layered materials as Li-ion battery cathode. J Electrochem Soc. 2014; 161: A934.

99. Neelakantaiah RR, Dasari BB, Ette PM, Ramesha K. Improving the electrochemical performance of $\mathrm{Li}_{2} \mathrm{RuO}_{3}$ through chemical substitution: A case study of $(x) \mathrm{LiCOO}_{2}-(1-x) \mathrm{Li}_{2} \mathrm{RuO}_{3}$ solid solution ( $x \leq 0.4)$. ChemElectroChem. 2020; 7: 328-335.

100.Wang J, Wu H, Cui Y, Liu S, Tian X, Cui Y, et al. A new class of ternary compound for lithium-ion battery: From composite to solid solution. ACS Appl Mater Interfaces. 2018; 10: 5125-5132.

101.Wu F, Zhang X, Zhao T, Li L, Xie M, Chen R. Multifunctional $\mathrm{AlPO}_{4}$ coating for improving electrochemical properties of low-cost $\mathrm{Li}\left[\mathrm{Li}_{0.2} \mathrm{Fe}_{0.1} \mathrm{Ni}_{0.15} \mathrm{Mn}_{0.55}\right] \mathrm{O}_{2}$ cathode materials for lithiumion batteries. ACS Appl Mater Interfaces. 2015; 7: 3773-3781.

102.Kumar SK, Ghosh S, Martha SK. Synergistic effect of magnesium and fluorine doping on the electrochemical performance of lithium-manganese rich (LMR)-based Ni-Mn-Co-oxide (NMC) cathodes for lithium-ion batteries. Ionics. 2017; 23: 1655-1662.

103.Wang QY, Liu J, Murugan AV, Manthiram A. High capacity double-layer surface modified $\mathrm{Li}\left[\mathrm{Li}_{0.2} \mathrm{Mn}_{0.54} \mathrm{Ni}_{0.13} \mathrm{Co}_{0.13}\right] \mathrm{O}_{2}$ cathode with improved rate capability. J Mater Chem. 2009; 19: 4965-4972.

104.Zhang S, Gu H, Tang T, Du W, Gao M, Liu Y, et al. In situ encapsulation of the nanoscale $\mathrm{Er}_{2} \mathrm{O}_{3}$ phase to drastically suppress voltage fading and capacity degradation of a Li-and Mn-rich layered oxide cathode for lithium ion batteries. ACS Appl Mater Interfaces. 2017; 9: 3386333875. 
105. Meng $\mathrm{H}$, Jin $\mathrm{H}$, Gao J, Zhang $\mathrm{L}$, $\mathrm{XU}$ Q. $\operatorname{Pr}_{6} \mathrm{O}_{11}$-coated high capacity layered $\mathrm{Li}\left[\mathrm{Li}_{0.17} \mathrm{Ni}_{0.17} \mathrm{CO}_{0.10} \mathrm{Mn}_{0.56}\right] \mathrm{O}_{2}$ as a cathode material for lithium ion batteries. J Electrochem Soc. 2014; 161: A1564.

106.Zheng J, Gu M, Xiao J, Polzin BJ, Yan P, Chen X, et al. Functioning mechanism of $\mathrm{AlF}_{3}$ coating on the Li-and Mn-rich cathode materials. Chem Mater. 2014; 26: 6320-6327.

107. Martha SK, Nanda J, Kim Y, Unocic RR, Pannala S, Dudney NJ. Solid electrolyte coated high voltage layered-layered lithium-rich composite cathode: $\mathrm{Li}_{1.2} \mathrm{Mn}_{0.525} \mathrm{Ni}_{0.175} \mathrm{Co}_{0.1} \mathrm{O}_{2}$. J Mater Chem A. 2013; 1: 5587-5595.

108.Meng H, Li L, Liu J, Han X, Zhang W, Liu X, et al. Surface modification of Li-rich layered $\mathrm{Li}\left[\mathrm{Li}_{0.17} \mathrm{Ni}_{0.17} \mathrm{Co}_{0.10} \mathrm{Mn}_{0.56}\right] \mathrm{O}_{2}$ oxide with $\mathrm{LiV}_{3} \mathrm{O}_{8}$ as a cathode material for $\mathrm{Li}$-ion batteries. J Alloys Compd. 2017; 690: 256-266.

109.Yang CC, Liao PC, Wu YS, Lue SJ. Electrochemical performance of Li-rich oxide composite material coated with $\mathrm{Li}_{0.75} \mathrm{La}_{0.42} \mathrm{TiO}_{3}$ ionic conductor. Appl Surf Sci. 2017; 399: 670-681.

110.Wu Y, Manthiram A. Effect of surface modifications on the layered solid solution cathodes (1-z) $\mathrm{Li}\left[\mathrm{Li}_{1 / 3} \mathrm{Mn}_{2 / 3}\right] \mathrm{O}_{2}-(\mathrm{z}) \mathrm{Li}\left[\mathrm{Mn}_{0.5-\mathrm{y}} \mathrm{Ni}_{0.5-\mathrm{y}} \mathrm{Co}_{2 y}\right] \mathrm{O}_{2}$. Solid State Ion. 2009; 180: 50-56.

111.Zhang $H$, Yang $T$, Han $Y$, Song D, Shi X, Zhang L, et al. Enhanced electrochemical performance of $\mathrm{Li}_{1.2} \mathrm{Ni}_{0.13} \mathrm{Co}_{0.13} \mathrm{Mn}_{0.54} \mathrm{O}_{2}$ by surface modification with the fast lithium-ion conductor Li-La-Ti-O. J Power Sources. 2017; 364: 272-279.

112.Ding $X$, Li YX, Deng MM, Wang S, Aqsa $Y, H u$, et al. Cesium doping to improve the electrochemical performance of layered $\mathrm{Li}_{1.2} \mathrm{Ni}_{0.13} \mathrm{Co}_{0.13} \mathrm{Mn}_{0.54} \mathrm{O}_{2}$ cathode material. J Alloys Compd. 2019; 791: 100-108.

113.Chen S, Chen Z, Xia M, Cao C, Luo Y. Toward alleviating voltage decay by sodium substitution in lithium-rich manganese-based oxide cathodes. ACS Appl Energy Mater. 2018; 1: 4065-4074.

114.Wang D, Huang Y, Huo Z, Chen L. Synthesize and electrochemical characterization of Mg-doped Li-rich layered $\mathrm{Li}\left[\mathrm{Li}_{0.2} \mathrm{Ni}_{0.2} \mathrm{Mn}_{0.6}\right] \mathrm{O}_{2}$ cathode material. Electrochim Acta. 2013; 107: 461-466.

115. Nayak PK, Grinblat J, Levi E, Levi M, Markovsky B, Aurbach D. Understanding the influence of $\mathrm{Mg}$ doping for the stabilization of capacity and higher discharge voltage of Li-and $\mathrm{Mn}$-rich cathodes for Li-ion batteries. Phys Chem Chem Phys. 2017; 19: 6142-6152.

116.Vanaphuti P, Chen J, Cao J, Bigham K, Chen B, Yang L, et al. Enhanced electrochemical performance of the lithium-manganese-rich cathode for Li-ion batteries with $\mathrm{Na}$ and $\mathrm{F}$ codoping. ACS Appl Mater Interfaces. 2019; 11: 37842-37849.

117.Song B, Zhou C, Wang H, Liu H, Liu Z, Lai MO, et al. Advances in sustain stable voltage of Crdoped Li-rich layered cathodes for lithium ion batteries. J Electrochem Soc. 2014; 161: A1723.

118.Feng X, Gao Y, Ben L, Yang Z, Wang Z, Chen L. Enhanced electrochemical performance of Tidoped $\mathrm{Li}_{1.2} \mathrm{Mnn}_{0.54} \mathrm{Co}_{0.13} \mathrm{Ni}_{0.13} \mathrm{O}_{2}$ for lithium-ion batteries. J Power Sources. 2016; 317: 74-80.

119.Xu Y, $\mathrm{Cu}$ Q. Nb-doped $\mathrm{Li}_{1.20}\left[\mathrm{Mn}_{0.54} \mathrm{Ni}_{0.13} \mathrm{Co}_{0.13}\right] \mathrm{O}_{2}$ cathode material with enhanced electrochemical properties for lithium-ion battery. Int J Electrochem Sci. 2020; 15: 803-815.

120.Kumar SK, Ghosh S, Ghosal P, Martha SK. Synergistic effect of 3D electrode architecture and fluorine doping of $\mathrm{Li}_{1.2} \mathrm{Ni}_{0.15} \mathrm{Mn}_{0.55} \mathrm{Co}_{0.1} \mathrm{O}_{2}$ for high energy density lithium-ion batteries. J Power Sources. 2017; 356: 115-123.

121.Zhang HZ, Qiao QQ, Li GR, Gao XP. $\mathrm{PO}_{4}{ }^{3-}$ polyanion-doping for stabilizing Li-rich layered oxides as cathode materials for advanced lithium-ion batteries. J Mater Chem A. 2014; 2: 7454-7460. 
122. Martha SK, Nanda J, Veith GM, Dudney NJ. Electrochemical and rate performance study of highvoltage lithium-rich composition: $\mathrm{Li}_{1.2} \mathrm{Mn}_{0.525} \mathrm{Ni}_{0.175} \mathrm{Co}_{0.1} \mathrm{O}_{2}$. J Power Sources. 2012; 199: 220226.

123.Kobayashi G, Irii Y, Matsumoto F, Ito A, Ohsawa Y, Yamamoto S, et al. Improving cycling performance of Li-rich layered cathode materials through combination of $\mathrm{Al}_{2} \mathrm{O}_{3}$-based surface modification and stepwise precycling. J Power Sources. 2016; 303: 250-256.

124.Kumar SK, Martha SK. Li $\mathrm{Li}_{1.2} \mathrm{Mn}_{0.55} \mathrm{Ni}_{0.15} \mathrm{Co}_{0.1} \mathrm{O}_{2}$ (LMR-NMC)-carbon coated-LiMnPO ${ }_{4}$ blended electrodes for high performance lithium ion batteries. J Electrochem Soc. 2018; 165: A463.

125.Li B, Yan H, Ma J, Yu P, Xia D, Huang W, et al. Manipulating the electronic structure of Li-rich manganese-based oxide using polyanions: Towards better electrochemical performance. Adv Funct Mater. 2014; 24: 5112-5118.

126.Song B, Lai MO, Lu L. Influence of $\mathrm{Ru}$ substitution on Li-rich $0.55 \mathrm{Li}_{2} \mathrm{MnO}_{3} \cdot 0.45 \mathrm{LiNi}_{1 / 3} \mathrm{Co}_{1 / 3} \mathrm{Mn}_{1 / 3} \mathrm{O}_{2}$ cathode for Li-ion batteries. Electrochim Acta. 2012; 80: 187-195.

127.Ji H, Urban A, Kitchaev DA, Kwon DH, Artrith N, Ophus C, et al. Hidden structural and chemical order controls lithium transport in cation-disordered oxides for rechargeable batteries. Nat Commun. 2019; 10: 592.

128.Chen D, Ahn J, Chen G. An overview of cation-disordered lithium-excess rocksalt cathodes. ACS Energy Lett. 2021; 6: 1358-1376.

129.Twu N, Li X, Urban A, Balasubramanian M, Lee J, Liu L, et al. Designing new lithium-excess cathode materials from percolation theory: Nanohighways in $\mathrm{Li}_{x} \mathrm{Ni}_{2-4 x / 3} \mathrm{Sb}_{x / 3} \mathrm{O}_{2}$. Nano Lett. 2015; 15: 596-602.

130.Clément RJ, Lun Z, Ceder G. Cation-disordered rocksalt transition metal oxides and oxyfluorides for high energy lithium-ion cathodes. Energy Environ Sci. 2020; 13: 345-373.

131.Lee J, Urban A, Li X, Su D, Hautier G, Ceder G. Unlocking the potential of cation-disordered oxides for rechargeable lithium batteries. Science. 2014; 343: 519-522.

132.Urban A, Lee J, Ceder G. The configurational space of rocksalt-type oxides for high-capacity lithium battery electrodes. Adv Energy Mater. 2014; 4: 1400478.

133.Li N, Sallis S, Papp JK, Wei J, McCloskey BD, Yang W, et al. Unraveling the cationic and anionic redox reactions in a conventional layered oxide cathode. ACS Energy Lett. 2019; 4: 2836-2842.

134.Zhao C, Wang Q, Lu Y, Hu YS, Li B, Chen L. Review on anionic redox for high-capacity lithiumand sodium-ion batteries. J Phys D. 2017; 50: 183001.

135. Hong J, Gwon H, Jung SK, Ku K, Kang K. Lithium-excess layered cathodes for lithium rechargeable batteries. J Electrochem Soc. 2015; 162: A2447.

136. Choi D, Kang J, Han B. Unexpectedly high energy density of a Li-lon battery by oxygen redox in $\mathrm{LiNiO}_{2}$ cathode: First-principles study. Electrochim Acta. 2019; 294: 166-172.

137. Källquist I, Naylor AJ, Baur C, Chable J, Kullgren J, Fichtner M, et al. Degradation mechanisms in $\mathrm{Li}_{2} \mathrm{VO}_{2} \mathrm{~F}$ Li-rich disordered rock-salt cathodes. Chem Mater. 2019; 31: 6084-6096.

138.Shin Y, Kan WH, Aykol M, Papp JK, McCloskey BD, Chen G, et al. Alleviating oxygen evolution from Li-excess oxide materials through theory-guided surface protection. Nat Commun. 2018; 9: 4597.

139.Cambaz MA, Vinayan BP, Geßwein H, Schiele A, Sarapulova A, Diemant T, et al. Oxygen activity in Li-rich disordered rock-salt oxide and the influence of $\mathrm{LiNbO}_{3}$ surface modification on the electrochemical performance. Chem Mater. 2019; 31: 4330-4340. 
140.Richards WD, Dacek ST, Kitchaev DA, Ceder G. Fluorination of lithium-excess transition metal oxide cathode materials. Adv Energy Mater. 2018; 8: 1701533.

141.Lee J, Papp JK, Clément RJ, Sallis S, Kwon DH, Shi T, et al. Mitigating oxygen loss to improve the cycling performance of high capacity cation-disordered cathode materials. Nat Commun. 2017; 8: 981.

142.Lyu Y, Ben L, Sun Y, Tang D, Xu K, Gu L, et al. Atomic insight into electrochemical inactivity of lithium chromate $\left(\mathrm{LiCrO}_{2}\right)$ : Irreversible migration of chromium into lithium layers in surface regions. J Power Sources. 2015; 273: 1218-1225.

143. Huang J, Zhong P, Ha Y, Kwon DH, Crafton MJ, Tian Y, et al. Non-topotactic reactions enable high rate capability in Li-rich cathode materials. Nat Energy. 2021; 6: 706-714.

144.Chen R, Ren S, Knapp M, Wang D, Witter R, Fichtner M, et al. Disordered lithium-rich oxyfluoride as a stable host for enhanced $\mathrm{Li}^{+}$intercalation storage. Adv Energy Mater. 2015; 5: 1401814.

145.Ren S, Chen R, Maawad E, Dolotko O, Guda AA, Shapovalov V, et al. Improved voltage and cycling for $\mathrm{Li}^{+}$intercalation in high-capacity disordered oxyfluoride cathodes. Adv Sci. 2015; 2: 1500128.

146. Wang R, Li X, Liu L, Lee J, Seo DH, Bo SH, et al. A disordered rock-salt Li-excess cathode material with high capacity and substantial oxygen redox activity: $\mathrm{Li}_{1.25} \mathrm{Nb}_{0.25} \mathrm{Mn}_{0.5} \mathrm{O}_{2}$. Electrochem Commun. 2015; 60: 70-73.

147. Hoshino S, Glushenkov AM, Ichikawa S, Ozaki T, Inamasu T, Yabuuchi N. Reversible threeelectron redox reaction of $\mathrm{Mo}^{3+} / \mathrm{Mo}^{6+}$ for rechargeable lithium batteries. ACS Energy Lett. 2017; 2: 733-738.

148. Matsuhara T, Tsuchiya Y, Yamanaka K, Mitsuhara K, Ohta T, Yabuuchi N. Synthesis and electrode performance of $\mathrm{Li}_{4} \mathrm{MoO}_{5}-\mathrm{LiFeO}_{2}$ binary system as positive electrode materials for rechargeable lithium batteries. Electrochemistry. 2016; 84: 797-801.

149.Sathiya M, Rousse G, Ramesha K, Laisa CP, Vezin H, Sougrati MT, et al. Reversible anionic redox chemistry in high-capacity layered-oxide electrodes. Nat Mater. 2013; 12: 827-835.

150.Wang X, Huang W, Tao S, Xie H, Wu C, Yu Z, et al. Attainable high capacity in Li-excess Li-Ni-RuO rock-salt cathode for lithium ion battery. J Power Sources. 2017; 359: 270-276.

151. Lee J, Seo DH, Balasubramanian M, Twu N, Li X, Ceder G. A new class of high capacity cationdisordered oxides for rechargeable lithium batteries: Li-Ni-Ti-Mo oxides. Energy Environ Sci. 2015; 8: 3255-3265.

152. Huang B, Wang R, Gong Y, He B, Wang H. Enhanced cycling stability of cation disordered rocksalt $\mathrm{Li}_{1.2} \mathrm{Ti}_{0.4} \mathrm{Mn}_{0.4} \mathrm{O}_{2}$ material by surface modification with $\mathrm{Al}_{2} \mathrm{O}_{3}$. Front Chem. 2019; 7: 107.

153. Wu F, Yushin G. Conversion cathodes for rechargeable lithium and lithium-ion batteries. Energy Environ Sci. 2017; 10: 435-459.

154.Yu SH, Feng X, Zhang N, Seok J, Abruña HD. Understanding conversion-type electrodes for lithium rechargeable batteries. Acc Chem Res. 2018; 51: 273-281.

155.Li L, Meng F, Jin S. High-capacity lithium-ion battery conversion cathodes based on iron fluoride nanowires and insights into the conversion mechanism. Nano Lett. 2012; 12: 6030-6037.

156. Martha SK, Nanda J, Zhou H, Idrobo JC, Dudney NJ, Pannala S, et al. Electrode architectures for high capacity multivalent conversion compounds: Iron (II and III) fluoride. RSC Adv. 2014; 4: 6730-6737.

157. Scheers J, Fantini S, Johansson P. A review of electrolytes for lithium-sulphur batteries. J Power Sources. 2014; 255: 204-218. 
158.Kang W, Deng N, Ju J, Li Q, Wu D, Ma X, et al. A review of recent developments in rechargeable lithium-sulfur batteries. Nanoscale. 2016; 8: 16541-16588.

159. Wild M, O'neill L, Zhang T, Purkayastha R, Minton G, Marinescu M, et al. Lithium sulfur batteries, a mechanistic review. Energy Environ Sci. 2015; 8: 3477-3494.

160.Fang R, Zhao S, Sun Z, Wang DW, Cheng HM, Li F. More reliable lithium-sulfur batteries: Status, solutions and prospects. Adv Mater. 2017; 29: 1606823.

161.Jayaprakash N, Shen J, Moganty SS, Corona A, Archer LA. Porous hollow carbon@ sulfur composites for high-power lithium-sulfur batteries. Angew Chem Int Ed. 2011; 50: 5904-5908.

162.Seh ZW, Li W, Cha JJ, Zheng G, Yang Y, McDowell MT, et al. Sulphur-TiO 2 yolk-shell nanoarchitecture with internal void space for long-cycle lithium-sulphur batteries. Nat Commun. 2013; 4: 1331.

163.Nan C, Lin Z, Liao H, Song MK, Li Y, Cairns EJ. Durable carbon-coated $\mathrm{Li}_{2} \mathrm{~S}$ core-shell spheres for high performance lithium/sulfur cells. J Am Chem Soc. 2014; 136: 4659-4663.

164.Gao X, Sun Q, Yang X, Liang J, Koo A, Li W, et al. Toward a remarkable Li-S battery via 3D printing. Nano Energy. 2019; 56: 595-603.

165. Ma Z, Yuan X, Li L, Ma ZF, Wilkinson DP, Zhang L, et al. A review of cathode materials and structures for rechargeable lithium-air batteries. Energy Environ Sci. 2015; 8: 2144-2198.

166.Tan $P$, Jiang $H R$, Zhu XB, An L, Jung $C Y, W u ~ M C$, et al. Advances and challenges in lithium-air batteries. Appl Energy. 2017; 204: 780-806.

167.Ren X, Zhang SS, Tran DT, Read J. Oxygen reduction reaction catalyst on lithium/air battery discharge performance. J Mater Chem. 2011; 21: 10118-10125.

168.Imanishi N, Yamamoto O. Perspectives and challenges of rechargeable lithium-air batteries. Mater Today Adv. 2019; 4: 100031.

169.Imanishi N, Yamamoto O. Rechargeable lithium-air batteries: Characteristics and prospects. Mater Today. 2014; 17: 24-30.

170.Li G, Azuma H, Tohda M. LiMnPO 4 as the cathode for lithium batteries. Electrochem Solid State Lett. 2002; 5: A135.

171.Amine K, Yasuda H, Yamachi M. Olivine $\mathrm{LiCOPO}_{4}$ as $4.8 \mathrm{~V}$ electrode material for lithium batteries. Electrochem Solid State Lett. 2000; 3: 178.

172.Devaraju MK, Truong QD, Hyodo H, Sasaki Y, Honma I. Synthesis, characterization and observation of antisite defects in $\mathrm{LiNiPO}_{4}$ nanomaterials. Sci Rep. 2015; 5: 11041.

173. Membreño N, Park K, Goodenough JB, Stevenson KJ. Electrode/electrolyte interface of composite $\alpha-\mathrm{Li}_{3} \mathrm{~V}_{2}\left(\mathrm{PO}_{4}\right)_{3}$ cathodes in a nonaqueous electrolyte for lithium ion batteries and the role of the carbon additive. Chem Mater. 2015; 27: 3332-3340.

174.Ren MM, Zhou Z, Su LW, Gao XP. LiVOPO 4 : A cathode material for $4 \mathrm{~V}$ lithium ion batteries. J Power Sources. 2009; 189: 786-789.

175.Barker J, Gover RK, Burns P, Bryan A, Saidi MY, Swoyer JL. Structural and electrochemical properties of lithium vanadium fluorophosphate, LiVPO ${ }_{4}$ F. J Power Sources. 2005; 146: 516520.

176.Okada S, Ueno M, Uebou Y, Yamaki JI. Fluoride phosphate $\mathrm{Li}_{2} \mathrm{CoPO}_{4} \mathrm{~F}$ as a high-voltage cathode in Li-ion batteries. J Power Sources. 2005; 146: 565-569.

177.Nagahama M, Hasegawa N, Okada S. High voltage performances of $\mathrm{Li}_{2} \mathrm{NiPO}_{4} \mathrm{~F}$ cathode with dinitrile-based electrolytes. J Electrochem Soc. 2010; 157: A748. 
178. Hasumi $\mathrm{M}$, Taniguchi I. Synthesis and characterization of $\mathrm{Li}_{2} \mathrm{MnP}_{2} \mathrm{O}_{7} / \mathrm{C}$ composite by a combination of spray pyrolsis and wet ball milling followed by annealing. Mater Lett. 2014; 134 : 202-205.

179.Kim H, Park I, Seo DH, Lee S, Kim SW, Kwon WJ, et al. New iron-based mixed-polyanion cathodes for lithium and sodium rechargeable batteries: Combined first principles calculations and experimental study. J Am Chem Soc. 2012; 134: 10369-10372.

180.Pralong V. Lithium intercalation into transition metal oxides: A route to generate new ordered rock salt type structure. Prog Solid State Ch. 2009; 37: 262-277.

181.Arroyo-de Dompablo ME, Armand M, Tarascon JM, Amador U. On-demand design of polyoxianionic cathode materials based on electronegativity correlations: An exploration of the $\mathrm{Li}_{2} \mathrm{MSiO}_{4}$ system (M = Fe, Mn, Co, Ni). Electrochem Commun. 2006; 8: 1292-1298.

182.Barker J. In-situ measurement of the thickness changes associated with cycling of prismatic lithium ion batteries based on $\mathrm{LiMn}_{2} \mathrm{O}_{4}$ and $\mathrm{LiCoO}_{2}$. Electrochim Acta. 1999; 45: 235-242.

183.Zhang Y, Alarco JA, Khosravi M, Mackinnon ID. Nanoscale differentiation of surfaces and cores for olivine phosphate particles-a key characteristic of practical battery materials. J Phys Energy. 2021; 3: 032004.

184. Mauger A, Julien CM. Olivine positive electrodes for Li-ion batteries: Status and perspectives. Batteries. 2018; 4: 39.

185.Aravindan V, Gnanaraj J, Lee YS, Madhavi S. LiMnPO 4 -a next generation cathode material for lithium-ion batteries. J Mater Chem A. 2013; 1: 3518-3539.

186. Mauger A, Julien CM, Armand M, Goodenough JB, Zaghib K. $\mathrm{Li}(\mathrm{Ni}, \mathrm{Co}) \mathrm{PO}_{4}$ as cathode materials for lithium batteries: Will the dream come true? Curr Opin Electrochem. 2017; 6: 63-69.

187. Minakshi M, Singh P, Appadoo D, Martin DE. Synthesis and characterization of olivine $\mathrm{LiNiPO}_{4}$ for aqueous rechargeable battery. Electrochim Acta. 2011; 56: 4356-4360.

188.Garcia-Moreno O, Alvarez-Vega M, Garcia-Alvarado F, Garcia-Jaca J, Gallardo-Amores JM, Sanjuán $\mathrm{ML}$, et al. Influence of the structure on the electrochemical performance of lithium transition metal phosphates as cathodic materials in rechargeable lithium batteries: A new high-pressure form of $\mathrm{LiMPO}_{4}(\mathrm{M}=\mathrm{Fe}$ and Ni). Chem Mater. 2001; 13: 1570-1576.

189. Martha SK, Grinblat J, Haik O, Zinigrad E, Drezen T, Miners JH, et al. LiMn $0.8 \mathrm{Fe}_{0.2} \mathrm{PO}_{4}$ : An advanced cathode material for rechargeable lithium batteries. Angew Chem Int Ed. 2009; 48: 8559-8563.

190.Martha SK, Markovsky B, Grinblat J, Gofer Y, Haik O, Zinigrad E, et al. LiMnPO 4 as an advanced cathode material for rechargeable lithium batteries. J Electrochem Soc. 2009; 156: A541.

191.Zhang M, Garcia-Araez N, Hector AL. Understanding and development of olivine $\mathrm{LiCoPO}_{4}$ cathode materials for lithium-ion batteries. J Mater Chem A. 2018; 6: 14483-14517.

192.Xing LY, Hu M, Tang Q, Wei JP, Qin X, Zhou Z. Improved cyclic performances of $\mathrm{LiCoPO}_{4} / \mathrm{C}$ cathode materials for high-cell-potential lithium-ion batteries with thiophene as an electrolyte additive. Electrochim Acta. 2012; 59: 172-178.

193.Dimesso L, Becker D, Spanheimer C, Jaegermann W. Investigation of graphitic carbon foams/LiNiPO 4 composites. J Solid State Electrochem. 2012; 16: 3791-3798.

194.Gaubicher J, Wurm C, Goward G, Masquelier C, Nazar L. Rhombohedral form of $\mathrm{Li}_{3} \mathrm{~V}_{2}\left(\mathrm{PO}_{4}\right)_{3}$ as a cathode in Li-ion batteries. Chem Mater. 2000; 12: 3240-3242. 
195.Yang J, Zhang J, Lau VW, Park M, Lee S, Kim J, et al. Interface-controlled rhombohedral $\mathrm{Li}_{3} \mathrm{~V}_{2}\left(\mathrm{PO}_{4}\right)_{3}$ embedded in carbon nanofibers with ultrafast kinetics for Li-ion batteries. J Phys Chem Lett. 2020; 11: 4059-4069.

196. Huang H, Yin SC, Kerr T, Taylor N, Nazar LF. Nanostructured composites: A high capacity, fast rate $\mathrm{Li}_{3} \mathrm{~V}_{2}\left(\mathrm{PO}_{4}\right)_{3} /$ carbon cathode for rechargeable lithium batteries. Adv Mater. 2002; 14: 15251528.

197.Yin SC, Grondey H, Strobel P, Anne M, Nazar LF. Electrochemical property: Structure relationships in monoclinic $\mathrm{Li}_{3-\mathrm{y}} \mathrm{V}_{2}\left(\mathrm{PO}_{4}\right)_{3}$. J Am Chem Soc. 2003; 125: 10402-10411.

198. Lee S, Park SS. Atomistic simulation study of monoclinic $\mathrm{Li}_{3} \mathrm{~V}_{2}\left(\mathrm{PO}_{4}\right)_{3}$ as a cathode material for lithium ion battery: Structure, defect chemistry, lithium ion transport pathway, and dynamics. J Phys Chem C. 2012; 116: 25190-25197.

199.Ding $M$, Zhao M, Gong H, Zheng Q, Song X. Novel high-rate performance of dual carbon-coated $\mathrm{Li}_{3} \mathrm{~V}_{2}\left(\mathrm{PO}_{4}\right)_{3}$ materials used in an aqueous electrolyte. Ind Eng Chem Res. 2018; 58: 790-797.

200.Chen Y, Zhao Y, An X, Liu J, Dong Y, Chen L. Preparation and electrochemical performance studies on $\mathrm{Cr}$-doped $\mathrm{Li}_{3} \mathrm{~V}_{2}\left(\mathrm{PO}_{4}\right)_{3}$ as cathode materials for lithium-ion batteries. Electrochim Acta. 2009; 54: 5844-5850.

201.Kuang Q, Zhao Y, An X, Liu J, Dong Y, Chen L. Synthesis and electrochemical properties of Codoped $\mathrm{Li}_{3} \mathrm{~V}_{2}\left(\mathrm{PO}_{4}\right)_{3}$ cathode materials for lithium-ion batteries. Electrochim Acta. 2010; 55: 15751581.

202.Kuang $Q$, Zhao $Y$, Liang Z. Synthesis and electrochemical properties of $\mathrm{Na}$-doped $\mathrm{Li}_{3} \mathrm{~V}_{2}\left(\mathrm{PO}_{4}\right)_{3}$ cathode materials for Li-ion batteries. J Power Sources. 2011; 196: 10169-10175.

203.Xia Y, Zhang W, Huang H, Gan Y, Li C, Tao X. Synthesis and electrochemical properties of Nbdoped $\mathrm{Li}_{3} \mathrm{~V}_{2}\left(\mathrm{PO}_{4}\right)_{3} / \mathrm{C}$ cathode materials for lithium-ion batteries. Mater Sci Eng B. 2011; 176: 633-639.

204.Yuan W, Yan J, Tang Z, Sha O, Wang J, Mao W, et al. Mo-doped $\mathrm{Li}_{3} \mathrm{~V}_{2}\left(\mathrm{PO}_{4}\right)_{3} / \mathrm{C}$ cathode material with high rate capability and long term cyclic stability. Electrochim Acta. 2012; 72: 138-142.

205.Zhang LL, Liang G, Peng G, Zou F, Huang YH, Croft MC, et al. Significantly improved electrochemical performance in $\mathrm{Li}_{3} \mathrm{~V}_{2}\left(\mathrm{PO}_{4}\right)_{3} / \mathrm{C}$ promoted by $\mathrm{SiO}_{2}$ coating for lithium-ion batteries. J Phys Chem C. 2012; 116: 12401-12408.

206. Masquelier C, Croguennec L. Polyanionic (phosphates, silicates, sulfates) frameworks as electrode materials for rechargeable Li (or Na) batteries. Chem Rev. 2013; 113: 6552-6591.

207.Lin YC, Wen B, Wiaderek KM, Sallis S, Liu H, Lapidus SH, et al. Thermodynamics, kinetics and structural evolution of $\varepsilon$-LiVOPO${ }_{4}$ over multiple lithium intercalation. Chem Mater. 2016; 28: 1794-1805.

208. Ateba Mba JM, Masquelier C, Suard E, Croguennec L. Synthesis and crystallographic study of homeotypic LiVPO ${ }_{4} \mathrm{~F}$ and $\mathrm{LiVPO}_{4} \mathrm{O}$. Chem Mater. 2012; 24: 1223-1234.

209. He G, Kan WH, Manthiram A. Delithiation/lithiation behaviors of three polymorphs of $\mathrm{LiVOPO}_{4}$. Chem Commun. 2018; 54: 13224-13227.

210.Wang D, Xiao J, Xu W, Nie Z, Wang C, Graff G, et al. Preparation and electrochemical investigation of $\mathrm{Li}_{2} \mathrm{CoPO}_{4} \mathrm{~F}$ cathode material for lithium-ion batteries. J Power Sources. 2011; 196: 2241-2245.

211. Nishimura SI, Nakamura M, Natsui R, Yamada A. New lithium iron pyrophosphate as $3.5 \mathrm{~V}$ class cathode material for lithium ion battery. J Am Chem Soc. 2010; 132: 13596-13597. 
212. Uebou Y, Okada S, Egashira M, Yamaki Jl. Cathode properties of pyrophosphates for rechargeable lithium batteries. Solid State Ion. 2002; 148: 323-328.

213.Tamaru M, Barpanda P, Yamada Y, Nishimura SI, Yamada A. Observation of the highest $\mathrm{Mn}^{3+} / \mathrm{Mn}^{2+}$ redox potential of $4.45 \mathrm{~V}$ in a $\mathrm{Li}_{2} \mathrm{MnP}_{2} \mathrm{O}_{7}$ pyrophosphate cathode. J Mater Chem. 2012; 22: 24526-24529.

214.Kim H, Lee S, Park YU, Kim H, Kim J, Jeon S, et al. Neutron and X-ray diffraction study of pyrophosphate-based $\mathrm{Li}_{2-x} \mathrm{MP}_{2} \mathrm{O}_{7}(\mathrm{M}=\mathrm{Fe}, \mathrm{Co})$ for lithium rechargeable battery electrodes. Chem Mater. 2011; 23: 3930-3937.

215.Ng MF, Sullivan MB. First-principles characterization of lithium cobalt pyrophosphate as a cathode material for solid-state Li-ion batteries. J Phys Chem C. 2019; 123: 29623-29629.

216. Wen B, Chernova NA, Zhang R, Wang Q, Omenya F, Fang J, et al. Layered molybdenum (oxy) pyrophosphate as cathode for lithium-ion batteries. Chem Mater. 2013; 25: 3513-3521.

217. He G, Popov G, Nazar LF. Hydrothermal synthesis and electrochemical properties of $\mathrm{Li}_{2} \mathrm{CoSiO}_{4} / \mathrm{C}$ nanospheres. Chem Mater. 2013; 25: 1024-1031.

218.Nytén A, Kamali S, Häggström L, Gustafsson T, Thomas JO. The lithium extraction/insertion mechanism in $\mathrm{Li}_{2} \mathrm{FeSiO}_{4}$. J Mater Chem. 2006; 16: 2266-2272.

219.Dominko R, Bele M, Kokalj A, Gaberscek M, Jamnik J. $\mathrm{Li}_{2} \mathrm{MnSiO}_{4}$ as a potential Li-battery cathode material. J Power Sources. 2007; 174: 457-461.

220.Gong ZL, Li YX, Yang Y. Synthesis and electrochemical performance of $\mathrm{Li}_{2} \mathrm{CoSiO}_{4}$ as cathode material for lithium ion batteries. J Power Sources. 2007; 174: 524-527.

221.Lyness C, Delobel B, Armstrong AR, Bruce PG. The lithium intercalation compound $\mathrm{Li}_{2} \mathrm{CoSiO}_{4}$ and its behaviour as a positive electrode for lithium batteries. Chem Commun. 2007. Doi: 10.1039/B711552K.

222.Akimoto J, Takahashi Y, Gotoh Y, Mizuta S. Single crystal X-ray diffraction study of the spineltype $\mathrm{LiMn}_{2} \mathrm{O}_{4}$. Chem Mater. 2000; 12: 3246-3248.

223.Xia H, Luo Z, Xie J. Nanostructured $\mathrm{LiMn}_{2} \mathrm{O}_{4}$ and their composites as high-performance cathodes for lithium-ion batteries. Prog Nat Sci. 2012; 22: 572-584.

224.Zhou G, Sun X, Li QH, Wang X, Zhang JN, Yang W, et al. Mn ion dissolution mechanism for lithium-ion battery with $\mathrm{LiMn}_{2} \mathrm{O}_{4}$ cathode: In situ ultraviolet-visible spectroscopy and $\mathrm{Ab}$ initio molecular dynamics simulations. J Phys Chem Lett. 2020; 11: 3051-3057.

225. Yi TF, Xie Y, Zhu YR, Zhu RS, Ye MF. High rate micron-sized niobium-doped $\mathrm{LiMn}_{1.5} \mathrm{Ni}_{0.5} \mathrm{O}_{4}$ as ultra high power positive-electrode material for lithium-ion batteries. J Power Sources. 2012; 211: 59-65.

226.Spence SL, Xu Z, Sainio S, Nordlund D, Lin F. Tuning the morphology and electronic properties of single-crystal $\mathrm{LiMn}_{1.5} \mathrm{Ni}_{0.5} \mathrm{O}_{4-\delta}$ : Exploring the influence of $\mathrm{LiCl}-\mathrm{KCl}$ molten salt flux composition and synthesis temperature. Inorg Chem. 2020; 59: 10591-10603.

227.Kim Y, Dudney NJ, Chi M, Martha SK, Nanda J, Veith GM, et al. A perspective on coatings to stabilize high-voltage cathodes: $\mathrm{LiNi}_{0.5} \mathrm{Mn}_{1.5} \mathrm{O}_{4}$ with sub-nanometer lipon cycled with $\mathrm{LiPF}_{6}$ electrolyte. J Electrochem Soc. 2013; 160: A3113.

228. Mao J, Dai K, Xuan M, Shao G, Qiao R, Yang W, et al. Effect of chromium and niobium doping on the morphology and electrochemical performance of high-voltage spinel $\mathrm{LiNi}_{0.5} \mathrm{Mn}_{1.5} \mathrm{O}_{4}$ cathode material. ACS Appl Mater Interfaces. 2016; 8: 9116-9124.

229.Ooms FG, Kelder EM, Schoonman J, Wagemaker M, Mulder FM. High-voltage $\mathrm{LiMg}_{\delta} \mathrm{Ni}_{0.5-}$ ${ }_{\delta} \mathrm{Mn}_{1.5} \mathrm{O}_{4}$ spinels for Li-ion batteries. Solid State Ion. 2002; 152: 143-153. 
230.Locati C, Lafont U, Simonin L, Ooms F, Kelder EM. Mg-doped $\mathrm{LiMn}_{1.5} \mathrm{Ni}_{0.5} \mathrm{O}_{4}$ spinel for cathode materials. J Power Sources. 2007; 174: 847-851.

231.Aklalouch M, Amarilla JM, Rojas RM, Saadoune I, Rojo JM. Sub-micrometric LiCr ${ }_{0.2} \mathrm{Ni}_{0.4} \mathrm{Mn}_{1.4} \mathrm{O}_{4}$ spinel as $5 \mathrm{~V}$-cathode material exhibiting huge rate capability at 25 and $55^{\circ} \mathrm{C}$. Electrochem Commun. 2010; 12: 548-552.

232.Yi TF, Mei J, Zhu YR. Key strategies for enhancing the cycling stability and rate capacity of $\mathrm{LiNi}_{0.5} \mathrm{Mn}_{1.5} \mathrm{O}_{4}$ as high-voltage cathode materials for high power lithium-ion batteries. J Power Sources. 2016; 316: 85-105.

233.Zuo D, Tian G, Li X, Chen D, Shu K. Recent progress in surface coating of cathode materials for lithium ion secondary batteries. J Alloys Compd. 2017; 706: 24-40.

234.Pang WK, Lin HF, Peterson VK, Lu CZ, Liu CE, Liao SC, et al. Enhanced rate-capability and cyclingstability of $5 \mathrm{~V} \mathrm{SiO}$-and polyimide-coated cation ordered $\mathrm{LiNi}_{0.5} \mathrm{Mnn}_{1.5} \mathrm{O}_{4}$ lithium-ion battery positive electrodes. J Phys Chem C. 2017; 121: 3680-3689.

235.Tao S, Kong F, Wu C, Su X, Xiang $\mathrm{T}$, Chen $\mathrm{S}$, et al. Nanoscale $\mathrm{TiO}_{2}$ membrane coating spinel $\mathrm{LiNi} .5 \mathrm{Mn}_{1.5} \mathrm{O}_{4}$ cathode material for advanced lithium-ion batteries. J Alloys Compd. 2017; 705: 413-419.

236.Wu Q, Yin Y, Sun S, Zhang X, Wan N, Bai Y. Novel AlF 3 surface modified spinel $\mathrm{LiMn}_{1.5} \mathrm{Ni}_{0.5} \mathrm{O}_{4}$ for lithium-ion batteries: Performance characterization and mechanism exploration. Electrochim Acta. 2015; 158: 73-80.

237. Wei WU, Xing QI, Jianling GU, Jiangfeng W, Huiyu YA, Li WA. Influence of cerium doping on structure and electrochemical properties of $\mathrm{LiNi}_{0.5} \mathrm{Mnn}_{1.5} \mathrm{O}_{4}$ cathode materials. J Rare Earths. 2017; 35: 887-895.

238. Li S, Lan L, Lu L, Lu Y, Li S, Li J, et al. Cerium doped $\mathrm{LiNi}_{0.5} \mathrm{Mn}_{1.5} \mathrm{O}_{4}$ composite with improved high temperature performance as a cathode material for Li-ion batteries. AIP Adv. 2019; 9: 025210.

239.Xu XX, Yang J, Wang YQ, NuLi YN, Wang JL. LiNi ${ }_{0.5} \mathrm{Mn}_{1.5} \mathrm{O}_{3.975} \mathrm{~F}_{0.05}$ as novel $5 \mathrm{~V}$ cathode material. J Power Sources. 2007; 174: 1113-1116.

240.Shaju KM, Bruce PG. Nano-LiNi $\mathrm{L}_{0.5} \mathrm{Mn}_{1.5} \mathrm{O}_{4}$ spinel: A high power electrode for Li-ion batteries. Dalton Trans. 2008. Doi: 10.1039/B806662K.

241.Zhao H, Li F, Shu X, Liu J, Wu T, Wang Z, et al. Environment-friendly synthesis of high-voltage $\mathrm{LiNi}_{0.5} \mathrm{Mn}_{1.5} \mathrm{O}_{4}$ nanorods with excellent electrochemical properties. Ceram Int. 2018; 44: 2057520580.

242.Xu R, Zhang X, Chamoun R, Shui J, Li JC, Lu J, et al. Enhanced rate performance of $\mathrm{LiNi}_{0.5} \mathrm{Mn}_{1.5} \mathrm{O}_{4}$ fibers synthesized by electrospinning. Nano Energy. 2015; 15: 616-624.

243. Yang S, Chen J, Liu Y, Yi B. Preparing $\mathrm{LiNi}_{0.5} \mathrm{Mn}_{1.5} \mathrm{O}_{4}$ nanoplates with superior properties in lithium-ion batteries using bimetal-organic coordination-polymers as precursors. J Mater Chem A. 2014; 2: 9322-9330.

244.Park SB, Eom WS, Cho WI, Jang $\mathrm{H}$. Electrochemical properties of $\mathrm{LiNi}_{0.5} \mathrm{Mn}_{1.5} \mathrm{O}_{4}$ cathode after $\mathrm{Cr}$ doping. J Power Sources. 2006; 159: 679-684.

245.Wang J, Lin W, Wu B, Zhao J. Syntheses and electrochemical properties of the Na-doped $\mathrm{LiNi}_{0.5} \mathrm{Mn}_{1.5} \mathrm{O}_{4}$ cathode materials for lithium-ion batteries. Electrochim Acta. 2014; 145: 245253.

246.Yang $\mathrm{T}$, Zhang $\mathrm{N}$, Lang $\mathrm{Y}$, Sun K. Enhanced rate performance of carbon-coated $\mathrm{LiNi}_{0.5} \mathrm{Mn}_{1.5} \mathrm{O}_{4}$ cathode material for lithium ion batteries. Electrochim Acta. 2011; 56: 4058-4064. 
247.Chong J, Xun S, Zhang J, Song X, Xie H, Battaglia V, et al. $\mathrm{Li}_{3} \mathrm{PO}_{4}$-Coated $\mathrm{LiMn}_{1.5} \mathrm{Ni}_{0.5} \mathrm{O}_{4}$ : A stable high-voltage cathode material for lithium-ion batteries. Chem A Eur J. 2014; 20: 7479-7485.

248. Kim JW, Kim DH, Oh DY, Lee H, Kim JH, Lee JH, et al. Surface chemistry of $\mathrm{LiNi}_{0} \mathrm{SMn}_{1.5} \mathrm{O}_{4}$ particles coated by $\mathrm{Al}_{2} \mathrm{O}_{3}$ using atomic layer deposition for lithium-ion batteries. J Power Sources. 2015; 274: 1254-1262.

249.Arrebola JC, Caballero A, Hernán L, Morales J. Re-examining the effect of $\mathrm{ZnO}$ on nanosized $5 \mathrm{~V}$ $\mathrm{LiNi}_{0.5} \mathrm{Mn}_{1.5} \mathrm{O}_{4}$ spinel: An effective procedure for enhancing its rate capability at room and high temperatures. J Power Sources. 2010; 195: 4278-4284.

250. Huang YY, Zeng XL, Zhou C, Wu P, Tong DG. Electrochemical performance and thermal stability of $\mathrm{GaF}_{3}$-coated $\mathrm{LiNi}_{0.5} \mathrm{Mn}_{1.5} \mathrm{O}_{4}$ as $5 \mathrm{~V}$ cathode materials for lithium ion batteries. J Mater Sci. 2013; 48: 625-635.

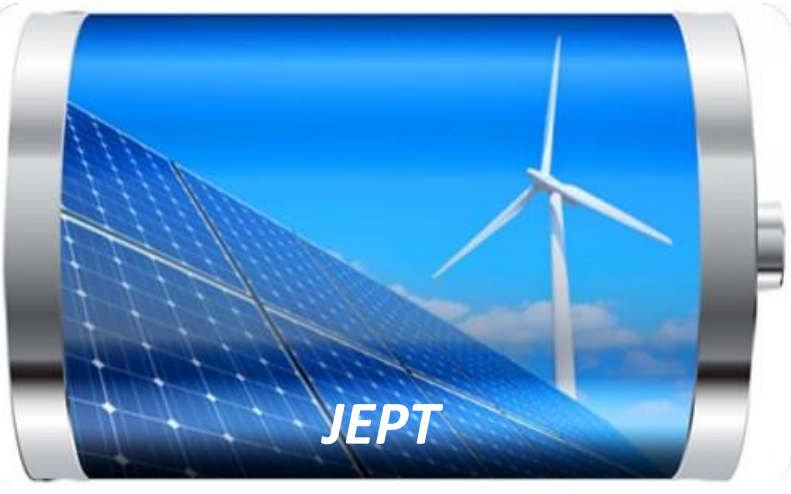

Enjoy JEPT by:

1. Submitting a manuscript

2. Joining in volunteer reviewer bank

3. Joining Editorial Board

4. Guest editing a special issue

For more details, please visit:

http://www.lidsen.com/journal/jept 